\title{
DELIBERATION, EAST MEETS WEST: \\ EXPLORING THE CULTURAL DIMENSION OF CITIZEN DELIBERATION
}

\section{DISSERTATION}

\author{
Presented in Partial Fulfillment of the Requirements for \\ the Degree Doctor of Philosophy in the Graduate \\ School of The Ohio State University
}

By

Seong-Jae Min, M.A.

*****

The Ohio State University

2009

Dissertation Committee:

Professor Gerald Kosicki, Advisor

Approved by

Professor William Eveland

Professor Young Mie Kim

Professor Michael Neblo

Advisor

Graduate Program in Communication 



\begin{abstract}
Recent democratic theories have put a greater emphasis on citizen deliberation and participation in public affairs. Guided by the normative ideals of deliberative democracy, furthermore, empirical research has started blooming and citizen forums and town meetings have become common democratic practices recently.

The core idea of any definition of deliberation concerns free, equal, and rational political discussion — involving disagreement and argumentation — in the public sphere. This idea of deliberation is, arguably, rooted in the Enlightenment traditions of rationality, autonomy, and equality. As such, deliberation theory and practice have been developed predominantly in Western cultural and philosophical contexts. This understanding of deliberation in Western Enlightenment traditions raises an interesting question: Can the model of deliberative democracy ingrained in Western philosophy be applied to Far Eastern Confucian societies that have different cultural assumptions? The present study explores the potential of deliberative democracy in non-Western contexts, such as East Asian societies. Herein, several cultural traits relating to deliberation in collectivist East Asian societies are identified: The lower value of public talk; the strong influence of social position in talk; the increased pressure to conform; and the unique traits of their cognitive and moral reasoning processes. These traits of East Asians pertaining to deliberation originate from the region's dominant collectivist cultural
\end{abstract}


orientations and from Confucian philosophy. Considering these traits, deliberation in the East Asian context will require special care.

For the empirical portion of this study, a series of small group deliberation sessions among Americans - representing a Western, individualist culture - and Koreans - representing an Eastern, collectivist culture - have been conducted. They deliberated the same issues either in the face-to-face setting or over the Internet. Findings suggest that deliberation, overall, was beneficial to all participants. However, it was observed that deliberation among individualist Americans featured more arguments than collectivist Koreans and was perhaps more deliberative. Individualist Americans also felt more freedom to express their views in the public setting and assessed the deliberation experience more positively than their Korean counterparts. Measures to promote deliberation in East Asian societies and in non-Western cultural contexts in general are discussed. 


\section{ACKNOWLEDGMENTS}

I wish to deliver my deepest appreciation to my advisor, Dr. Gerald Kosicki, for his unwavering support over the past four years. Dr. Kosicki provided consistent guidance and encouragement, and without his assistance, I could not have completed my dissertation. I have been genuinely inspired by his extensive knowledge in the broad social sciences, his respect for cultural diversity, and his technological vision, which have formed the fundamental building blocks upon which this dissertation was built.

I wish to thank all the members of my dissertation committee for their sincere contributions to my academic work: Dr. William Eveland, Dr. Young Mie Kim, and Dr. Michael Neblo. Dr. Eveland's prudence and diligence in academic work set me an example of what a scholastic life should be. Dr. Kim provided not only keen theoretical and methodological insights to my work but also great social and emotional support throughout my often turbulent times. Dr. Neblo has been a wonderful mentor whose enthusiasm and passion have been major forces that drove the core of my dissertation work.

I wish to thank my colleagues at Ohio State whose help made this dissertation possible in many different ways. My heartfelt gratitude also goes to my family who, as always, provided endless love and devotion to me. 
Of course, despite all the assistance provided by my committee members and others, I alone remain responsible for the content of the following, including any errors or omissions which may unwittingly remain. 
VITA

April 19, 1974............................Born - Seoul, Republic of Korea

1999......................................... B.A., Korea University

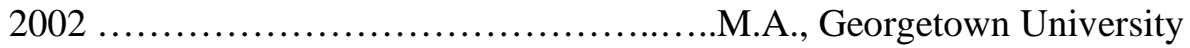

$2002-2005$..............................Staff Writer,

International Herald Tribune-JoongAng Daily

Seoul, Korea

2005 - present.............................Graduate Teaching Associate,

The Ohio State University

\section{PUBLICATIONS}

Research Publication

1. S.J. Min (2007). Online vs. face-to-face deliberation: Effects on civic engagements. Journal of Computer-Mediated Communication, 12(4), 1369-1387.

\section{FIELDS OF STUDY}

Major Field: Communication 


\section{TABLE OF CONTENTS}

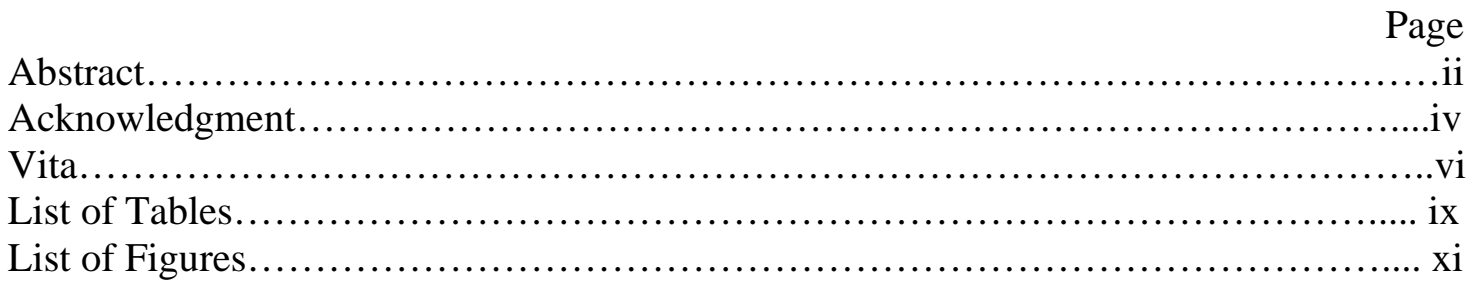

Chapters:

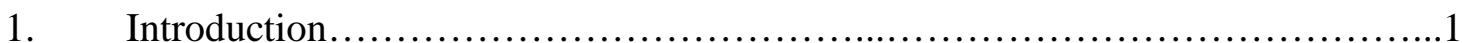

2. Deliberation, communication, and democracy.................................

2.1 Why deliberative democracy?........................................10

2.2 Deliberation and its critics............................................ 14

2.3 Deliberation and societal communication................................18

3. The cultural dimension of deliberation...................................... 21

3.1 Deliberation, a Western bias? ........................................ 22

3.2 Confucianism and collectivism in East Asia ............................... 24

3.3 Citizen deliberation in East Asian contexts.............................. 28

4. Communication technology and deliberation.................................39

4.1 Anatomy of online communicative action............................. 40

4.2 Contexts for effective online deliberation.................................46

4.3 Opinion expression in online deliberation............................. 50

5. Research questions and hypotheses....................................... 53

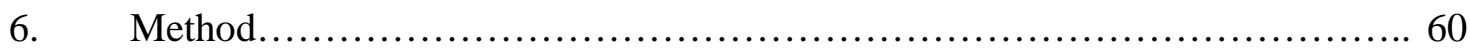

6.1 Procedure................................................................ 61

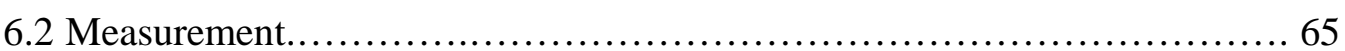

6.2.1 Cultural orientation.............................................. 65

6.2.2 Self-assessment of deliberation................................. 66 
6.2.3 Issue opinion and variance...................................67

6.2.4 Freedom to express.........................................67

6.2.5 Political efficacy...........................................67

6.2.6 Control and other variables..................................68

6.2.7 Judges' evaluation of deliberation.............................69

6.2.8 Reasoned arguments........................................71

6.2.9 Equality of participation..................................... 72

6.3 Statistical models.....................................................73

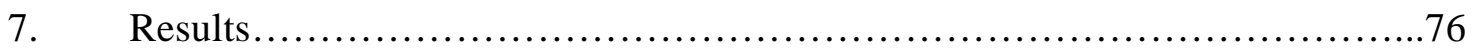

7.1 Collectivism vs. individualism.........................................76

7.2 Self-assessment of deliberation........................................77

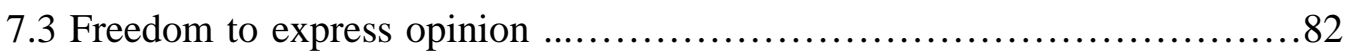

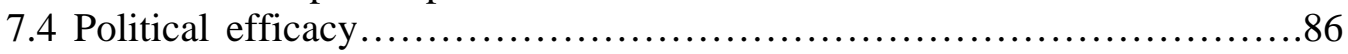

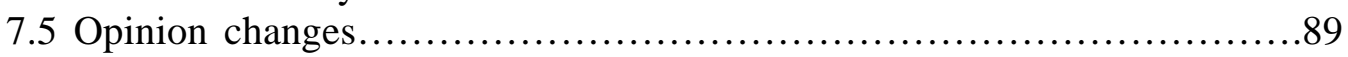

7.6 Opinion variances.................................................93

7.7 Judges' evaluation of deliberation......................................95

7.8 Reasoned arguments..................................................

7.9 Equality of participation............................................ 100

8. Discussion........................................................... 105

8.1 Interpreting the results............................................ 105

8.1.1 Deliberative differences between cultures.....................106

8.1.2 The effects of online deliberation..............................107

8.2 Strengths and limitations of the study.....................................

9. Conclusion............................................................... 114

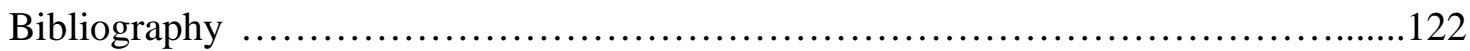

Appendix A: Survey questionnaire for discussants...............................134

Appendix B: Discussion guide...................................................142

Appendix C: Moderator's guide................................................146

Appendix D: Observational rating sheet.........................................150 


\section{LIST OF TABLES}

Table

5.1 Summary of hypotheses and research questions.............................59

$6.1 \quad$ Participant profiles........................................................69

6.2 Reliability statistics for each deliberation evaluation item......................70

7.1 Mean scores for self-assessment of deliberation...............................77

7.2 Coefficient estimates of independent variables for self-assessment of deliberation

7.3 Mean scores for freedom to express..................................... 82

7.4 Coefficient estimates of independent variables for freedom to express............85

7.5 Political efficacy changes after deliberation..................................86

7.6 Coefficient estimates of independent variables for post-deliberation efficacy.....88

7.7 Opinion changes after deliberation........................................89

7.8 Opinion changes after deliberation by condition...........................90

7.9 Number of participants who moved from the no opinion position to an opinionated position......................................................................

7.10 Variance changes after deliberation..........................................93

7.11 Variance changes after deliberation by condition..............................94

7.12 Judges' average ratings by condition......................................96

7.13 Judges' average ratings by culture and mode..............................98 
7.14 Average proportions of reasoned arguments by condition....................99

7.15 Average proportions of reasoned arguments by culture and mode...............100

7.16 Proportions of spoken words and standard deviations by condition.................101

7.17 Proportions of spoken words and standard deviations by culture and mode.......101

7.18 Summary of findings....................................................... 


\section{LIST OF FIGURES}

Figure

7.1 Self-assessment deliberation score by culture and mode.......................78

7.2 Freedom to express score by culture and mode.................................83 


\section{CHAPTER 1}

\section{INTRODUCTION}

Since their recent “deliberative turn,” (Dryzek, 2000) democratic theories have put a great emphasis on citizen deliberation and participation in public affairs. Guided by the normative ideals of deliberative democracy, furthermore, empirical research has started blooming in recent years. Indeed, the deliberation enterprise has since assumed a prominent place in the Western democratic thoughts and practices.

Although there are a variety of conceptualizations of deliberation, the core idea of any definition of deliberation concerns free, equal, and rational political discussion — involving disagreement and argumentation — in the public sphere. Arguably, this idea of deliberation is rooted in the Enlightenment traditions of rationality, autonomy, and equality. As Benhabib (2002) noted, Western philosophy promotes the normative content of human reason and that it is the basis of validity in the procedures of inquiry, evidence, and questioning that have been considered the cognitive legacy of the Enlightenment. This view is steeped in the normative assumptions of current deliberation theory. Hence, Cooke (2000) argues that deliberative democracy elucidates an ideal of democracy that is most congruent with "whom we are” (p. 954). Here Cooke uses "we” to refer to the Westerners who value unconstrained rational discussion, publicity, and autonomy. 
The understanding of deliberation in Western Enlightenment traditions raises an interesting question: Can the model of deliberative democracy ingrained in Western philosophy be applied to Far Eastern Confucian societies, where it is often considered that the public sphere is less developed, that there exists a high degree of social hierarchy, and that people value social harmony to the extent that they are reluctant to publicly display disagreement? What would the promises and perils of deliberative democracy be in non-Western cultural contexts? These are important questions, because the vibrant dynamics of deliberative democracy are spreading to other parts of the globe over time. The present study attempts to answer these questions by reviewing theories and empirical evidence pertaining to deliberative democracy, cross-cultural communication, and social and cultural psychology. The basic claim made here is that deliberation theories and practices would require special care if they are to be applied to non-Western societies whose political discussion culture seems to run counter to the current deliberation norms and rules embedded in Western philosophy. To substantiate this claim, a deliberation experiment with participants from different cultural backgrounds is conducted. The experiment would show how individuals' approach to deliberation is different depending on their cultural orientations.

The analysis is mainly focused on how culture shapes patterns of human communication. Although it refers to a larger deliberative system at times, the analysis is essentially a micro-level analysis exploring dialogic human communication processes. At the macro-level, there exist such questions as whether the deliberative democracy model is useful to East Asian countries whose modernization paths have been different from those of Western democracies. An example of a macro-level analysis would be 
structural analysis, discussing whether the deliberative model of democracy can ever be successful in China, where the conditions of free press and liberal democratic institutions are not satisfied. This issue, while very important, is being handled by an increasing number of political scientists and sociologists (e.g., Bell, 1999; Leib \& He, 2006) and is beyond the scope of this paper. Instead, this study focuses on the cultural assumptions of human communication processes and how these apply to deliberation. This is because how people deliberate cannot be understood separately from the culture of which they are part. This would be one area where the discipline of communication can contribute to the study of deliberation and deliberative democracy.

In the following Chapter 2, the concept of deliberation from the perspective of communication is explored. In doing so, it traces the origins of the concept and discusses major rationales for promoting deliberation and the utility of the deliberative democracy model in contemporary society. The chapter also introduces major criticisms against deliberation and discusses cases where deliberation can go bad. In Chapter 3, the role of culture in deliberation is discussed. It criticizes deliberation theory as representing the Western-centric, Enlightenment ideals. It then explores specific attitudinal and behavioral traits of Confucian, collectivistic individuals of East Asia and how the Western-specific deliberative norms may (or may not) apply to East Asian citizen deliberation forums. In Chapter 4, the role of communication technology in deliberation is discussed. This chapter starts off with broad observations on the new technology's democratic potential and then move on to discuss specific applications of the new technology in deliberation contexts. In doing so, it discusses how the technology is useful for individuals of certain cultural backgrounds. Chapters 5 through 8 are the 
empirical part. In Chapter 5, specific research questions and hypotheses are presented. Chapter 6 details the design of the social psychological deliberation experiment and lays out statistical models for analysis. Chapter 7 presents the results in detail and Chapter 8 discusses the findings. Chapter 9, which is the concluding chapter, seeks broad implications of the study on the larger field of deliberative democracy and offers some thoughts about how deliberation can be promoted in non-Western societies. 


\section{CHAPTER 2}

\section{DELIBERATION, COMMUNICATION, AND DEMOCRACY}

Over the last decade, the study of deliberation and deliberative democracy has received a great amount of attention from many fields including philosophy, political science, psychology, and public opinion research. Theories of deliberative democracy are now well developed and empirical studies are accumulating. Surprisingly, however, a relatively small number of deliberation studies come from the discipline of communication. Although human communication and communication processes are critical in deliberation research, little theoretical elaboration and empirical endeavors have been made in this regard. Most well-known and ambitious deliberation projects to date such as Fishkin’s Deliberative Polling consider deliberation as given and they tend to be concerned only about the outcomes of deliberation that are limited to opinion changes and knowledge increase. Deliberation, however, is much more than identifying certain outcomes. Beyond the outcomes, there exist complex human communication processes that constitute deliberation. More importantly, communication forms the very basis of deliberation and thus understanding the key communication characteristics of deliberation will be necessary.

Perhaps the general understanding of deliberation as communication starts from the social constructionist perspective. A social constructionist understanding views 
human realities as a product of endless social interaction. Human interaction is intimately tied to our ability to create and maintain definitions of self and others, and these definitions are created by society and supported by communication (Trentholm, 1991). Also under a social constructionist perspective, Pearce and Cronen (1980) argue that it is through human communication and dialogue that we construct the "self." In this perspective, communication is not a static concept, nor a mere medium of expression. It has independent power to create meanings for social interaction.

This idea of communication as a powerful social interaction mechanism can be traced to the early Chicago School of Dewey and Mead. For Dewey (1927), what enables the public to form the "Great Society" is communication. He writes,

Till the Great Society is converted into a Great Community, the public will remain in eclipse. Communication can alone create a great community. Our Babel is not one of tongues but of the signs and symbols without which shared experience is impossible. (p.142)

At Chicago, Mead shared Dewey’s vision on communication and democracy. Mead's symbolic interactionism, rooted in American pragmatic philosophy represented by Dewey, holds that human communication occurs through the exchange of symbols and their meanings. Symbolic interactionism suggests that human beings have the unique capacity to situate themselves in relation to other individuals and social groups and interact with them to make meanings in the process. In his essay Mind, self, and society (1934), Mead emphasized that whereas animals act “without deliberation,” humans have the unique capacity to think and communicate reflectively (p. 34). Mead’s idea that people make meanings through conversation is reflected in contemporary deliberation theory which suggests people develop self identities and take perspectives through deliberation. 
Although a communicative understanding of deliberation can be traced to Dewey, Mead, and some social constructionists, much of the development of modern deliberative democratic theory has been credited to Habermas and his extensive theoretical work in this area. Since his original German language version of The structural transformation of the public sphere appeared in the 1960s and the two-volume, Theories of communicative action in the 1980s, his work has had major impacts on deliberative democratic theories. The basic ideas of public sphere and communicative action then culminated in his more recent Between facts and norms.

Habermas (1984) drew upon Mead to develop his theories of deliberation. His “communicative action" refers to the interaction of at least two subjects capable of speech and action who establish interpersonal relations (p. 86). To summarize Habermas's points crudely, the public sphere is a public space where citizens voluntarily use their reason outside the influence of government. Communicative action taking place in such a public sphere is oriented to achieving, sustaining, and renewing consensus to form a political will of the public (p.17). Through communicative interaction in the public sphere, citizens exchange warrant-establishing arguments, and ideally, “no force except that of the better argument” (Habermas, 1975, p.108) is exercised to establish a public reason and democratic legitimacy. Habermas (1996) terms this conception of democracy as the "discourse theory of democracy," saying it reckons with the "higherlevel of intersubjectivity of processes of reaching understanding that take place through democratic procedures or in the communicative network of public spheres” (p. 299).

Habermas’s idea has been adopted and enlarged by many contemporary deliberation theorists. Cohen (1989), for example, lays out the principles of deliberation. 
According to him, deliberation is 1) an argumentative form of communication in which reasons are exchanged, 2) an inclusive and public communication in that all those who are possibly affected by the decisions have equal chances to enter and take part, 3) a communication free of external coercion in which participants are bound only by the presuppositions of communication and rules of argumentation, and 4) an ideal communication that aims to arrive at a rationally motivated consensus. In a similar vein, Gutmann and Thompson (1996) identify reciprocity, publicity, and accountability as the three core principles of organizing deliberative democracy. A key theme of Gutmann and Thompson's work is that deliberation should involve disagreement, as the goal of deliberative democracy is to accommodate and resolve moral and political disagreement through reasoned communication. In a small group communication tradition, Gouran and Hirokawa's (1983) functional perspective on communication suggests that communication can promote logical and informed public decision making. They argue that deliberative decision making needs the four functional communication requirements of problem analysis, goal setting, identification of alternatives, and evaluation of positive and negative consequences.

A general view toward deliberation as described above is that it is free, equal, reflexive, and rational discussion of public issues. In this perception, deliberation becomes a special form of rational communication operating in formal arenas and under specified norms. Several theorists, however, oppose this conceptualization of deliberation as being too rigid and argue that everyday, "ordinary” discussion should be included in a larger deliberative system (Mansbridge, 1999). These scholars argue that ordinary political conversation can produce beneficial effects on public opinion 
and democracy (e.g., Conover, Searing, \& Crew, 2005; Kim \& Kim, 2008; Kim, Wyatt, \& Katz, 1999). For these scholars, deliberation and deliberative democracy are based on "non-purposive talk” rather than problem-solving, purposeful talk. Kim and Kim thus define deliberation rather loosely and argue that casual conversation is important in deliberative democracy because citizens can be better motivated to discuss and engage in political affairs under a non-artificial and voluntary environment. They suggest that everyday political conversation represents a self-regulating democratic system in which citizens themselves create democratic norms and rationality. In other words, rationality is not a given priori but something internally generated by citizens' everyday interaction. This is a very important contribution to deliberative democracy because it expands the horizon of the theory and it identifies very "practical" sources of deliberation, countering the critique that deliberation is too idealistic and impractical. Indeed, everyday political conversation is useful because,

It is through this everyday political talk that people come to understand what their own interests are, what others want, and what fits the common good; without this understanding, citizens may not be able to participate in instrumental deliberation in a meaningful way to make rational decisions. (Kim \& Kim, 2008, p.54)

For the reasons described above, deliberative democracy research should include the study of everyday political conversation. However, one may be reluctant to regard everyday political talk as the "archetype of communicative action” as Kim and Kim (2008, p.54) claim. This is because everyday political talk tends to take place only among like-minded people. It is human nature to prefer to talk to those who have similar views. But such an "enclave” talk is detrimental to democracy as it forges conformity (Sunstein, 2003). Open discussion of disagreement in the public arena is a key feature of 
deliberation. Only when people experience disagreement and publicity, will their understanding of public life and democracy be enhanced. Therefore, it would stand to reason to differentiate deliberation from other types of talk. It is different from everyday political talk or discussion in that it requires publicity, disagreement, and some structures. It is not, however, a debate to determine a winner. The purpose of deliberation is to improve citizens' understanding of alternatives and their consequences so that citizens can make informed decisions. Deliberation is a dialogic communication to reach understanding, and if possible, consensus.

From Dewey to Mead and from Habermas to more contemporary theorists, there is variation on how to define deliberation. But at the heart of any definitions of deliberation and deliberative democracy lies the idea that rational, dialogic, and egalitarian human communication should be the core principle of democratic decision making. Hence, Burkhalter, Gastil, and Kelshaw (2002) define deliberation as "the combination of careful problem analysis and an egalitarian process in which participants have adequate speaking opportunities and engage in attentive listening or dialogue concerning public issues” (p. 398).

\subsection{Why Deliberative Democracy?}

Even a glimpse at the principles of deliberation suggests that it is idealistic. Still, a great deal of attention is paid to deliberative decision making in politics, or more broadly, deliberative democracy. Why do we see such an attention being paid to this concept? Why do we need deliberative democracy? What is the value of deliberative democracy given the current political reality in which representative institutions account for most of the democratic decision making mechanism? 
There are many reasons to promote deliberative democracy. The first concerns the limit of the dominant liberal democratic paradigm of today. In the liberal notion of democracy, individual freedom is the utmost value of democracy and democratic legitimacy is considered to stem from private individuals and their secret votes. To secure individual freedom, such institutional arrangements as bills of rights, checks and balances of power, territorial representation, and aggregation of preferences are emphasized. Here, voting is the chief mechanism in which individual preferences are manifested, aggregated, and used as a decision making-method (Schumpeter, 1942). The liberal notion of democracy is thus often called "aggregative” democracy (Knight \& Johnson, 1994). It is also often termed “majoritarian” or "representative” democracy due to its emphasis on the majoritarian method of decision making and the electoral representation principles.

But in this liberal, aggregative conception of democracy, a citizen is reduced to a passive voter, or in Gutmann and Thompson’s (2004) word, “consumer.” That is, citizens typically have no inputs on important policies that will determine their lives and are forced to choose from a limited set of policy alternatives. Gutmann and Thompson (p.14) argue that in the current electoral process, politicians and parties formulate their positions in response to the demands of voters who, like consumers, express their preferences by choosing among competing products. Here, political discussion taking place in a campaign, if any, is reduced to sound-bites in advertising. Furthermore, the aggregative conception of democracy is criticized as lacking in moral resources to generate and sustain collective will. This is because outcomes of such decision making can only claim to represent winners and not a common will. Therefore, in a tyranny of 
the majority, the aggregative conception of democracy accepts, and may even reinforce, existing distributions of power in society, oppressing minorities (Gutmann \& Thompson, 2004). From a rather different perspective, furthermore, it has also been argued that the aggregation of self-interested individuals’ preferences do not necessarily produce rational outcomes. In what is known as the "tragedy of commons" (Hardin, 1968), and the "logic of collective action” (Olson, 1965), rational choice theorists demonstrated that there is no satisfactory way of mapping individual preferences onto a desirable social decision.

The republican model of democracy is often suggested as an alternative to ailing liberal democracy. The republican tradition, unlike the liberal tradition, emphasizes the common good and active citizen participation in politics. However, the problem with the republican tradition is that it understands politics as a form of deliberation which takes place within groups that are already socially and culturally integrated (Habermas, 1996). The republican model, thus, is not well-suited for an increasingly complex, multicultural, and heterogeneous society. This is why deliberative democracy based on communicative rationality is emphasized as the third model. Hence, Habermas argues,

Practical reason no longer resides in universal human rights, or in the ethical substance of a specific community, but in the rules of discourse and forms of argumentation that borrow their normative content from the validity basis of action oriented to reaching understanding. (p. 296-297)

As described above, deliberative democracy is justified as a normative alternative or complement to the problems of current democratic arrangements. It can also be justified at the micro-level because it can promote norms and benefits that are conducive to democracy. Gutmann and Thompson (1996) suggest that deliberation is beneficial for democracy because deliberation among citizens not only facilitates healthy public opinion but also forms attitudes and norms that are supportive of engagement, 
such as social trust and political efficacy. Another important aspect of deliberation is that it can, at least theoretically, increase deliberators’ political efficacy and facilitate political participation. Through deliberation, it is expected that participants become confident in their views and willing to express them and hence increase self-efficacy in political affairs. That is, the more citizens learn, think, and talk about politics, the more they tend to feel capable of dealing with it and will be likely to participate in it. Katz (1992) writes how deliberation can increase citizens' political participation: "By the very process of talking to one another, the vague dispositions which people have are crystallized, step by step, into specific attitudes, acts, or votes” (p. 80). Many other theorists (e.g., Chambers, 1996; Warren, 1992) also maintain that deliberation and participation are inextricably intertwined. Warren, for example, argues that deliberation exercises some transformative effects on participants by empowering them with a public spirit.

Although the evidence is not conclusive, a good number of empirical studies on deliberation to date support the above observation that deliberation can create "better citizens” for democracy by improving citizens’ issue knowledge, political efficacy, and participation. Findings show a clear positive association between deliberation and citizens’ political knowledge (e.g., Eveland, 2004; Fishkin \& Luskin, 1999; Gastil \& Dilliard, 1999). Price, Cappella and Nir (2002) show that deliberation contributes to people's ability to generate reasons and thereby improves the quality of their opinions.

In sum, it has been argued that deliberative democracy can be justified both in terms of theory and practice. But empirical research of deliberation seems to fall short of catching up with its broad theoretical constellations. More detailed and contextualized empirical research of deliberation is thus needed. 


\subsection{Deliberation and Its Critics}

Deliberation research, however, has been under intense criticism. The main criticism has been that deliberative democracy tends to be guided by normative ideals and is thus too idealistic; but more systematic and detailed criticism against deliberation comes from feminist/critical studies and small group communication studies informed by social psychology. A major criticism raised by the critical studies tradition is that deliberation largely ignores the issues of power and emotion. Young (1996, 2000), Sanders (1997), and Mouffee (1999) provide the sharpest critique here. They argue that current deliberative practices favor the positions of the powerful and discriminate against the minority. Sanders further argues that the rules governing deliberation come from aristocratic, elitist values in which legitimate democratic discussion must be calm, rational, and moderate. Therefore, better educated, white, middle class men have the best cultural resources to benefit from deliberation. These researchers promote alternative deliberative democratic models to ensure more inclusion of minority groups and to accommodate their emotions. Young (2000) proposed there were forms of speech and argument that should be considered "female." She argues that a tentative, exploratory, and conciliatory form of speech may be good for deliberation rather than typical maletype speech such as advocating opinions and initiating controversies. Young suggests three ways of talk: greeting, rhetoric, and storytelling. These involve personal narratives — one's lived story — that engage the audience and explain to them the life conditions and situations of disadvantaged groups. Similarly, Sanders argues for the use of testimony, so that minorities can describe their historical experience through forms of personalized communication. 
A second set of criticisms of deliberation comes from small group communication studies informed by social psychology; studies that are typically accompanied by empirical findings. Mendelberg (2002) and Ryfe (2005) provide the most extensive review of social psychological literature relating to deliberation. Their main point is that maintaining high quality deliberation is not an easy task and, in some situations, deliberation may actually produce undesirable outcomes. According to Mendelberg, such factors as the types of issues, group norms, individual deliberators' traits, moderation style, and the nature of language may determine the process and outcome of deliberation. She introduces studies where deliberation did not turn out to be very effective for valueladen issues, as opposed to fact-oriented issues. Other cases where deliberation is least effective include when the deliberating group’s norm values social harmony, when the moderating style is directive, and when individuals who are "cognitively central" disproportionately influence the group’s decision-making process.

Another important issue raised by Mendelberg is group polarization, whereby members of a deliberating group move toward a more extreme point in the direction indicated by the members’ pre-deliberation tendencies. Mendelberg illustrates cases in which the minority in the deliberation group often capitulates to the majority because of social pressure during deliberation. She writes that sometimes deliberation "affects people's decision making not through the exchange of reason but by setting the social norms of the overall group. Social muscle, not persuasive argumentation, carries the day” (p.159).

In another extensive but more benign review of deliberation, Ryfe (2005) suggests that there are cases in which outcomes from deliberation are not necessarily deliberative. 
He argues that deliberation presents a disturbance of people’s everyday reasoning habits. People are cognitive misers and they make judgments based on information shortcuts that mobilize scripts, but deliberation about public issues is complex and thus it may produce anxiety and frustration in the participants. Ryfe also points to accountability, high stakes, and diversity as the three factors that may determine the effectiveness of deliberation. That is, individuals who are told that they will have to discuss their judgments publicly are more likely to process more information more objectively because they maintain a sense of accountability. The perceptions of consequences will influence deliberation because if consequences of deliberation are perceived to be great and direct, then individuals ought to expend more energy to get decisions right. Diversity is important as well because when one encounters others different from oneself, one may become motivated to deliberate.

The above criticism has its merit. As observed in several empirical studies, we do see dominance of majority groups and power dynamics in deliberation forums (e.g., Mendelberg \& Oleske, 2000). We also see limited human cognitions and rationality in real deliberation (e.g., Ryfe, 2006). Deliberative forums are sometimes characterized by uncivil behavior and deliberation often results in deeper conflicts and anti-democratic outcomes. But this does not necessarily suggest that deliberation itself is flawed. There are a couple of responses to the problems presented above. The first is that deliberation, properly designed and operated, can safeguard, to a certain extent, against the potential negative effects. As observed by Delli Carpini, Cook, and Jacobs (2004), deliberation is highly “context dependent.” That is, deliberation may produce good or negative effects depending on situations. If so, to the defenders of deliberative democracy, a critical issue 
is to identify contexts that can promote procedures and outcomes conducive to democracy. Here, such issues as how a deliberative forum is designed and who the moderator is are critical in satisfying the normative assumptions of deliberation. For example, the problem of power inequality in deliberation suggested by Young (1996) and Sanders (1997) can be mitigated by appropriate control and design of deliberation such as the organization of deliberative forums by a multi-partisan, neutral group and use of trained facilitators.

Another defense for deliberation is that deliberation theory and practice are still new and they are further developing constructively, accommodating the criticisms. Although the core of deliberation as a rational, reflexive, and civil communication remains intact, there are attempts to incorporate the insights from critics and practitioners. As noted above, Sanders (1997) and Young (1996) proposed alternative forms of speech to redress the power inequality problems of deliberation. Such suggestions, to a certain extent, are now adopted by deliberation theory and practice. Those alternative forms of speech are usually accommodated by "dialogue” before deliberation. While deliberation is focused on addressing a shared problem and arriving at solutions to that problem, dialogue emphasizes mutual understanding as a means to an end of establishing a shared ethic, or moral foundation for a just society (Levine, Fung, \& Gastil, 2005). Dialogue is a form of communication that allow deliberators to forge a shared way of speaking when there exist important cultural and linguistic differences and different conceptions of discourse norms and ethics among groups. As Ryfe (2006) observes, actual deliberation in reality is preceded by such conciliatory dialogue. Newer theories of deliberation thus attempt to incorporate those insights from actual deliberation practices. 


\subsection{Deliberation and Societal Communication}

Up to this point, the concept of deliberation has been discussed as a type of communication. In doing so, the paper focused on citizens' face-to-face, interpersonal communication. This is because in the discipline of communication, deliberation tends to be studied as an interpersonal political communication or small-group decision making phenomenon. But discussion of deliberation can concern various levels of analysis, not just the interpersonal level. For example, political scientists study deliberation and its connection to democratic legitimacy, which usually involves group, societal, country, or international levels of analysis. Microscopic analysis of deliberation is where the discipline of communication has strength. However, it would be necessary for communication scholars to go beyond the micro level and also study a macro level, societal communication flow involving deliberation. At the macro level, scholars may adopt a systematic perspective and study how different deliberative practices and institutions work together and how deliberative practices are created and mediated by the mass media system.

Neblo (2005) employs such a systemic perspective. He argues that the ideal circulation of communicative power calls for deliberation within civil society to set a broad agenda that is communicated to the formal institutions of government, who deliberately develop concrete policies that interpret and implement that agenda, and are then responsible to convince the weak public. This view stems from Habermas’s (1998) distinction of weak/strong communicative actions and weak/strong public spheres. In general, the weak public sphere refers to the broad civil society and the strong public sphere refers to parliamentary assemblies and other formal, institutionalized bodies. 
Weak communicative action is oriented toward reaching understanding and strong communicative action is oriented toward consensus. In the weak public sphere, broad opinions are formed through free and open citizen communication, but will-formation and decision making are reserved for institutionalized deliberation in the political system. Communication studies have focused on deliberation occurring in the weak public sphere and at the interpersonal level. Many political science studies concern deliberation in the strong public sphere. What is lacking is a more systemic study on how the weak and strong public spheres are communicated. It is in this sense that Neblo and other scholars (e.g., Dryzek, 2006, Hove, 2009) call for organizing principles for the various sites of deliberation for healthy functioning of deliberative democracy.

The connecting of the weak and strong public spheres can be implemented by professional communicators. According to Habermas (2006), the vital components of a mediated communication system are journalists, experts, lobbyists, moral entrepreneurs, advocates, and intellectuals. They, on condition that they gain independence from their social environment, can facilitate deliberative legitimating processes in complex societies. Habermas suggests that such a mass mediated deliberation is expected to fulfill important societal functions:

To mobilize and pool relevant issues and required information, and to specify interpretations; to process such contributions discursively by means of proper arguments for and against; and to generate rationally motivated yes and no attitudes that are expected to determine the outcome of procedurally correct decisions. (p. 416)

The emphasis on the enhanced role of professional communicators in deliberative democracy is well illustrated in the recent public or civic journalism movement. In public journalism, the job of the press is encouraging deliberation among citizens, not 
just providing more information. In addition to that, Ettema (2007) argues the mission of public journalism is not only recording the processes of deliberation but also acting as a reasoning participant in those processes. In Ettema's vision, journalism becomes a "reason-giving” practice where the press provides reason about the application of substantive values to particular cases (p. 146). Indeed, journalists are the key factor who can connect the weak and the strong public spheres and facilitate the functioning of the whole deliberative system and thus public journalism warrants more attention. 


\section{CHAPTER 3}

\section{THE CULTURAL DIMENSION OF DELIBERATION}

What might be added to the present discussion of deliberation and deliberative democracy is the role of culture. Both proponents and critics of deliberation have seldom explored the role of culture in deliberation. There are some theoretical works on how deliberation may work in multi-cultural societies (e.g., Benhabib, 2002), but currently almost no studies exist on how the deliberative democracy model can be applied to nonWestern cultures. Recently, there have been some deliberation experiments in China (Leib \& He, 2006), but the specific role of local culture was not explored thoroughly. As the theory and practice of deliberative democracy extend their scope to the global arena, there is a need to explore whether the current deliberative model is applicable to nonWestern contexts. While the deliberation business is blooming across North America, the idea of deliberative democracy is foreign to some parts of the world. In East Asia, in particular, the concept is difficult to find. Is deliberative democracy a purely Western concept? Is it applicable to non-Western countries? How can researchers be sensitive to different cultural values concerning deliberation? This chapter explores those issues by focusing on deliberation prospects in East Asia. It starts with a broad critique of deliberation theory as a Western concept. 


\subsection{Deliberation, a Western Bias?}

As noted earlier, rationality, criticality, argumentation and open discussion of disagreement constitute the core values of deliberation. Those are also the fundamental assumptions of Habermas's grand theory of communicative action and the public sphere, which serves as the backbone of most contemporary deliberation theories. Perhaps Habermas's theory will be best understood as an extended Enlightenment project of the modern West. Due to his implicit emphasis on modern Western rationality, a handful of scholars criticized Habermas’s theory as being “eurocentric,” or “occidental.” Delanty (1997), for example, in a careful critique of Habermas' universal morality and rationality, argues that Habermas’s theory has a residual eurocentrism. According to him, Habermas' concept of universal morality is "an evolutionary theory culminating in the discourse of occidental rationalism and thus fails to see that universal morality can be articulated in more than one cultural form and in more than one logic of development” (p. 42). Delanty further argues that Habermas demands a too-radical distinction between discourse and cultural contexts. He thus argues that Habermas tends to see culture and identity as something people leave behind when they enter public communication.

Gunaratne (2006) makes a similar claim, but does so in the context of Eastern philosophy. First, his assessment of Habermasian theory is that it does not reflect an effort to understand or analyze non-Western philosophical thinking on rationality because Habermas operated by following the path of the occidental sociological approaches to societal rationalization. Therefore, concepts like the public sphere are less useful in nonWestern contexts. This is echoed in Li's (1995) argument that the Western distinction between the public and private spheres has historically hardly existed in Confucian 
societies. As Gunaratne argues, "in the absence of bourgeois revolutions in post-colonial societies, bourgeois public spheres in the Habermasian mold are unlikely to take hold” (p.117). Gunaratne then argues that truth, rightfulness and truthfulness, which are the three criteria of validity in Habermas' speech acts, might be Western-culture specific. Citing examples of Indian and Chinese philosophies, Gunarantne explains that the realization of truth is facilitated not by rational validity claims but by intuition in traditional Eastern culture.

Culture is the modus operandi of a group of people; the shared value system. In Habermasian terms, culture reveals an affinity with the "lifeworld." The lifeworld represents a "culturally transmitted and linguistically organized stock of interpretive patterns” (Habermas, 1987, p. 124). The lifeworld is sustained by cultural reproduction, social integration and socialization. A key characteristic of the lifeworld is that it is “preconscious” among its constituents, meaning that it provides us with meanings, identities, and pre-contexts that we can never leave behind. What this suggests is that cultural norms in the lifeworld are resilient. Hence, Jacobson (2008, p. 33), discussing Chinese civil society, argues that Confucian norms are part of society's cultural lifeworld and that “it is not reasonable to imagine China 'not' carrying some of its Confucian norms forward."

If we posit the cultural distinctiveness and resilience of the lifeworld in nonWestern societies, then the applicability of the deliberative democracy model to nonWestern contexts will be put into question. The current deliberative democracy model and actual deliberative forums have arrangements that encourage specific Western norms and attitudes, but attitudes toward political conversation do not necessarily originate from 
such arrangements. They are likely to be "by-products of a preexisting culture" (Gambetta, 1998, p. 20). This means that there may be a clash between Western-imposed deliberation norms and the local forms of political conversation. Gambetta thus argues that, in some societies, the pre-existing culture may well be antithetical to deliberation. He divides the world into roughly two cultural areas based on people's beliefs concerning the structure of knowledge. The analytical knowledge society is where knowledge is deemed to be the result of good reasoning and empirical verification, and the indexical knowledge society is where knowledge is assumed holistic. Many of the Western, Anglo-Saxon countries belong to the analytical knowledge category, whereas (southern) Italy, Latin America and many authoritarian regimes are deemed to operate as indexical knowledge societies. According to Gambetta, there are dozens of behavioral consequences of an indexical approach to knowledge that pertain to political conversation. These include having strong opinions, having opinions on every issue and expressing strong emotions. Ordinary people in indexical knowledge societies generally refrain from publicly voicing their views. People will make their views known only if they are so taxed by some issue or contrary opinion that they build up enough aggressiveness to speak up. Moreover, it is harder for indexical knowledge people to change an opinion once expressed, and rhetoric rather than persuasion based on argument will likely to be more successful. These conversation-related traits of indexical knowledge societies may run counter to the norms of deliberation.

\subsection{Confucianism and Collectivism in East Asia}

Although Gambetta (1998) never mentions oriental cultures, some of the conversation traits of the indexical knowledge societies he introduces also apply to the 
East Asian societies of Korea, Japan, and China. What complicates things further is that these East Asian countries have strong Confucian and Buddhist cultural traditions that might not be well-suited to the current Western-style deliberation model. Here, it would be useful to review the cultural differences between Western and Eastern societies and how those differences may relate to deliberation.

Defining and differentiating cultures is a common task for anthropologists. The most significant work in this area comes from the cultural anthropologists Hall (1976) and Hofstede (2001). Based on how information is transmitted among individuals, Hall introduces the concept of high- and low-context cultures. A communication or message in a high-context culture involves most of the information to be either in the physical context or internalized in the person, while very little is in the coded, explicit part of the message. A low-context communication is just the opposite in that information is vested in the explicit code. High context cultures are more common in the Eastern cultures than in the Western, as well as in countries with low racial diversity. Japan is a prime example of a high context culture and the United States is a good example of a lowcontext culture, according to Hall.

The low versus high context distinction is closely in line with the individualist versus collectivist cultural distinction. This popular distinction is well documented in the empirical studies of Hofstede (1991, 2001) and Triandis (1995) and has been used as a major dimension of cultural variability in cross-cultural and intercultural communication studies for decades (Gudykunst \& Lee, 2002). According to Hofstede (1991), individualism exists in societies in which the ties between individuals are loose and thus everyone is expected to look after himself or herself and his or her immediate family; 
collectivism pertains to societies where people from birth onwards are integrated into strong, cohesive in-groups, which, throughout the people's lifetimes, continue to protect them in exchange for unquestioning loyalty. Hofstede developed a collectivism versus individualism index for the empirical study and the index shows that China, Japan and Korea are among the most collectivist countries. The United States was a leading individualistic country.

In addition to the famous collectivism versus individualism dimension, Hofstede's work has other cultural dimensions that merit discussion. The power distance dimension pertains to the extent to which the less powerful members of society expect and accept that power is distributed unequally. This is the way people receive power differences; in countries where large power distance exists, people feel more comfortable with the power inequalities of the society and decision making of those in power. According to Hofstede, China has a very high power distance index, suggesting significant power inequalities in society, whereas the United States has a relatively low index. Other East Asian nations, such as Japan, Korea and Taiwan, were also shown to have a relatively high power distance index.

The high collectivism and power distance scores Hofstede found in East Asian countries may have resulted from the region's dominant Confucian cultural heritage. Confucianism has remained a mainstream orthodoxy for two millennia in China and has had great influence in Korea and Japan for hundreds of years. Confucianism is a philosophy of human nature which considers proper human relationships as the basis of society (Yum, 1988). Confucian principles dictate that individuals should follow proper rites in social interaction. Based on those principles, scholars have identified several 
themes that define social communication and interactions in Confucian cultures (Hofstede \& Bond, 1988; Yum, 1988).

One of the key Confucian themes identified by Hofstede and Bond (1988) is social hierarchy. The hierarchical relationship typical in East Asia is influenced by Confucius's Five Codes of Ethics, which stipulate that the ruler should show justice and the subjects should show loyalty; the father should show love and the son should show filial piety; the husband should show initiation and the wife should show obedience; the older brother should show brotherly love and the younger brother should show reverence in return; and friends should show mutual faith in each other. These ethics are said to have created justifications for unequal social relationships in Confucian society (Chen \& Chung, 1994).

Another Confucian theme is the family system as a basic social unit. Confucianism is "like social cement that fixes family members in the network of their appropriate hierarchical relationship” and basic familial values, such as loyalty and obedience, are transferred to social organizations (Chen \& Chung, 1994, p. 96). Similarly, Yum (1988) argues that East Asian interpersonal relations and communication patterns are characterized by, among other things, the particularistic relationship rules that vary according to contextual factors, such as the interaction partners' social standings, the in-group/out-group distinction arising from allegiance to one's own group, the use of intermediaries in relationships, the overlap of personal and private relationships, and the emphasis on indirect communication.

Overall, it can be said that all Confucian ethical principles have existed to achieve the ultimate societal goal that Confucius saw as most important: Social harmony. What 
is assumed in the Confucian philosophy is that if each member of society knows his or her place in the social order and acts according to specific principles, social harmony will be achieved.

\subsection{Citizen Deliberation in East Asian Contexts}

What would be the specific attitudinal and behavioral consequences of such a Confucian, collectivistic culture that can be manifested during deliberation, then? How do they interact with the norms of formal deliberation? The distinctiveness of East Asian political deliberation can be mapped along several themes: In comparison to the West, people in East Asia appreciate the value of public talk less, are more sensitive to the role of power and status differentials during public conversation, are more susceptible to pressure to conform, and possess a different reasoning process which may be antithetical to the current Western norms of deliberation. To substantiate this claim, some insights from cross-cultural communication and psychology in terms of both theory and empirical evidence are presented in this section.

In the West, open discussion of public affairs has been considered the "soul of democracy.” From Aristotle to Dewey to Tarde, political discussion is an essential element for the proper functioning of democracy. Tarde (1898/1969) thus praised the role of political conversation:

From the political point of view, conversation is, before the press, the only brake on governments, the unassailable fortress of liberty. It creates reputations and prestige, determines glory and therefore power. It tends to equate the speakers by assimilating them to one another and destroys hierarchies by expressing them. (p.313)

Tarde's romantic view of conversation, however, is in stark contrast to that of Confucius. Confucian teachings admonish followers to be cautious about their speech, 
because the "smartness" of speech elicits hatred from others. Therefore, one’s speech should be simple (Chen \& Chung, 1994). Also consider this Buddhist expression: "Words, words, words: Fluttering drizzle and snow. Silence, silence, silence: A roaring thunderbolt” (Johnson \& Paulenich, 2001). In Buddhism, another major philosophy of East Asia, silence is praised as a way of meditation and learning. According to Buddhist traditions, a higher perception of the truth is triggered not by Buddha's verbal preaching but by experience (Tsujimura, 1987). Due to this Buddhist tradition, silence, which is often associated with passivity and negativity in the West, takes on positive meanings in the East.

It might be overgeneralization and simplification to say that speech is not valued in East Asia. Also, it is unclear how the Confucian and Buddhist teachings exercised in theory in high culture have been manifested in the everyday life of ordinary people. We do observe, however, that conversation is freer and more frequent in Western societies than in the East. Loud and lively conversations are easily heard in environments from train cabins to school classrooms across America. Argumentative individuals are often considered confident and intelligent in the West. On the other hand, East Asians are more cautious toward speech and often the maxim "silence is golden” is valued. Many teachers and professors in the U.S. do report that students from East Asian origins are more reticent and reserved regardless of their language ability, though this may reflect prejudice on behalf of the perceivers. This notion is actually supported by some empirical academic studies, as well. Giles, Coupland and Wiemann (1992) surveyed Chinese and Americans and found that Chinese were more tolerant of silence. Elliot, Scott, Jensen and McDonough (1982) found that reticent individuals were perceived 
more positively by Koreans whereas verbal individuals were perceived more positively by Americans. Cross-cultural studies of communication apprehension and argumentativeness also suggest that East Asians, as compared to Westerners, show a high level of apprehension and/or a low level of argumentativeness, especially when they talk to older people or people in a superior social position (e.g., Kim, Tasaki, Kim, \& Lee, 2007; Prunty, Klopf, \& Ishii, 1990). In their study, Kim et al. explain that talk is appreciated and is generally rewarding in mainstream U.S. culture and thus a high premium on the amount/frequency of talk is imposed on the U.S. culture, which is not the case in East Asia.

The above observations suggest that there are more cultural inhibitors of talk among East Asians. Those inhibitors may become particularly strong when the talk is a "public" talk involving disagreement or public deliberation. In this regard, TingToomey’s (1988) face negotiation theory provides further insights into how East Asians approach talk characterized by conflict. The face negotiation theory, a well-developed research program in intercultural communication, suggests cultural differences in the means of managing conflict situations. Deliberation, of course, is not the same as interpersonal conflict, but deliberation does involve disagreement and its resolution, which suggests the existence of a certain level of conflict and therefore her theory is useful here. Drawing on Goffman’s (1967) work, Ting-Toomey explains that “face” represents an individual's claimed sense of positive image in the context of social interaction. Face is considered a metaphor for the public self-image, which one wants to be positively perceived. Ting-Toomey argues people try to maintain and negotiate face in all communication situations, but the style of face negotiation differs by cultural 
background. Different face concepts will subsequently result in diverging response strategies in conflict situations. Based on the distinction of individualism vs.

collectivism, she explains that individualistic members will be more concerned about their own face because of their "I-identity" priority, and will tend to use more self-face defending strategies in conflict situations, such as justifications and situational excuses. But collectivists are more concerned about others' or mutual face, and thus they tend to use more self-effacing strategies in conflict situations to ward off potential face threats (Ting Toomey \& Kurogi, 1998). In other words, individualist members are more likely to try to save their own face whereas collectivist members are more likely to save others' or mutual face.

Ting-Toomey and colleagues (Ting-Toomey, Oetzel, \& Yee-Jung, 2001) proposed eight different types of conflict management styles. These are avoiding, obliging, compromising, dominating, integrating, emotional expression, passive aggression and third-party help. People from an individualistic culture tend to have more concern for self-face and, when facing a conflict, they are likely to dominate others, express strong emotions, and be (passively) aggressive to manage conflict. People from a collectivistic culture, on the other hand, are likely to avoid conflict, oblige to others, seek compromise, seek third-party help or seek integration. To a varying degree, her theory has been supported by many empirical studies (e.g., Oetzel \& Ting-Toomey, 2003; TingToomey, Gao, Trubisky, Yang, Kim, Lin \& Nishida, 1991; Ting-Toomey, Oetzel \& YeeJung, 2001).

Summarizing the arguments so far, talk has less value in East Asia compared to Western culture. We may suspect that collectivist individuals from East Asia are less 
likely than the individualists of Western culture to appreciate open discussion of disagreement, a core principle of deliberation. If an open discussion of disagreement does take place, collectivist members may avoid direct confrontation and use indirect language and innuendos. They will also care about their mutual face or public image. They may want to be seen harmonious publicly and hope to reach understanding or consensus in public deliberation forums, even though they disagree substantially in private. It has been suggested that Americans will also avoid public political talk with individuals with differing viewpoints for the sake of social harmony (Mutz, 2006), but the degree of aversion to controversial public talk will be much greater and the strategies of dealing with uncomfortable public talk may be more nuanced for East Asians than it is for Americans.

Another core principle of deliberation is that communication among the deliberators should be equal and only the "force of better argument," not coercion or any other form of power, should dictate the talk, but it has been observed that power dynamics sometimes dominate deliberation (e.g., Mendelberg \& Oleske, 2000; Sanders, 1997). The issue of power becomes more prominent in the deliberative forums of East Asia, where social hierarchy by age, status and gender is much more pronounced than it is in Western societies. As evidenced in Hofstede’s (2001) power distance index, China, Japan and Korea have a stricter social hierarchy and people are relatively comfortable with power inequality. Indeed, it is a social norm in East Asian society for juniors not to directly refute the positions of elders.

This notion is also supported by several empirical studies. Richey (2006)’s study of everyday political discussion in Japan suggests that Japanese political discussion is 
characterized by pressure from superiors. The pressure was especially prominent on lowstatus participants such as women and laborers, according to Richey. Another study by Richey and a colleague (Ikeda \& Richey, 2005) found that the Japanese easily perceive social hierarchy, clearly suggesting that hierarchy in Japanese life is not a stereotype but rather a cultural reality. Kim, Tasaki, Kim, and Lee’s (2007) study also found that levels of communication apprehension were higher for collectivist East Asian students in conversations with high status communicators than in conversations with low status communicators, a trend that was less pronounced among individualist American students.

The Western deliberation norms emphasizing equality and egalitarian communication may become problematic among East Asian deliberators. Due to enhanced power dynamics in discussion, it is likely that East Asian participants will be more concerned about the face of their elders or people with higher social status. It may be observed that elderly people and people with high social status exert more influence regardless of the quality of their argument, and juniors give respect, at least publicly, to the opinions of the seniors.

Western scholars sensitive to the issue of power in deliberation advocate alternative forms of speech in deliberation, such as narratives and rhetoric instead of direct argumentation (Sanders, 1997; Young, 2000); that solution will be less effective for East Asian participants, however. This is because of the inherent characteristics of East Asian languages. Korean, Japanese, and, to a lesser degree, Chinese reflect the Confucian ethics of human relationships and feature a complex system of vocabulary and locutions that vary widely according to age, social status, occasion, and gender. This complex language system is necessary because human relationships are well defined in 
East Asian societies and a particular system of etiquette is already prescribed (Yum, 1988). Since the East Asian languages themselves are structured by power relations, it will be difficult to achieve equal and free communication even using alternative forms of speech.

What is even more antithetical to the current Western norm of deliberative equality is the Confucianism-influenced tendency to defer to the power of authority. Obedience and deference to authority are often observed in Japanese society and are also pronounced in communist China, where speech is limited. Public deliberation many times involves a discussion of governmental policies. In discussing governmental issues, Chinese citizens’ willingness to criticize their government will be seriously limited. Currently, almost all citizen deliberation forums in China are organized by local governments that are regulated by the authoritarian Chinese Communist Party. Free and equal deliberation free from the influence of power will be difficult to conduct in those conditions.

The discussion so far strongly correlates with conventional "conformity" research. Conformity refers to discussion participants' tendency to conform to majority opinion due to social pressure. Conformity is a universal human behavior found across cultures. Since the seminal social psychological experiments of Asch (1951), the existence of conformity has been well documented in individualistic American culture. Considering the collectivist nature of East Asians and their tendency to more readily defer to authority and elders, it can be argued that the degree of conformity will be higher among East Asian deliberators. Indeed, many cultural and social-psychological studies document a high degree of conformity among East Asians during group decision-making 
processes. Bond and Smith (1996) conducted a meta-analysis of conformity and found that, although conformity existed in all cultures, its degree was higher for collectivist societies.

Spiral of silence research, a popular research program on public opinion and communication, produced similar results. The spiral of silence theory (Noelle-Neuman, 1993) suggests that people who possess minority opinions will not express theirs for fear of isolation, and therefore there will be a downward spiral of minority opinion. The spiral of silence theory thus essentially is a theory of conformity. Recent spiral of silence research has turned to cross-cultural comparisons, and the findings suggest that the theory receives more support in the collectivist culture than in the individualist culture. A stronger tendency to withhold minority opinions was observed in Taiwan (Huang, 2005), and Singapore (Lee, Detenbar, Willnat, \& Graf, 2004) than that seen in the U.S. These studies controlled for individual traits and psychological variables, such as self-efficacy, and still found culture affected the willingness to express opinions.

One interesting issue that is worth discussing is that conformity among East Asians is more nuanced; the relationship among participants is a key factor in determining the levels of conformity. A study by Harris and Niebler (1998) found that a group of Chinese in-group participants, participants among other Chinese whom they knew well, reported feeling more rebellious, dominating and pressured than did Americans among their in-group participants. This contradicted the conventional wisdom that Chinese are more likely to conform. But the authors argued that the results made sense, because Chinese people are very willing to engage in conflict with their family or a circle of intimates in situations where their standing in the group is well 
established by tradition and time. This pattern was also observed in a study on Japanese participants; it was shown that Japanese students behaved more assertively with their friends than with strangers, whereas the American participants were more consistent with their assertiveness regardless of whom they talked to (Singhal \& Nagao, 1993).

Overall, conformity will be more likely to take place in deliberative forums among East Asians. Although it was found that East Asians are willing to engage in argumentation among intimates, they will not be eager to engage in direct argumentation or conflict in public deliberation forums made up of strangers from a variety of backgrounds. While deliberation often regards “consensus” as its ideal goal, conformity refers to situations in which individuals conform to majority social pressure even when they disagree in private. Conformity is not an ideal deliberation outcome as suggested by Western deliberation theorists, as the result was not achieved through rational argumentation.

Last but not least, there is the issue of cultural differences in cognitive and moral reasoning between Westerners and Easterners. Some psychologists argue that differences in culture will result in different modes of cognition and understandings of morality (Cole, 1996). For example, Rosenberg (2006) suggests that differences in the structure of the social and communicative contexts to which individuals are exposed may produce basic differences in how these individuals reason. In this view, our reasoning is patterned by the cultural resources available as we matured. Such differential reasoning can also be mapped onto the individualist-collectivist dimension. Peng and Nisbett (1999) argue that cognitive reasoning about contradiction is guided by tacit ontologies and epistemologies about the nature of the world and the nature of knowledge, and that there are fundamental 
differences in the ways Chinese and Westerners reason. They argue that individualist Westerners are influenced by Aristotelian logic and tend to polarize contradictory perspectives in an effort to determine which fact or position is correct. Westerners believe in the constancy of the world and believe it is possible to decontextualize propositions, understanding them just in relation to one another, not attending to the larger field of facts and theories in which the propositions are embedded. Collectivist Chinese, on the other hand, who are used to holistic approaches, prefer dialectical reasoning. They deal with contradiction through what might be considered a compromise approach, showing a tolerance of contradiction by finding a "middle way" by which the truth can be found in each of two competing propositions (p. 742). In a series of experiments, Peng and Nisbett found that Chinese participants preferred dialectical resolutions to social conflicts and preferred dialectical arguments over classical Western logical arguments. Furthermore, they found that when faced with two contradictory propositions, American participants polarized their views, whereas Chinese participants were moderately accepting of both propositions. Peng and Nisbett called this tendency of Chinese to seek compromise "naïve dialecticism", which assumes that there can be some truth to both of two opposing propositions and hence implies that no side should win in a debate. They emphasized that naïve dialecticism implies the Chinese fundamental philosophy that "concepts and words are flexible and only auxiliary to human actions, and hence verbal debate and argumentation are not meaningful tools for understanding truth and reality” (p. 747).

Based on such a finding, we may suspect that East Asian deliberators may prefer to accept elements of both positions to the same degree in political deliberation forums 
where one position is in conflict with another. This further implies that deliberation based on Western-style rational argumentation and conflict resolution is less likely in East Asian deliberation contexts.

Similarly, there may be a cultural factor at work in moral development and reasoning. In his influential developmental psychology work, Kohlberg $(1981,1984)$ laid out six stages of moral development, which are the basis of human moral reasoning. The six stages range from the most primitive one-the obedience and punishment orientation — to the development of universal ethical principles. Ma (1988) criticizes Kohlberg's theory, saying that it is based on Judeo-Christian Western concepts of morality. He then revises the theory to include Chinese perspectives on morality. He thus adds such principles as the Golden Mean, or behaving in dialectical ways to maintain social harmony. Ma’s subsequent empirical study (1989) found that Chinese participants, when compared to English participants, tend to perform altruistic acts toward others and to abide by the law. Chinese participants also emphasized the role of human affection in moral reasoning. Ma's studies suggest that it may be the case that a different type of reasoning may be at work in East Asian deliberative forums involving moral issues. 


\section{CHAPTER 4}

\section{COMMUNICATION TECHNOLOGY AND DELIBERATION}

Current innovations in new media and computer technologies allow us to practice novel ways of social interaction. In the realm of politics, there is a rosy hope that computer-mediated-communication (CMC) may become a site of rational and critical discourse as envisioned by Habermas, contributing to overall advancement in politics and democracy. This is why we see many studies connecting the Internet and deliberative democracy (e.g., Bohman, 2004; Shane, 2004). At the same time, however, we are already observing disenchantment with the democratic possibilities of CMC, as there is a growing number of studies critical of politics online. The existence of a diverse array of studies confirms this heated controversy: For some, the Internet becomes an electronic frontier where the previous power relationship is reversed and the new forms of politics are experimented with (Rheingold, 1993). For others, however, the Internet is the medium in which we see politics as usual (Margolis \& Resnick, 2000) or the real-world inequalities are even exacerbated (Wilhelm, 2000). This chapter will evaluate the democratic potential of the Internet focusing particularly on the medium's impact on dialogic communication in the public sphere. It will then discuss CMC's implication for deliberators with collectivist cultural orientations. 


\subsection{Anatomy of Online Communicative Action}

Many of the studies concerning the Internet and the public sphere adopted a macro perspective and mostly concern the social outcomes of the changes that the new technology may bring. In doing so, little attention has been paid to actual dialogic communicative processes taking place in the public sphere. As Verstraeten (1996) emphasizes, however, the dynamics of communicative action in the public sphere can only be understood if one also considers the micro level. Indeed, in order to get a more proper picture of communicative action online, a micro level analytic framework will be necessary.

To broaden our understanding of the role of the Internet in dialogic human interaction, it might be useful to look at theories from the discipline of communication. Although most of them have been developed to account for interpersonal relationships, communication theories do provide some micro level perspectives that can be utilized to assess communicative action and the public sphere. Some of the theories, in particular, specifically concern online interaction and thus are useful to re-construct Habermas's deliberation theory for the new media environment.

Many traditional communication theories present a skeptical outlook toward online interaction. Social presence theory (Short, Williams, \& Christie, 1976) suggests that much of a medium's social effects are caused by the degree of social presence provided by the medium. Social presence refers to a communicator's sense of awareness of the presence of an interaction partner and it is critical because it allows the communicator to come to know and think about others, their characteristics, qualities, and inner states. Under social presence theory, communication is most effective when 
verbal and non-verbal cues are present because diverse cues increase social presence. If social presence theory is applied to CMC, then it follows that online communication is not effective because of the lack of social context cues. Similarly, media richness theory (Daft \& Lengel, 1984) suggests that a rich medium that has multiple channels and cues is most effective for cognitive information processing and exchanges of emotion. The theory establishes a media hierarchy in terms of richness: Face-to-face (FtF) communication is the richest followed by telephone, letter, etc. Media richness theory thus suggests that "lean” media such as text-based CMC would not be an efficient communication medium for exchanging emotionally complex messages. From a socialpsychological perspective, furthermore, social identity/de-individuation (SIDE) theory proposes that online opinion tends to polarize easily due to in-group out-group discrimination (Lea \& Spears, 1991; Spears \& Lea, 1992). According to the theory, online discussion participants remain anonymous and thus lose individual identity, instead developing a strong group identity, which may not necessarily be beneficial to deliberation.

Empirical studies of CMC, although not specifically involving deliberation, support the notion that effective online interaction is not an easy task. Kraut, Lundmark, Patterson, Kiesler, Mukhopadhyay, and Scherlis’s (1998) study shows that interactions over the Internet are associated with individuals' decreased social involvement and psychological well-being. Other researchers argue that communities on the Internet lack norms to sustain themselves and are marked by flaming, or irrational communication behavior (e.g., Blanchard \& Horan, 1998; Kaynay, 1998). Wilhelm (2000) who specifically analyzed online political discussion argues that online discussion is not 
deliberative as the messages are the short-lived, atomized cries of individuals. Reviewing previous research, SIDE theorists (Postmes, Spears, \& Lea, 1998) suggest that when communicators in CMC share a common social identity, they appear to be more susceptible to group influence, stereotyping and discrimination against other groups. Most of these studies are based on the idea that due to the anonymity and decreased social presence of online interaction, users are easily led to uninhibited, irrational behavior.

Other scholars, however, argue that online interaction can be effective and deliberative. Walther (1992) argues that even though non-verbal cues are filtered out in CMC, this does not create a serious problem for effective communication because of other distinctive features of CMC. He argues that verbal cues are sufficient for rational information processing and his empirical studies (e.g., Walther, 1993) support this. His studies suggest that the cognitive requirements of language that lead to rational communication behavior can be realized in CMC. Papacharissi’s (2004) analysis of online discussion forums, furthermore, shows that there were few flaming instances in online political discussion and much of the discussion was characterized by civility.

The contradictory perspectives above need to be reconciled. In particular, CMC’s potential needs to be assessed specifically in deliberation contexts for this study. To this aim, it will be useful to have an in-depth look at the deliberative potential of CMC, focusing on key normative assumptions of deliberation. That is, to what extent can CMC meet Habermas’ demanding criteria for ideal discourse relative to FtF deliberation? A handful of theorists have identified important discourse principles from Habermas’s work. Schneider (1997) argues that rational communication in the public sphere requires 
the four dimensions of equality, diversity, reciprocity, and quality. Cohen (1989) argues that freedom, reason, equality, and reflexivity matter in communicative action. Dahlberg (2001a) finds six requirements that he assesses specifically for the CMC environment: Autonomy from state and economic power; exchange and critique of criticizable moralpractical validity claims; reflexivity; ideal role-taking; sincerity; and equal and discursive inclusion. While all these criteria are equally important, it is only analyzed here the norms of rationality, reflexivity, sincerity, empathy (ideal role-taking), and equality that can be used to assess the quality of the micro-level dialogic process taking place online.

First, can discussion in CMC be rational? In principle, CMC is not necessarily inferior to face-to-face communication in terms of the rationality dimension. Rationality emerges from reasoning and argumentation and contributes to the quality of public opinion. This rationality, according to Habermas, is achieved solely by linguistic exchanges. In other words, communicative rationality is based on linguisticallygenerated inter-subjectivity among interlocutors. If so, there is no reason to believe that text-based messages in CMC cannot contain good "reasons" and "justifications." The quality of reasons and justifications should not be undermined just because they are presented in CMC contexts.

Second, reflexivity means that interlocutors should critically reflect upon others' arguments and their own positions. Is reflexivity undermined in CMC? Again, there is no reason to believe that $\mathrm{CMC}$ is inferior to FtF communication in terms of reflexivity. Whether discussants can carefully think about arguments typically depends on their motivations and capacity, not necessarily on communication mode. If communication mode does matter, then CMC may be even more conducive to encouraging reflexivity 
than FtF communication. Walther (1992) suggests that most communication taking place online is asynchronous, meaning that exchanges do not take place at the same time. Of course, synchronous interactions dominate online chat rooms, but a great portion of CMC usage involves asynchronous exchanges including emails and bulletin boards. In asynchronous exchanges, interlocutors may have more time to reflect upon the arguments and make more efforts to present them. Furthermore, text exchanges, which are the predominant mode of online interactions, can further promote reflexivity because written forms of communication usually require more thorough thinking and articulation when compared to speaking.

Third, the empathy requirement posits that discussants should put themselves in others' position to better understand others. Empathy has both emotional and cognitive dimensions. Emotional components include emotional involvement and identification and cognitive elements concern the process of perspective taking (Schaefer \& Dervin, 2001). A common criticism against CMC is that it will be difficult to have emotional empathizing under CMC due to lack of visual cues. Indeed, CMC may have a disadvantage in the empathy dimension as it is relatively difficult to exchange complex emotions over the Internet. But recent theory in cognitive psychology states that cognition and emotion are inextricably intertwined (LeDoux, 1996; Marcus, Neuman \& Mackuen, 2000) and this opens up a new window for CMC research, as emotion may be a part of each utterance (Glazer, 2002). For example, Marcus et al. argue that emotion is actually part of human information processing. If that is the case, then online discussants may convey task-related information and emotional content using the same words or symbols (Sproull \& Kiesler, 1991). Furthermore, novel ways of communicating 
emotions are developing in CMC. Emoticons are just one such an example. Therefore, as Lea and Spears (1995, p. 217) argue, online discussants can become adept at using and interpreting textual signs and paralinguistic codes and even first-time users form impressions of other communicant's dispositions and personalities based on their communication style. As it currently stands, however, exchanging complex emotions can be more readily achieved in the FtF mode where diverse social cues are present.

Fourth, sincerity is another important discourse principle because to reach an understanding, discussants should be civil to each other and make sincere efforts to exchange their true intentions and positions. A common criticism against CMC in terms of sincerity stems from the anonymity of CMC. As Wallace (1999) argues, people tend to become less inhibited by social restraints when they believe their actions cannot be attributed to them personally. In CMC, identity, although weak, still remains salient because online identity develops via multiple signifiers. These signifiers include, according to Dahlberg (2001a), nicknames, email address, language and writing style, and they provide online discussants with a degree of control over self presentation. But this high degree of self presentation is potentially also problematic because this means that users have a great capability to construct identities. It is fairly easy to change one's email address or screen name in CMC and thus online identities can be fluid. The rightness and truthfulness standards of Habermas’s communicative action rely upon mutual knowledge of socially situated subjectivity and the fact that identities are fluid or even can be manipulated in CMC thus become a challenge.

Fifth, is CMC discursively equal? The discussion of the digital divide aside, CMC has a big advantage here. Due to decreased social and visual cues, CMC 
discussants can interact more equally and their opinions can be judged by the arguments' validity, not by the discussants' social status or hierarchies. Therefore, CMC, in principle, can be more discursively equal than FtF communication. But as mentioned above, online identities are increasingly developing in CMC and this development of identity may lead to the reassertion of power differentials. As Dahlberg (2001a) argues, status develops online with every post, even when offline identities are not revealed and this may eventually lead to discursive inequalities. The identities revealed in CMC, however, are not as salient as the identities in FtF settings. Status and hierarchies are more quickly and easily defined in FtF settings by such factors as the locution and voice of the discussants, the way they dress themselves, their facial looks, and their body language. Fewer cues that will determine hierarchies exist in CMC and therefore discussants can be better judged by the merit of their arguments.

\subsection{Contexts for Effective Online Deliberation}

The above analysis suggests that CMC can meet the normative assumptions of deliberation to a certain degree. Even with some problems, CMC has many benefits that can encourage effective communicative action. Here, the bottom line is that CMC has very good deliberative potential and is not necessarily inferior to FtF communication to practice deliberative action. After all, what is important, whether it is online or face-toface, is to set an environment and process that are conducive to effective communicative action. If we approximate an ideal discourse environment and culture, both online and FtF communication will produce similar effects.

What are the contexts for effective online deliberation then? A systematic review of previous studies suggests that there are some conditions in which the normative 
assumptions of deliberation may be promoted in CMC. These conditions include the existence of codified rules, guidelines, and good moderation (Dahlberg, 2001b), extended interaction time with anticipation for future interaction (Walther, 1993) or some sorts of combination between CMC and FtF interactions (Etzioni \& Etzioni, 1999) and existence of a common identity and collective goals (Brunsting \& Postmes, 2002).

First of all, where right guidelines and rules exist, online deliberation is proven to be effective. The Minnesota E-democracy, one of the world's earliest e-democracy projects, is often praised as a successful online democratic dialogue project guided by appropriate regulations (Dahlberg, 2001b). According to Dahlberg, the success of the Minnesota project can be attributed to several factors: The forum had codified rules for rational and civil interactions and rule breakers were often suspended. For example, under a "signing post" rule, the discussants were required to put their real names, email address and city of residence. Also, there was a mentoring system in which new members were guided by old members to maintain and develop a culture of civility and cooperation in the forum. The role of the moderator in a deliberation forum is also important. The author's own previous study (Min, 2007) shows that when the moderator tries to maintain equal participation, control uncivil remarks, and keeps the topic on track, online deliberation can be quite successful. The existence of right guidelines, rules, and moderation is indeed crucial for the success of online deliberation.

Second, for effective CMC, an extended interaction time will be helpful, since interaction in CMC tends to be slower. Walther's (1993) study found that when given an extended time period, CMC groups gradually increased in impression development to a level of that in FtF groups. Furthermore, when extended interaction time is combined 
with discussants' anticipation for future interaction - either online of offline, this can create some normative expectations on the discussants, leading them to be more considerate to each other. Kline (1999) observes that online discussants, when they had future anticipation to meet with others face-to-face, reduced uncivil behavior dramatically. In general, it appears that $\mathrm{CMC}$ and FtF discussion forums are to some extent complementary in nature. Etzioni and Etzioni (1999) argue that discussant communities that combine both FtF and CMC systems would be able to bond better and share values more effectively than communities that rely upon only one or the other mode of communication. Turner, Grube, and Meyers’s (2001) empirical study supports this notion as they found that the online community is an avenue for gaining access to FtF relationships. Another reason that the Minnesota E-democracy was successful was because it was based on local communities that allowed possible future FtF interactions. That is, all participants there were Minnesotans and they knew that their online discussant partners were their neighbors whom they could meet easily in the FtF setting. This has an important implication: Aikens (1997) explains that a locally structured e-democracy project is a good mechanism because it increases the likelihood of adherence to normative values associated with the status of participants as citizens living within the proximity of concrete issues, activities and institutions. As Aikens emphasizes, "there is a very real incentive to adhere to normative values if one is involved in a discussion with individuals who are or could be a part of one's community life” (p. 136).

Third, a common group identity can be easily formed or manipulated to be formed in CMC and this may be helpful for deliberation. Here, the SIDE theory provides a good framework on how CMC can promote deliberation. SIDE theory often has been used to 
explain why online interaction may cause flaming and irrational behavior, but a different reading of the theory suggests a more benign side of online interaction. SIDE theorists (Spears \& Lea, 1992; Postmes, Spears \& Lea, 1998) argue that because CMC lacks visual and paralinguistic cues, users lose their individual identities and develop strong group identities. In the very absence of individual identities, CMC users become more susceptible to whatever identity is primed. Typically, these social or group identities are formed by the users' attention to the CMC group's collective goals and hence issueoriented. Indeed, many studies show that CMC users lose their individual identities and develop strong social identities and these identities are typically cognitive (e.g., Kim \& Min, 2007; Price, Nir, \& Cappella, 2006). What this suggests is that CMC deliberators, when reminded of citizenship and collective goals in advance, can develop enhanced attention to collective problem solving, which is beneficial to deliberation. That is, if it is manipulated in such a way that the most prominent identity in CMC is a collective citizenship identity, discussants will exert more energy on collective problem solving. The emergence of a collective identity, combined with balanced moderation and good guidelines for discussion, can promote deliberativeness of discussion.

As argued above, there are conditions under which online deliberation can become effective. It can be further argued that creating ideal discourse conditions can be more easily done in CMC settings. In FtF communication, creating certain discourse norms will take a great amount of time and resources. In CMC, however, the efficiency and malleability of technology make it easier to try out novel methods of communication and construct an environment for effective communicative action. For example, using technological settings in online forums, different types of moderation can be 
experimented with to find out the appropriate level of moderation ideal for deliberation; abusive language can be easily blocked by technological filters in online forums. As Bohman (2004) argues, the Internet can become a public sphere only if agents make it so. If deliberation researchers have recognized the deliberative potential of new technology, then now is time to focus on how to make online discussion forums more deliberative rather than discussing whether the technology or medium is intrinsically good or bad for democracy and deliberation. Researchers thus should try to find out and promote the right “discourse architecture” on CMC conducive to deliberation (Wright \& Street, 2007).

\subsection{Opinion Expression in Online Deliberation}

It has so far been argued that CMC has good deliberative potential comparable to FtF deliberation. There are even more advantageous aspects of online deliberation for specific populations. That is, CMC may provide unique deliberation opportunities to those who have cultural inhibition toward public talk.

In Chapter 3, Confucian, collectivist individuals’ cultural traits concerning public talk were discussed. These included the lower value of public talk, the strong influence of social position in talk, the increased pressure to conform, and the unique characteristics of their cognitive and moral reasoning processes. Such cultural traits are not necessarily favorable to public deliberation. To a certain degree, however, CMC may mitigate the collectivist individual's perceived difficulty in public talk. This is because of

the key characteristics of CMC: Decreased social presence and increased anonymity. In FtF discussion, the feeling of physical presence of discussants is strong and there is a variety of nonverbal and paralinguistic cues in discussion. These social cues and presence may exercise both conscious and unconscious normative influence on 
discussants (Burgoon, Buller, \& Woodall, 1989). In CMC, however, normative influence arising from social cues, although present, is decreased and this may contribute to more egalitarian communication. Influence arising from such factors as social status, age, or gender, is less pronounced in CMC and people with minority opinions may feel more freedom to express their views. This feature of CMC is especially encouraging for East Asian deliberators who are sensitive to social status and conformity pressure.

Although they did not specifically concern East Asians, existing studies of online discussion suggest that CMC can be a good venue of opinion expression for those who have attitudinal inhibitors toward public talk. Stromer-Galley’s (2002) comparative analysis of online and FtF political discussion shows that online political discussants are those who would not normally engage in FtF discussion. That is, the online political discussants were usually those who have less political efficacy and knowledge. These online discussants reported that they engaged in online political talk to hear diverse opinions and to have an opportunity to express opinions. Similarly, Ho and McLeod's (2008) survey found that CMC is conducive to opinion expression. They found that individuals with high "fear of social isolation” were less willing to speak out in general, but this effect was significantly attenuated in CMC settings. Studies in psychology also show that shy or introverted individuals find it easier to communicate online. Sheeks and Birchmeier's (2007) longitudinal study of CMC use suggests that individuals who indicated both higher levels of shyness and sociability reported closer and more satisfying online relationships than those who indicated lower levels of shyness and sociability. Amichai-Hamburger, Wainapel, and Fox (2002) found that introverted and neurotic 
individuals were more likely to reveal their true self in CMC, whereas extroverts and non-neurotic individuals were more likely to do so in FtF interactions.

The above studies did not include any cultural variables. But they consistently show results indicating that CMC is more beneficial to individuals and situations influenced by socio-psychological constraints because those constraints can be mitigated in CMC. It is very likely that cultural constraints toward public talk can also be mitigated in CMC, allowing collectivist individuals who are keen on conformity and social status to be more willing to express their opinions. 


\section{CHAPTER 5}

\section{RESEARCH QUESTIONS AND HYPOTHESES}

Based on the rationales discussed in previous chapters, several research questions and hypotheses are presented in this chapter. They are aimed at translating the broad observations into more specific statements for empirical investigation.

The first hypothesis concerns the cultural difference between Easterners and Westerners. Much has been discussed throughout this paper concerning the cultural distinction of individualism and collectivism. Are East Asians more collectivistic than Westerners as the wealth of empirical research suggests? The cultural difference between the two groups is a fundamental assumption that guides the rest of the research and it needs to be tested first. Therefore, the following hypothesis is presented.

H1: East Asian discussants will score higher on the collectivism scale than Western discussants will, and Western discussants will score higher on the individualism scale than East Asian discussants will.

To be qualified as deliberation, a discussion should satisfy normative assumptions such as rationality, civility and equality. Deliberation forums practiced today are aimed at promoting deliberativeness by pursuing such norms. To what extent are such norms met in deliberation? More interestingly for this study, how deliberative is the discussion for East Asian individuals who may not be familiar with Western-style deliberation 
forums? And how deliberative is online deliberation compared to FtF deliberation? The deliberativeness of each condition (Collectivist / Individualist / FtF / CMC) needs to be examined. Therefore,

RQ1: What is the level of deliberativeness in each deliberation condition?

The above research question may be answered by objective judgment of deliberation measured by discourse analysis or expert judges’ ratings. But it is of further importance to understand how the participants themselves feel toward deliberation. The main rationale of this study is that current deliberation practices are steeped in Westernspecific norms and rules that may run counter to the cultural traits of collectivist East Asians. As such, it is likely that collectivist discussants may perceive deliberation less favorably than individualist discussants. Furthermore, how discussants in the CMC deliberation condition, both collectivists and individualists, would perceive their deliberative experience relative to those in the FtF condition? Therefore,

RQ2: What is the discussants' self-assessment of deliberation in each deliberation condition?

Next, how does deliberation affect the opinions of discussants? It has been suggested that deliberation changes issue opinions, as observed in many experimental deliberation studies of Fishkin and colleagues’ Deliberative Polling. Post-deliberation opinions often are significantly different from pre-deliberation opinions as the result of enhanced discussion of the issues. In particular, it has been reported that individuals with no particular opinions often take a perspective after deliberation, resulting in decrease in the "don't know" or "neutral” option in a post-deliberation survey. The present study will look at how deliberation changes discussants' issue opinions looking at the 
magnitudes and directions of the changes. In line with many previous studies (e.g., Fishikin \& Luskin, 1999; Gastil \& Dillard, 1999), it is likely that mean issue opinions are different before and after deliberation across the deliberation conditions. Furthermore, the opinion changes may turn out differently depending on whether the discussants are in the CMC condition or in the FtF condition and whether they are in the collectivist condition or in the individualist condition. This is because different dynamics of discussion may exist in each condition due to differences in culture and communication mode. Therefore, the following research question is presented:

RQ3: What are the magnitudes and directions of opinion changes in each deliberation condition?

In empirical deliberation research, not only mean opinion but also the "variance" of the mean opinion is of interest. Here, variance refers to the degree to which individual opinions are dispersed from the mean opinion, which in fact is the same as the basic statistical concept of variance. Variance becomes an important measurement in deliberation research because it can serve as an indicator of opinion convergence. It has often been suggested that deliberation will produce unidirectional shifts in opinion (Habermas, 1990). After rational exchanges of arguments and information, a superior viewpoint may emerge and individuals’ opinions may cluster around this superior viewpoint, resulting in a lower opinion variance. However, there is a "polarization” possibility as well in which deliberation causes discussants to go to extreme opinions (Sunstein, 2003). If polarization does take place, this will result in a higher level of opinion variance after deliberation. This study will find out whether deliberation causes opinion convergence or polarization. More interestingly for this study, furthermore, the 
change in variance due to deliberation may turn out differently depending on deliberation conditions. As noted in the previous chapters, collectivist discussants in the FtF deliberation condition may show a greater likelihood of opinion convergence due to their increased concern for social harmony and their reasoning tendency to choose the "middle road” facing contradictory positions.

RQ4: What are the magnitudes of opinion variances in each deliberation condition before and after deliberation?

Concerning freedom to express opinions during deliberation, all discussants in the CMC condition should feel more freedom than those in the FtF condition due to increased anonymity of online deliberation. Therefore,

H2a: Overall, discussants in the CMC condition will feel more freedom to express views than discussants in the FtF condition.

Collectivist individuals generally less appreciate the value of public talk. Collectivists also tend to constantly monitor others' and their own opinion status and generally refrain from presenting views that directly challenge others. Collectivist discussants in the FtF setting will feel less freedom to express their opinions due to various cultural inhibitors toward public talk. This tendency, however, may disappear or be mitigated in the online setting where expression is considered to be freer. Therefore, H2b: Collectivist discussants in the FtF condition will feel less freedom to express their views than discussants in other conditions.

Social influence is always present in every human interaction. Deliberation is no exception to this rule. However, the degree of influence will be different depending on conditions. Social influence is likely to be stronger among collectivist discussants 
communicating in the FtF setting because collectivists are sensitive to social status in FtF interaction. Social presence and cues will be at work and those with higher social status are more likely to be influential for collectivist discussion groups. Age is perhaps the most pronounced social cue for collectivist individuals. Due to Confucian traditions in which elders are respected, older participants are more likely to have more freedom to express their views, and possibly may be more satisfied with deliberation. Even one year difference is considered very significant in social life for university students in East Asia. Indeed, social life in universities in East Asia is often structured by age. The importance of age, however, is less pronounced in individualists' social interactions. Also, it is likely that due to decreased social cues, the role of age in deliberation will be mitigated for collectivist individuals deliberating in the online condition. Therefore, Hypothesis 2c is presented as follows:

H2c: Older discussants (higher in school rank) will have relatively more freedom to express their views in the collectivist/FtF deliberation condition when compared to other conditions.

One of the chief benefits of deliberation is that it can increase participants' political efficacy. Through deliberation, it is expected that participants become confident in their views and willing to express them and hence increase self-efficacy in political affairs. That is, the more discussants learn, think, and talk about politics, the more they tend to feel capable of dealing with it and will likely to participate in it. Can deliberation increase political efficacy for collectivist individuals as well? How about discussants in the CMC condition? Therefore, 
RQ5: To what extent does deliberation affect discussants’ political efficacy in each condition?

The following table summarizes the hypotheses and research questions. 
No.

Research Questions / Hypotheses

RQ1 What is the level of deliberativeness in each deliberation condition?

RQ2 What is the discussants' self-assessment of deliberation in each deliberation condition?

RQ3 What are the magnitudes and directions of opinion changes in each deliberation condition?

RQ4 What are the magnitudes of opinion variances in each deliberation condition before and after deliberation?

RQ5 To what extent does deliberation affect discussants’ political efficacy in each condition?

H1 East Asian discussants will score higher on the collectivism scale than Western discussants will, and Western discussants will score higher on the individualism scale than East Asian discussants will.

H2a Overall, discussants in the CMC condition will feel more freedom to express views than discussants in the FtF condition

H2b Collectivist discussants in the FtF condition will feel less freedom to express their views than discussants in other conditions.

H2c Older discussants (higher in school rank) will have more freedom to express their views in the collectivist, FtF deliberation condition when compared to other conditions.

Table 5.1 Summary of Hypotheses and Research Questions 


\section{CHAPTER 6}

\section{METHOD}

The empirical design of this investigation entails a social-psychological experiment of group discussion. In the tradition of small group research, laboratory experimentation has been the dominant research method for many decades. But such a strongly positivistic paradigm is often criticized as being insufficient to explore the groups' embedding contexts. Specifically, McGrath, Arrow, and Berdahl (2000), in a review of small group research methods, criticized that laboratory experiment deals with groups as if they were simple systems composed of chain-like, unidirectional, causeeffect relations. The criticism is well warranted and field studies to study "real-life" groups are on the rise. In the present research, however, experimental method is deemed more appropriate. This is because, deliberation, by its nature, entails some experimental characteristics. First of all, deliberation concerns exchanges of disagreement in the public arena. Discussion of disagreement is less likely to occur in everyday, naturally occurring political discussion because it is human nature to prefer to talk with people possessing similar viewpoints. That deliberation itself requires exchange of disagreement means imposing some control on issue discussion. Similarly, deliberation is about creating ideal speech conditions, promoting rational and equal discussion of issues, and this also means imposing some controls. The controls usually appear in the form of the 
presence of a trained moderator and briefing materials. Indeed, this is how deliberation is conceptualized in popular deliberation forums and studies today such as the National Issues Forums, AmericaSpeaks and Deliberative Polling. A key goal of this study is to see how deliberation, as practiced currently, may work differently for individuals of collectivist cultural origins. To study this goal, it will be necessary to adopt the currently dominant, widely used methodological framework of experimentation.

A critical issue in empirical research of deliberation is measuring deliberation. Unlike previous research, the present study adopted multifaceted ways of measuring deliberation. Here, deliberation is measured by the discussants' self-assessment, external judges’ assessment, and content analysis.

\subsection{Procedure}

A total of 147 students in a large mid-Western university were sampled through class and public announcements. Seventy students were American students, representing the individualist culture and 77 were Korean students, representing the collectivist culture. Those who volunteered in the project through classes received extra credit and those who were recruited through public announcement received \$25 cash for participation. After informed consent, the students were assigned to small deliberation groups consisting of roughly 4-7 people $($ Mean $=5.25$, Mode $=5)$. American students were with other American students discussing in English, and Korean students joined their own ethnic group, discussing in their native language.

Between July and October, 2008, a total of 28 small deliberation groups were conducted: 14 individualist (American) and 14 collectivist (Korean) groups. Of the 14 individualist groups, 7 groups deliberated in the FtF setting and the other 7 deliberated in 
the CMC setting. Likewise, of the 14 collectivist groups, 7 groups deliberated in the FtF setting and the other 7 deliberated in the CMC setting. The assignment to the FtF and CMC conditions was randomly made. In essence, the experiment was a $2 * 2$ design where culture (individualist vs. collectivist) and mode of communication (FtF vs. CMC) were the two factors. The FtF groups deliberated in the school's conference room. CMC groups deliberated using chat software. Each CMC discussant used an individual, compartmentalized computer station and a pseudonym, making the discussants anonymous to each other. Each group spent around one hour in discussion.

All discussants took a survey before and after deliberation. In the pre-deliberation survey, their cultural orientations, demographics, personal traits and attitudes, and initial opinions on the issues to be deliberated were measured. In the post survey, issue opinions were measured again along with the discussants’ attitudes toward the deliberation. Before deliberation, discussants read short briefing materials to get acquainted with the issue. The existence of briefing material, however, might confound the effect of deliberation. To minimize this possibility, reading the briefing materials was preceded by the pre survey. In other words, the effect of reading briefing materials, if any, must have been captured in the pre survey.

The survey and briefing materials were originally written in English. The materials then were translated into Korean to be administered for the Korean group. The translation of the survey items required some care as it was required to maintain consistency of meaning for each item across English and Korean. Using the backtranslation technique used in cross-cultural survey research (e.g., Brislin, 1970), all items were translated from English to Korean. The Korean version was then back-translated to 
English by a bilingual, professional translator. The back-translated items were compared to the original English version to detect discrepancies. The Korean translation was then adjusted accordingly.

Moderators were present for deliberation. There were three moderators. One moderator, an American, presided over most of the online and FtF deliberation sessions for American students. The other moderator, a Korean, led most of the deliberation sessions for Korean students. The author led two sessions for the Korean and American groups each. There might be important differences between the moderators and any observable differences in deliberation processes and outcomes between the collectivist and individualist conditions might arise from moderator differences, not necessarily from cultural differences. To minimize this possibility, the moderators were advised to follow set discussion protocols, scripts, and questions. Before the start of deliberation, all discussants were asked to introduce themselves, stating their names (for CMC, they were given random pseudonyms reminding of school) and rank. They then were told their voice would matter a lot for school policy and asked to carefully weigh others' arguments during their discussion. This was to promote a collective, locally-based identity in the group discussion. They were also told the rules of deliberation, such that they need to respect others' opinions. The moderators then organized the discussion according to several topic areas and worked to keep it on topic. The moderators asked a series of questions for each issue. But other than controlling the flow of discussion, the moderators largely let the discussants talk freely over the main course of deliberation. Toward the end, the moderators suggested working toward an acceptable decision to all, 
hoping that the participants could reach a consensus, although consensus was not mandatory.

As all participants were students, the topic of deliberation had to address students' concerns. Therefore, a highly salient and relevant topic to students was chosen. The topic concerned safety on and around campus. Events such as a series of deadly campus shootings have raised a widespread concern for campus safety and measures to improve safety were being discussed campus-wide at the time of the experiment. During the deliberation sessions, students discussed how much they were concerned about crimes on and around campus, why crime became an issue, and what would be the best measure to achieve campus safety. After they discussed the campus safety topic broadly, they were directed to focus on specific policy issues. Three policy-related safety issues have emerged recently as particularly controversial and important. The first issue was about installing more video surveillance on and around campus to prevent crimes. The undergraduate student government has considered an option to install CCTVs on a busy street next to campus and some other campus locations, but it caused a controversy as the plan requires a budget increase and may infringe upon students' privacy. The second issue was whether it was acceptable for police officers to randomly patrol residence halls. Police officers at the university were encouraged to randomly patrol residence halls to enhance campus safety, but it has been suggested that the halls are akin to students' private residences and thus should not be monitored. The third one was the concealed handgun issue. The state laws allow licensed individuals to carry concealed handguns in many public settings, but they prohibit the carrying of handguns on campus. With a rising crime concern, however, it has been suggested that students should be allowed to 
carry concealed handguns on campus as well. This issue has been quite controversial in the undergraduate student community, as a bill that would allow concealed handguns on campus was endorsed by some undergraduate student government members. The students were asked to assess the three issues’ legitimacy as policy proposals. Before discussion, the students read short briefing materials on the issues. The materials are attached in the appendix.

All deliberation sessions were recorded. Face-to-face deliberation was videotaped and CMC deliberation was recorded by computer. They were then transcribed for content analysis.

\subsection{Measurement}

\subsubsection{Cultural Orientations}

Culture is the key independent variable in this study. It is assumed that the Korean group represents the collectivist culture and the American group represents the individualist culture. This assumption may be problematic because it treats a nation as a cultural unit and also ignores individual differences in cultural orientations. To make sure that there were cultural differences between the two groups, the groups' level of collectivism and individualism were measured and compared. The individualismcollectivism dimension of culture is the most widely studied construct in cross-cultural psychology and communication. Currently, there are more than 20 scales of individualism-collectivism and its variants. In the present study, the "self-construal" scale was selected to measure cultural orientations. Self-construal, or self-image, is the degree to which people conceive of themselves as relatively autonomous from, or, connected to, others (Ting-Toomey \& Kurogi, 1998). There are two types of self- 
construal. The independent self values I-identity and represents the individualist culture. The interdependent self values We-identity and represents the collectivist culture. Compared to the conventional individualism-collectivism scales (e.g., Hofstede, 2001; Triandis, 1995), it has been known that the self construal scale better predicts individuals' communication and conflict management styles (Oetzel, 1998). The self construal scale is more related to human communication behavior and has been widely used in crosscultural communication studies. In this study, the self construal scale of Gudykunst, Matsumoto, Ting-Toomey, Nishida, Kim, and Heyman (1996) was adopted. The instrument has been shown to have discriminant validity and be reliable in many crosscultural communication studies (Gudykunst et al., 1996; Oetzel, 1998; Oetzel \& TingToomey, 2003). A 12-item, shorter version of the original scale was used here. Hypothesis 1 was tested using this measure. The reliability statistics (Cronbach's $\alpha$ ) for the independent self construal scale for this research was .65 and for the interdependent self construal scale was .67. Americans were coded 0 and Koreans were coded 1 for a group comparison statistical test.

\subsubsection{Self-assessment of Deliberation}

Discussants’ self-assessment of deliberation was adopted from Gastil, Black, and Moscovitz’s (2008) deliberation study. In what they call the “democratic deliberation” measure, discussants were asked such questions as whether they had equal opportunities to participate, respected differing viewpoints, and were civil to each other. The scale was known to be reliable. In the present study, the scale was found to be reliable as well (Cronbach's $\alpha=.83$ ). Self-report, of course, is not an objective measure of deliberation and it has the usual problems associated with conventional self-report survey research. 
But how discussants feel toward deliberation is very important. If discussants are generally satisfied with the process of deliberation, then it would greatly enhance the legitimacy of deliberation. This self-assessment of deliberation was analyzed by the multi-level regression model specified in Section 6.3.

\subsubsection{Issue Opinions and Variances}

The pre and post polls gauged the students' initial opinions and following changes using a Likert-type scale. The participants were asked during the pre/post polls, "On a scale of 1 to 7 , how strongly do you agree or disagree with the following statements: “OSU should install CCTVs on High Street and major campus locations to prevent crimes"; "Police officers should be permitted to patrol college dormitories in order to enhance campus safety"; "Students should be allowed to carry concealed handguns on campus for self defense." 1 meant "strongly disagree” and 7 denoted "strongly agree." Along with mean issue opinions, the variances of the mean opinions were measured as well. Variances were used to gauge the degree of opinion convergence after deliberation. These measures were used to answer Research Questions 3 and 4.

\subsubsection{Freedom to Express}

This measured how free discussants felt in expressing their views during deliberation. It was measured on a 7-point scale during the post-deliberation survey. This measure was to test Hypothesis 2. It was also analyzed by the multi-level model described in Section 6.3.

\subsubsection{Political Efficacy}

To answer Research Question 5, the level of political efficacy was measured before and after deliberation. The political efficacy scale was adapted from the American 
National Election Studies (ANES). The items were revised so that they could address school-related issues. The pre-deliberation reliability of the efficacy scale was .70.

\subsubsection{Control and Other Variables}

There were other important variables that needed to be measured. First of all, mode of communication concerned whether the deliberation took place online or face-toface. It was coded as a dichotomous variable $(\mathrm{FtF}=0, \mathrm{CMC}=1)$. There were 14 online and 14 FtF deliberation sessions. Second, several personal traits and attitudes were measured. It was possible that effects on the dependent variables, if any, might not come from differences in culture or mode of communication, but from individual-level differences in personal traits. For example, people with a high level of shyness might feel less freedom to talk during the deliberation. To control for such possibilities, the following variables were measured as controls: the levels of shyness and political interest. Political interest was measured on a 7-point scale $(M=4.28, S D=1.38)$. Shyness was measured using a shortened version of the popular shyness scale by Cheek and Buss (Cheek, 1983). The shyness scale’s reliability was .69 $(M=8.60, S D=3.17$ on a composite 21- point index). Sex (Male $=58.5 \%)$ and age $(M=22.93, S D=4.99)$ were also included as demographic measurements. The following table summarizes the participants' profiles and their measurement scores on some variables above. As shown in Table 6.1, the American and Korean samples were similar in terms of gender composition, age, political interest and shyness. However, the American sample had more juniors and seniors. 


\begin{tabular}{cccc}
\hline & Total & American & Korean \\
& $(\mathrm{n}=147)$ & $(\mathrm{n}=70)$ & $(\mathrm{n}=77)$ \\
\hline Gender (\%) & 58.5 & 60.0 & 57.1 \\
Male & 41.5 & 40.0 & 42.9 \\
Female & & & 15.6 \\
Rank (\%) & 10.9 & 5.7 & 29.9 \\
Freshmen & 20.4 & 10.0 & 16.9 \\
Sophomore & 23.8 & 31.4 & 37.7 \\
Junior & 44.9 & 52.9 & 23.1 \\
Senior and above & 22.9 & 22.7 & 4.14 \\
Mean Age & 4.31 & 4.50 & 8.84 \\
Political Interest & 8.60 & 8.31 & \\
Shyness & & & \\
\hline
\end{tabular}

Table 6.1 Participant Profiles

\subsubsection{Judges' Evaluation of Deliberation}

As a more objective measure of deliberation, each condition's deliberativeness was rated by two judges. The judges got acquainted with deliberation literature and were trained by the author about how to evaluate the deliberation. The judges rated each discussion by the following criteria: extensiveness of information search; weighing pros and cons of each issue; examination of causes and effects of each issue; civility of discussion; enthusiasm demonstrated during the discussion; provision of new ideas. 
These criteria were based on the rational communication functions discussed in Gastil and Sawyer (2004) and Hirokawa and Gouran (Gouran \& Hirokawa, 1983; Hirokawa, 1985). All deliberation sessions were transcribed by the author, and the two judges who were bilingual in English and Korean carefully examined the transcribed documents and graded them on a series of 7-point items. The inter-coder reliability between the two judges was measured by Krippendorff's $\alpha$, a widely used reliability index for ordinal or interval scales. Based on about 25\% (7 sessions) of the total sample, the inter-coder reliability achieved a level of .82 on average. The reliability statistics were calculated by the SPSS macro written by Hayes and Krippendorff (2007). The following table presents the reliability statistics by evaluation item.

\begin{tabular}{cc}
\hline Evaluation Item & Reliability \\
Exchanged Extensive information & .88 \\
Examined causes & .77 \\
Examined effects & .84 \\
Weighed positive consequences & .82 \\
Weighed negative consequences & .81 \\
Respected differing viewpoints & .82 \\
Demonstrated enthusiasm & .77 \\
Provided new ideas & .84 \\
AVERAGE & .82 \\
\hline
\end{tabular}

Table 6-2 Reliability Statistics for Each Deliberation Evaluation Item 


\subsubsection{Reasoned Arguments}

To complement self-assessment and judges' rating of deliberation, a simple content analysis was conducted. For each session, “reasoned arguments” were identified and their proportion to total speech in each session was calculated. Here, arguments that have justifications or reasons were identified by two coders. All deliberation sessions were transcribed and the coders were instructed to identify reasoned arguments. They identified any relevant reasons for stated opinions and that portion of the speech was marked as reasoned arguments. The quality and accuracy of the reasons were not taken into consideration. This measure resembles the "argument repertoire" assessment by Cappella, Price, and Nir (2002) or another similar measure used by Price, Nir, and Cappella (2006). This type of reason-counting measure is simple to conduct and provides some indication on the deliberativeness of the discussion. A full-scale content analysis would have been useful to tap into other norms of deliberation. But a full-scale content analysis was not performed because existing coding schemes of deliberation are fraught with problems. For example, even one of the better coding schemes such as the Discourse Quality Index of Steiner, Bächtiger, Spörndli, and Steenbergen (2004) has difficulty in coding the level of justifications and respect during discussion. Although they report a relatively high reliability in coding, reliability does not necessarily guarantee construct validity. As Black, Burkhalter, Gastil, and Stromer-Galley (2009) observe, it is possible that two coders can apply the rules of the codebook reliably to an element of a deliberation yet not actually capture the phenomenon of interest. Krippendorff (2004) also states that achieving construct validity in discourse analysis is not an easy task because meaning is not in the text to be coded but is constructed in the 
moment of interaction. There are some other problems in content analysis as well. There is virtually no way of coding other important deliberation norms such as truthfulness and passion in speech. Stromer-Galley (2007) reports that even after extensive efforts, there are many portions of deliberation that the coders could not agree upon. Furthermore, there is also a problem of coding online interaction. It is possible that one coding scheme, developed for FtF deliberation contexts may not capture interactions unique to online deliberation. In sum, it can be argued that a full-scale content analysis capturing all key deliberative norms is almost impossible to conduct, and considering the significant time and monetary commitment typical in content analysis, its benefit is unclear. Therefore, this research employed simple counting of instances of "reasons" that were relatively easy to code and could be used as an objective judgment for some aspects of deliberation. Unlike previous research, however, the unit of analysis in this analysis was words. That is, the proportion of reasoned arguments in words to total words was measured for each session. Previous studies used speaking turns or utterances as the unit of analysis, but that would have presented some issues in the present study as several reasons altogether were contained in each speaking turn or utterance. Therefore, counting the number of words, although a proxy measure, was a good alternative. In the presenstudy, the two coders achieved an inter-coder reliability of .93. The reliability index was calculated by Hayes and Krippendorff's (2007) formula for Krippendorff's $\alpha$ for categorical measurements.

\subsubsection{Equality of Participation}

Equality of participation is another important norm of deliberation. When discussants have roughly equal amount of speech, deliberation can be deemed more 
legitimate. Equality was measured from the content analysis described above. For each discussant, the proportion of individual spoken words to his or her session's total spoken words was measured. Then mean proportions and standard deviations were calculated for each condition. A high standard deviation would mean a high variation in terms of the number of spoken words by that condition, suggesting relatively unequal participation in that group.

\subsection{Statistical Models}

The data gathered was analyzed using a variety of statistical techniques. First of all, opinion changes before and after deliberation were analyzed descriptively for each condition. The descriptive statistics would identify the percentage of those who changed opinions and those who took a perspective (moving from the don't know/neutral option to an opinionated position) after deliberation. Also, statistically significant changes between post deliberation mean opinion $\left(\mathrm{O}_{2}\right)$ and pre deliberation mean opinion $\left(\mathrm{O}_{1}\right)$ were identified using t-tests for each condition and for each issue. Likewise, changes in the variances of mean opinions were descriptively analyzed and any statistically significant changes between post deliberation variance $\left(\mathrm{V}_{2}\right)$ and pre deliberation variance $\left(V_{1}\right)$ were identified using the variance ratio test for each condition and for each issue. Judges' deliberativeness ratings, the proportion of justified arguments to total speech, and equality of participation were compared across conditions using descriptive and, where applicable, group comparison statistics.

Second, most of the survey data were analyzed using the advanced multi-level regression technique. Many constructs in this research involve both individual level and group level measurements. For example, freedom to express, political efficacy, and 
discussants' self-assessment of deliberation were measured at the individual level but they were expected to vary across deliberation sessions the individuals belong to. Therefore, the major statistical model employed here was multi-level modeling. A chronic statistical problem in small group deliberation research is that it violates the standard statistical assumption of independence. This is because, in group deliberation, discussants are typically nested in small groups. A multi-level model would allow us to account for dependence among observations within groups and parse out individual level and group level effects (Raudenbush \& Bryk, 2002). In the present study, the individual level (level 1) independent variables included discussants' sex, rank, political interest, and shyness. The dependent variables of self-report deliberation assessment, freedom to express, and political efficacy were also level 1. At level 2, which was the group level, culture and mode of communication were included in the model. Furthermore, an interaction term between culture and mode of communication was included at level 2 to find out the interactive effect of culture and mode, if any. The full model is specified as below.

$$
\begin{aligned}
& Y_{i j}=\beta_{0 j}+\beta_{1 j} \text { Rank }+\beta_{2 j} \text { Sex }+\beta_{3 j} \text { Interest }+\beta_{4 j} \text { Shyness }+r_{i j} \\
& \beta_{0 j}=\gamma_{00}+\gamma_{01} \text { Culture }+\gamma_{02} \text { Mode }+\gamma_{03} \text { Culture } * \text { Mode }+u_{0 j} \\
& \beta_{1 j}=\gamma_{10}+\gamma_{11} \text { Culture }+\gamma_{12} \text { Mode }+u_{1 j} \\
& \beta_{2 j}=\gamma_{20} \\
& \beta_{3 j}=\gamma_{30} \\
& \beta_{4 j}=\gamma_{40}
\end{aligned}
$$

where $Y_{i j}$ is the dependent variables (e.g., freedom to express). The slopes for rank $\left(\beta_{1 \mathrm{j}}\right)$ was specified as randomly varying at level 2 . This is because the effect of rank on the dependent variables may differ depending on the types of culture and mode. For example, 
as hypothesized, senior students in the collectivist group may feel more freedom to express their views because of the cultural tradition respecting older peoples' views. Other slopes were specified as fixed across the group. 


\section{CHAPTER 7}

\section{RESULTS}

This chapter presents the results of inferential tests of the hypotheses and research questions described in Chapter 5, along with the results of descriptive analyses of variables used in the hypotheses and research questions. The order of the findings presented here does not necessarily follow that of Chapter 5.

\subsection{Collectivism vs. Individualism}

The first Hypothesis (H1) suggested that Koreans will have a more collectivist cultural orientation than Americans, and Americans will have a more individualist orientation than Koreans. This hypothesis was tested by comparing the independent self construal (individualism) and the interdependent self construal (collectivism) scores of the Korean and American samples. The American sample’s independent self construal score $(M=37.10, S D=2.85)$ was statistically significantly higher than that of the Korean sample's $(M=34.81, S D=3.26), t=4.95, p<.001$, whereas the Korean sample scored higher on the interdependent self-construal scale $(M=31.88, S D=3.74)$ than the American sample did $(M=30.81, S D=4.03), t=-1.73, p<.10$. This result supported Hypothesis 1. 


\subsection{Self-assessment of Deliberation}

How did the participants perceive the deliberation? Were there differences in the assessment of deliberation based on their cultural backgrounds and/or the communication mode they used? To answer this question (RQ2), first of all the groups' self-assessed mean deliberativeness scores were calculated using descriptive statistics. The table below suggests that American participants who deliberated in the FtF condition scored highest on self-assessment of deliberation, followed by American participants in the CMC condition, Korean participants in the FtF condition, and Korean participants in the CMC condition.

\begin{tabular}{ccccc}
\hline & American / FtF & American / CMC & Korean / FtF & Korean / CMC \\
\hline Mean & 39.97 & 38.91 & 37.76 & 37.63 \\
& $(2.34)$ & $(3.22)$ & $(2.92)$ & $(3.34)$ \\
\hline
\end{tabular}

Note. Standard deviations are reported in parenthesis.

Table 7-1 Mean Scores for Self-Assessment of Deliberation

A two-way ANOVA was conducted and there was a significant main effect of culture on the self-assessment of deliberation score, $F(1,143)=12.5, p<.05$. There was no significant main effect of mode, nor interaction of mode and culture. Figure 7-1 represents the deliberation scores by the two factors of mode and culture. 


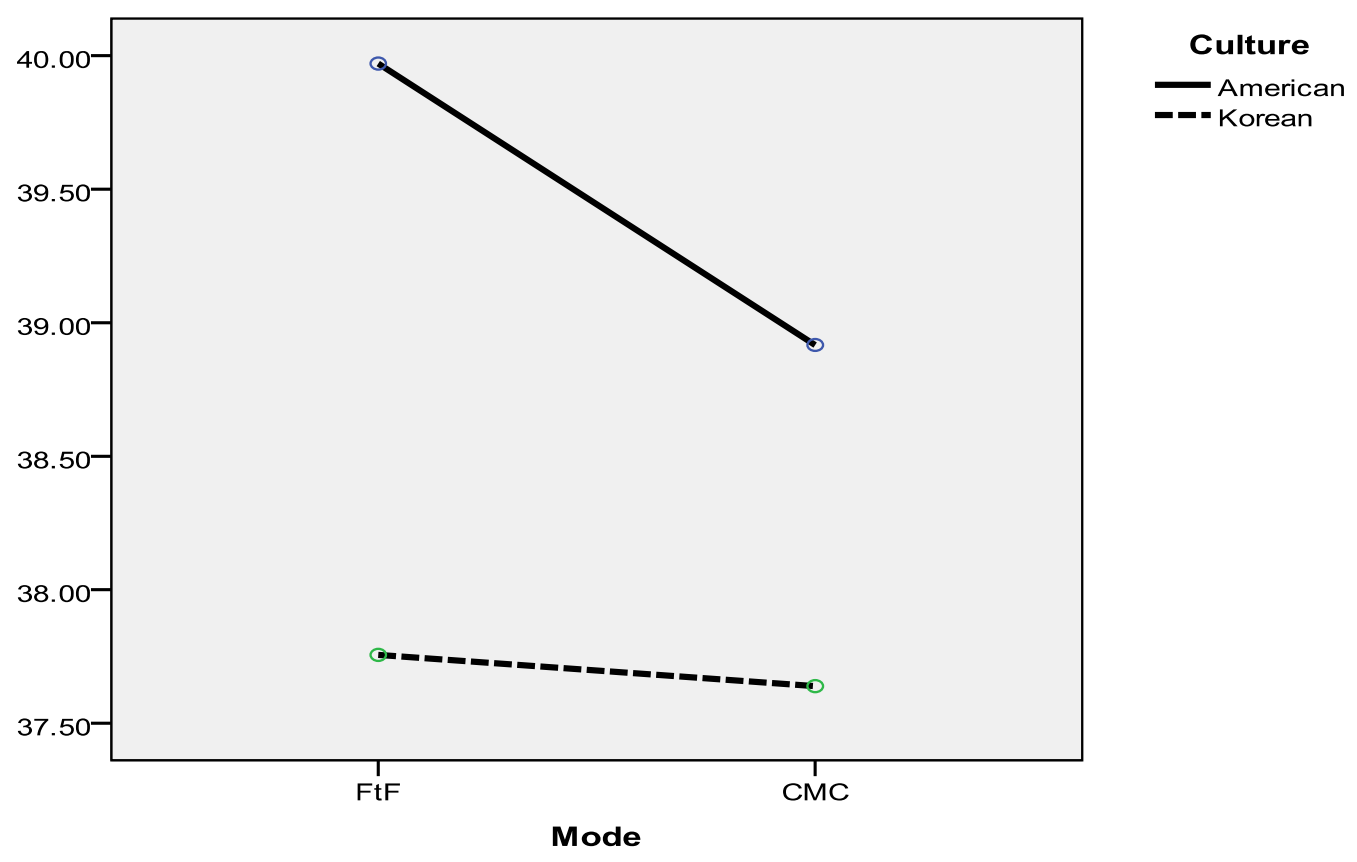

Figure 7-1 Self-assessment Deliberation Score by Culture and Mode

The ANOVA model above, however, did not account for the nesting of observations within deliberation groups. Therefore, the participants' self-assessment of deliberation was probed further using multi-level regression models. The first task here was to see whether there was evidence that groups differ, on average, on how they evaluated deliberation. To answer this question, an initial, null model was constructed (Model 1). This model was,

$$
\begin{array}{ll}
Y_{i j}=\beta_{0 j}+r_{i j} & (\text { Level 1) } \\
\beta_{0 j}=\gamma_{00}+u_{0 j} & (\text { Level 2) }
\end{array}
$$

where $\mathrm{Y}_{\mathrm{ij}}$ was self-assessment of deliberation of individual $i$ in group $j . \quad \gamma_{00}$ represented mean $\mathrm{Y}$ across the groups and $u_{0 j}$ represented the discrepancy between the grand mean 
and each group's mean on Y. Substitution of the level 2 equation into the level 1 equation yielded the mixed model: $Y_{i j}=\gamma_{00}+u_{0 j}+r_{i j}$ (Model 1). Using the maximum likelihood estimation method, the variance components of the model were estimated. As can be seen in Model 1 of Table 7-2, the estimated between-group variance in selfassessment of deliberation was $\hat{V}\left(u_{0 j}\right)=\hat{\tau}_{00}=1.41(p<.01)$. Intra Class Correlation (ICC) was .15, meaning that approximately $15 \%$ of the variance in self assessment of deliberation was explained by the differences between groups. This suggested that there was a significant difference in self-assessment of deliberation across the groups. In the second step, level-1 covariates were added to the model. These included sex, rank, political interest, and shyness. Sex was a dichotomous variable and thus added uncentered, and all other covariates were added grand-mean centered. At level 2, culture and mode were added to the equation. They were dichotomously coded and thus entered uncentered. This yielded the following equations:

$$
\begin{aligned}
& Y_{i j}=\beta_{0 j}+\beta_{1 j} \text { Rank }+\beta_{2 j} \text { Sex }+\beta_{3 j} \text { Interest }+\beta_{4 j} \text { Shyness }+r_{i j} \\
& \beta_{0 j}=\gamma_{00}+\gamma_{01} \text { Culture }+\gamma_{02} \text { Mode }+u_{0 j} \\
& \beta_{1 j}=\gamma_{10} \\
& \beta_{2 j}=\gamma_{20} \\
& \beta_{3 j}=\gamma_{30} \\
& \beta_{4 j}=\gamma_{40}
\end{aligned}
$$

When the model (Model 2 in Table 7-2) was fit, the coefficients for culture, shyness, and rank turned out to be statistically significant. The coefficient for culture was $-1.88(p<.01)$. This statistically significant, negative coefficient of culture suggests that as culture changes by one unit, which is equivalent to a change from individualism (independent self construal) to collectivism (inter-dependent self construal), the level of 
self-assessment of deliberation decreased by 1.88. In other words, the collectivist Korean participants assessed deliberation less favorably than the individualist American group. But the non-significant coefficient for the mode of communication suggests that there was no difference in the level of self-assessed deliberativeness depending on the mode of communication. The negative coefficients of shyness and rank suggest that as shyness and rank increase, the level of self-assessed deliberativeness decreased. The final model (Model 3) added an interactive term of culture * mode to the previous model. However, the interactive term was not found to be statistically significant. Assuming the coefficient was significant, it would mean that being collectivist and being in the CMC condition would increase self-assessment of deliberation. 


\begin{tabular}{|c|c|c|c|}
\hline & Model 1 & Model 2 & Model 3 \\
\hline Intercept & $38.55^{* * *}$ & $39.74^{* * *}$ & $39.96 * * *$ \\
\hline Sex & & .09 & .11 \\
\hline Rank & & $-.45 \#$ & $-.46 \#$ \\
\hline Interest & & -.08 & -.07 \\
\hline Shyness & & $-.24 * *$ & $-.23 * *$ \\
\hline Culture & & $-1.88 * *$ & $-2.32 * *$ \\
\hline Mode & & -.53 & -.98 \\
\hline Culture * Mode & & & .87 \\
\hline$\hat{\tau}_{00}$ & $1.41^{* *}$ & $.63^{*}$ & $.57 *$ \\
\hline$\hat{\sigma}^{2}$ & 8.25 & 7.50 & 7.51 \\
\hline Deviances (-2LL) & 744.63 & 723.53 & 722.90 \\
\hline
\end{tabular}

Note. $\# p<.10 .{ }^{*} p<.05 .{ }^{* *} p<.01 .{ }^{* * *} p<.001$.

Table 7-2 Coefficient Estimates of Independent Variables for Self Assessment of

Deliberation 


\subsection{Freedom to Express Opinion}

To answer hypotheses 2a, 2b, and 2c, how free students felt to express their views during the deliberation was measured. The following table illustrates the mean scores for freedom to express depending on conditions. According to the table, American participants who deliberated in the CMC condition had the highest freedom to express score. Korean participants who deliberated in the FtF condition had the lowest freedom to express score.

\begin{tabular}{ccccc}
\hline & American / FtF & American / CMC & Korean / FtF & Korean / CMC \\
\hline Mean & 6.59 & 6.64 & 6.07 & 6.25 \\
& $(.56)$ & $(.49)$ & $(.85)$ & $(.81)$ \\
\hline
\end{tabular}

Note. Standard deviations are reported in parenthesis.

Table 7-3 Mean Scores for Freedom to Express

A two-way ANOVA was conducted and only the main effect of culture on freedom to express turned out to be significant, $F(1,143)=15.25, p<.001$. Figure $7-2$ graphically represents the freedom to express score by factor. 


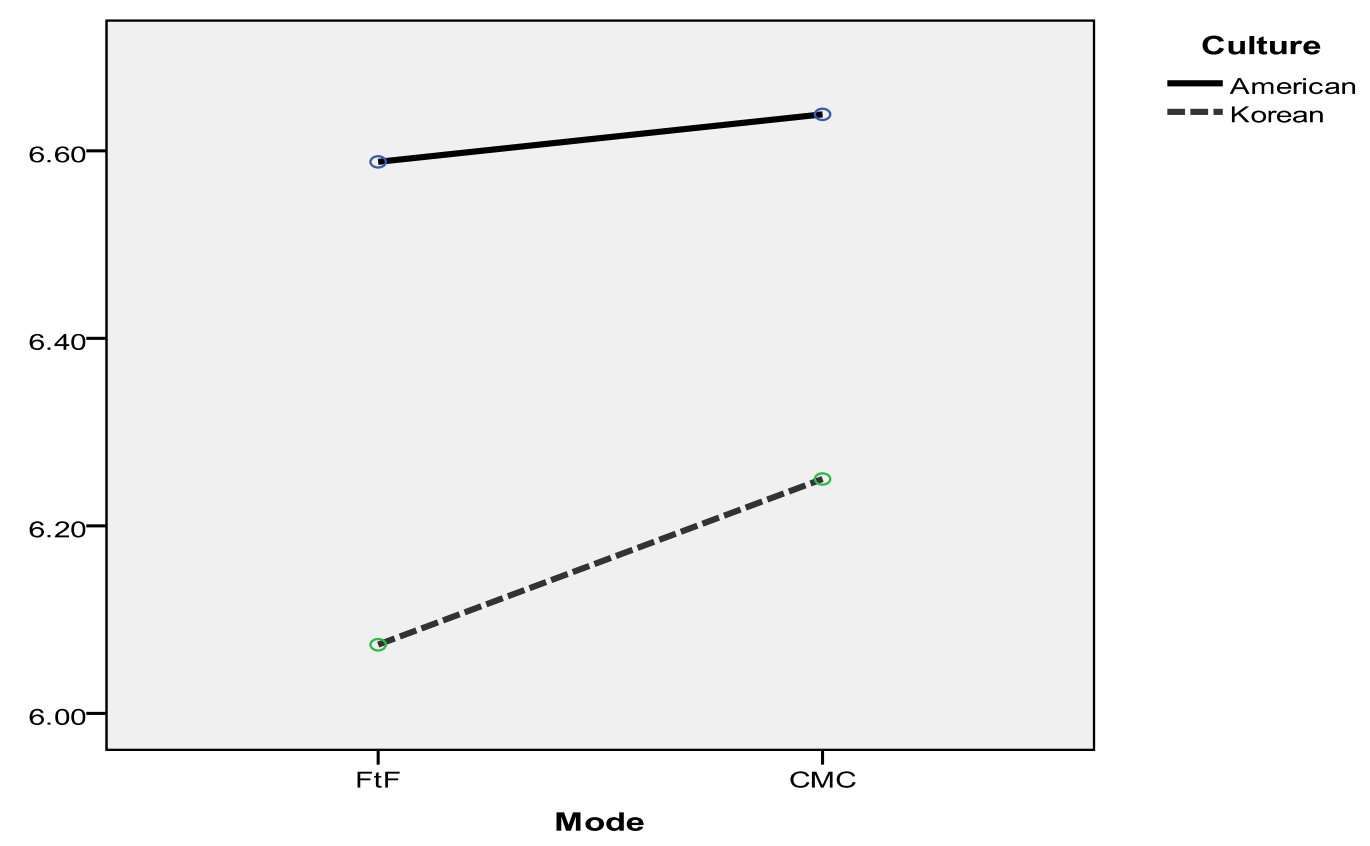

Figure 7-2 Freedom to Express Score by Culture and Mode

Again, multi-level regression models were built with the freedom to express as the dependent variable. The null model ( $Y_{i j}=\gamma_{00}+u_{0 j}+r_{i j}$, Model 1) in Table 7-4 suggests that the ICC for this model was .06, meaning that approximately $6 \%$ of the variance in freedom to express was explained by the differences between groups. The small ICC does not necessarily mean that there is no group-level variation and statisticians recommend further investigation (Raudenbush \& Bryk, 2002). Therefore, further multi-level models would be warranted. In Model 2, covariates were added to the previous model and estimated using the maximum likelihood method. As shown in the table, the coefficients for shyness and culture were statistically significant. Their negative coefficients suggest that freedom to express opinion decreased as the culture changed from individualism to collectivism and as the level of shyness increased. The 
coefficient for the mode of communication, although it was in the anticipated direction, was not statistically significant. An interactive term was added to Model 3. In this model, the coefficients for culture and shyness were again statistically significant, but the interactive term did not turn out to be significant. In Model 4 , the slope for rank $\left(\beta_{1 \mathrm{j}}\right)$ was specified as randomly varying at level $2\left(\beta_{l j}=\gamma_{10}+\gamma_{11}\right.$ Culture $+\gamma_{12}$ Mode $\left.+u_{1 j}\right)$. When the model was fit, the coefficients for culture and shyness again were significant. However, neither of the cross-level interactions between rank and culture, and rank and mode turned out to be statistically significant. Overall these results suggest being collectivist decreases freedom to express opinions. Hypothesis $2 \mathrm{~b}$ was supported, but Hypothesis 2a and 2c were not. 


\begin{tabular}{|c|c|c|c|c|}
\hline & Model 1 & Model 2 & Model 3 & Model 4 \\
\hline Intercept & $6.38 * * *$ & $6.53 * * *$ & $6.57 * * *$ & $6.53 * * *$ \\
\hline Sex & & .02 & .02 & .00 \\
\hline Rank & & -.01 & -.01 & .03 \\
\hline Interest & & .02 & .02 & .02 \\
\hline Shyness & & $-.04 \#$ & $-.04 \#$ & $-.04 \#$ \\
\hline Culture & & $-.43 * *$ & $-.50 * *$ & $-.43^{* *}$ \\
\hline Mode & & .12 & .05 & .13 \\
\hline Culture * Mode & & & .14 & \\
\hline Culture * Rank & & & & -.01 \\
\hline Mode * Rank & & & & -.06 \\
\hline$\hat{\tau}_{00}$ & $.03^{* *}$ & .00 & .00 & .00 \\
\hline$\hat{\tau}_{11}$ & & & & .02 \\
\hline$\hat{\sigma}^{2}$ & .51 & .46 & .46 & .44 \\
\hline Deviances (-2LL) & 327.73 & 304.07 & 303.70 & 303.31 \\
\hline
\end{tabular}

Note. $\# p<.10 .{ }^{*} p<.05 .{ }^{* *} p<.01 .{ }^{* * *} p<.001$.

Table 7-4 Coefficient Estimates of Independent Variables for Freedom to Express 


\subsection{Political Efficacy}

RQ5 asked how much deliberation would change the political efficacy of the discussants. The following table presents the statistics on the level of political efficacy before and after deliberation, broken down by conditions.

\begin{tabular}{ccccc}
\hline & & $\begin{array}{c}\text { Pre-deliberation } \\
\text { Mean Efficacy }\end{array}$ & $\begin{array}{c}\text { Post-deliberation } \\
\text { Mean Efficacy }\end{array}$ & Mean Change \\
\hline TOTAL & $\mathrm{N}=147$ & 12.59 & 14.68 & $2.09^{* * *}$ \\
American & FtF $(\mathrm{n}=34)$ & 13.02 & 15.79 & $2.77^{* * *}$ \\
& CMC $(\mathrm{n}=36)$ & 13.11 & 15.61 & $2.50^{* * *}$ \\
Korean & FtF $(\mathrm{n}=41)$ & 11.88 & 13.15 & $1.27^{* * *}$ \\
& CMC $(\mathrm{n}=36)$ & 12.50 & 14.44 & $1.94^{* * *}$ \\
\hline
\end{tabular}

Note. $\# p<.10 .{ }^{*} p<.05 .{ }^{* *} p<.01 .{ }^{* * *} p<.001$.

Table 7-5 Political Efficacy Changes after Deliberation

The above table suggests that deliberation significantly increased the discussants' political efficacy regardless of conditions. But the table also suggests that the absolute amount of mean change is higher for American discussants. To explore efficacy change in more detail, a multi-level model was constructed with post-deliberation efficacy as the dependent variable. A more conventional statistical approach here would be using repeated measures ANOVA measuring pre-post changes across conditions. Again, however, multi-level modeling would provide a more sophisticated statistical model than repeated measures ANOVA, because a multi-level model can account for design effects 
and it does not violate the statistical assumption of independence (Quene \& Van den Bergh, 2004). The multi-level model was specified as follows:

$$
\begin{aligned}
& Y_{i j}=\beta_{0 j}+\beta_{1 j} \text { Rank }+\beta_{2 j} \text { Sex }+\beta_{3 j} \text { Interest }+\beta_{4 j} \text { Shyness }+\beta_{5 j} \text { Preefficacy }+r_{i j} \\
& \beta_{0 j}=\gamma_{00}+\gamma_{01} \text { Culture }+\gamma_{02} \text { Mode }+u_{0 j} \\
& \beta_{1 j}=\gamma_{10} \\
& \beta_{2 j}=\gamma_{20} \\
& \beta_{3 j}=\gamma_{30} \\
& \beta_{4 j}=\gamma_{40} \\
& \beta_{5 j}=\gamma_{50}
\end{aligned}
$$

In the above, $Y_{i j}$ was the post-deliberation efficacy score for individual $i$ in group $j$.

In level 1, pre-deliberation efficacy score was added to the model with grand-mean centered. $\beta_{5 j}$ represented the slope for pre-deliberation efficacy score. When the model was fit, the coefficients for culture and pre-efficacy turned out to be statistically significant. These coefficients are reported in the following table. 


\begin{tabular}{|c|c|}
\hline & Coefficients \\
\hline Intercept & $15.44^{* * *}$ \\
\hline Sex & .17 \\
\hline Rank & -.06 \\
\hline Interest & .00 \\
\hline Shyness & -.04 \\
\hline Pre-efficacy & $.68 * * *$ \\
\hline Culture & $-1.89 * * *$ \\
\hline Mode & -.24 \\
\hline Culture * Mode & 1.13 \\
\hline$\hat{\tau}_{00}$ & .03 \\
\hline$\hat{\sigma}^{2}$ & 4.38 \\
\hline Deviance (-2LL) & 634.50 \\
\hline
\end{tabular}

Note. $\# p<.10 .{ }^{*} p<.05 .{ }^{* *} p<.01 .{ }^{* * *} p<.001$.

Table 7-6 Coefficient Estimates of Independent Variables for Post-deliberation Efficacy 
The statistically significant, negative coefficient for culture suggests that the postdeliberation efficacy score was lower for the Korean participants when compared to the American participants. In other words, although deliberation increased political efficacy for all participants, the degree of increase was smaller for the Korean participants.

\subsection{Opinion Changes}

How did the deliberation change the participants’ opinions? (RQ3) Overall, it appears that deliberation had some effects on the participants' issue opinions. As shown in Table 7-7 below, some issue opinions changed after deliberation to a statistically significant degree.

\begin{tabular}{lccc}
\hline \multicolumn{1}{c}{ Issues } & $\begin{array}{c}\text { Pre deliberation } \\
(\mathrm{O} 1)\end{array}$ & $\begin{array}{c}\text { Post-Deliberation } \\
(\mathrm{O} 2)\end{array}$ & $\begin{array}{c}\text { Mean Change } \\
(\mathrm{O} 2-\mathrm{O} 1)\end{array}$ \\
\hline Issue 1: CCTV & 5.01 & 5.22 & $.21 \#$ \\
Issue 2: Dorm Patrol & 4.10 & 3.56 & $-.54^{* * *}$ \\
Issue 3: Handgun & 1.71 & 1.73 & -.02 \\
\hline
\end{tabular}

Note. $\# p<.10 .{ }^{*} p<.05 .{ }^{* *} p<.01 .{ }^{* * *} p<.001$.

Table 7-7 Opinion Changes after Deliberation

The opinion changes were then broken down by condition

(Korean/American/FtF/CMC). The following table shows opinion changes by condition.

No particular patterns were observed here, however. 


\begin{tabular}{|c|c|c|c|c|c|}
\hline & & & Pre-opinion & Post-opinion & Mean change \\
\hline \multirow{6}{*}{ American } & $\mathrm{FtF}(\mathrm{n}=34)$ & Issue 1 & 4.71 & 5.5 & $.79 * *$ \\
\hline & & Issue 2 & 3.65 & 3.82 & .17 \\
\hline & & Issue 3 & 2.15 & 2.24 & .09 \\
\hline & CMC $(\mathrm{n}=36)$ & Issue 1 & 4.70 & 4.19 & $-.51^{*}$ \\
\hline & & Issue 2 & 3.44 & 2.56 & $-.88^{* *}$ \\
\hline & & Issue 3 & 1.80 & 1.55 & $-.25^{*}$ \\
\hline \multirow[t]{6}{*}{ Korean } & $\mathrm{FtF}(\mathrm{n}=41)$ & Issue 1 & 5.24 & 5.51 & .27 \\
\hline & & Issue 2 & 4.44 & 3.95 & $-.49 \#$ \\
\hline & & Issue 3 & 1.66 & 1.88 & .22 \\
\hline & CMC $(n=36)$ & Issue 1 & 5.33 & 5.64 & $.31 \#$ \\
\hline & & Issue 2 & 4.80 & 3.89 & $-.91 * *$ \\
\hline & & Issue 3 & 1.25 & 1.28 & .03 \\
\hline
\end{tabular}

Note. $\# p<.10 .{ }^{*} p<.05 .{ }^{* *} p<.01 .{ }^{* * *} p<.001$.

Table 7-8 Opinion Changes after Deliberation by Condition 
How did the deliberation change those who marked the “don’t know/neutral” position? In some cases, deliberation actually increased the “don't know” position. As for the entire sample, however, deliberation decreased the number of participants who marked “don’t know/neutral.” Before deliberation, a total of 31 participants indicated they had no particular opinions for one or more of the three issues. The number decreased to 23 after deliberation. Table 7-9 illustrates the number of participants who moved from the don't know/neutral position to an opinionated position after deliberation. 


\begin{tabular}{|c|c|c|c|c|c|}
\hline & & & Pre-deliberation & Post-deliberation & Change \\
\hline TOTAL & & & 31 & 23 & -8 \\
\hline \multirow[t]{6}{*}{ American } & FtF $(n=34)$ & Issue 1 & 1 & 2 & +1 \\
\hline & & Issue 2 & 1 & 3 & +2 \\
\hline & & Issue 3 & 5 & 2 & -3 \\
\hline & CMC $(n=36)$ & Issue 1 & 2 & 1 & -1 \\
\hline & & Issue 2 & 6 & 1 & -5 \\
\hline & & Issue 3 & 3 & 1 & -2 \\
\hline \multirow[t]{6}{*}{ Korean } & $\mathrm{FtF}(\mathrm{n}=41)$ & Issue 1 & 2 & 3 & +1 \\
\hline & & Issue 2 & 4 & 5 & +1 \\
\hline & & Issue 3 & 2 & 0 & -2 \\
\hline & CMC $(n=36)$ & Issue 1 & 0 & 2 & +2 \\
\hline & & Issue 2 & 5 & 3 & -2 \\
\hline & & Issue 3 & 0 & 0 & 0 \\
\hline
\end{tabular}

Table 7-9 Number of Participants who Moved from the No-opinion Position to an Opinionated Position after Deliberation 


\subsection{Opinion Variances}

The opinion variances of each deliberation condition were probed as well. A variance ratio test was conducted for the entire sample, but as shown in Table 7-10, no significant variance changes were observed.

\begin{tabular}{lccc}
\hline \multicolumn{1}{c}{ Issues } & $\begin{array}{c}\text { Pre-deliberation } \\
(\mathrm{V} 1)\end{array}$ & $\begin{array}{c}\text { Post-deliberation } \\
(\mathrm{V} 2)\end{array}$ & $\begin{array}{c}\text { Variance Change } \\
\text { (V2-V1) }\end{array}$ \\
\hline Issue 1: CCTV & 2.76 & 2.95 & .19 \\
Issue 2: Dorm Patrol & 3.53 & 3.95 & .42 \\
Issue 3: Handgun & 1.58 & 2.21 & .63 \\
\hline
\end{tabular}

Table 7-10 Variance Changes after Deliberation

The variance changes were then re-examined by condition. As shown in Table 711, significant opinion variance changes were observed for the Korean FtF and CMC groups concerning issue 3. These higher post-deliberation opinion variances suggest that opinions after deliberation varied more than opinions before deliberation. 


\begin{tabular}{|c|c|c|c|c|c|}
\hline & & & $\begin{array}{c}\text { Pre-opinion } \\
\text { Variance (V1) }\end{array}$ & $\begin{array}{l}\text { Post-opinion } \\
\text { Variance (V2) }\end{array}$ & $\begin{array}{l}\text { Change } \\
\text { (V2-V1) }\end{array}$ \\
\hline \multirow[t]{6}{*}{ American } & $\mathrm{FtF}(\mathrm{n}=34)$ & Issue 1 & 4.09 & 3.23 & -.86 \\
\hline & & Issue 2 & 3.99 & 3.85 & -.14 \\
\hline & & Issue 3 & 2.74 & 3.22 & -.48 \\
\hline & CMC $(n=36)$ & Issue 1 & 2.62 & 4.45 & 1.83 \\
\hline & & Issue 2 & 2.66 & 3.45 & .79 \\
\hline & & Issue 3 & 2.16 & 1.68 & -.48 \\
\hline \multirow[t]{6}{*}{ Korean } & $\mathrm{FtF}(\mathrm{n}=41)$ & Issue 1 & 1.59 & 1.45 & -.14 \\
\hline & & Issue 2 & 3.54 & 3.55 & .01 \\
\hline & & Issue 3 & 1.08 & 2.81 & $1.73 *$ \\
\hline & CMC $(\mathrm{n}=36)$ & Issue 1 & 2.86 & 1.72 & -1.14 \\
\hline & & Issue 2 & 2.96 & 3.93 & .97 \\
\hline & & Issue 3 & .19 & .78 & $.59 * * *$ \\
\hline
\end{tabular}

Note. $\# p<.10 .{ }^{*} p<.05 .{ }^{* *} p<.01 .{ }^{* * *} p<.001$.

Table 7-11 Variance Changes after Deliberation by Condition 


\subsection{Judges' Evaluation of Deliberation}

Two judges evaluated the deliberation sessions on eight dimensions (exact wording for the evaluation criteria are attached in the appendix). Their average scores were calculated and presented in Table 7-12. 


\begin{tabular}{ccccc}
\hline & $\begin{array}{c}\text { Korean/FtF } \\
(\mathrm{n}=7)\end{array}$ & $\begin{array}{c}\text { Korean/CMC } \\
(\mathrm{n}=7)\end{array}$ & $\begin{array}{c}\text { American/FtF } \\
(\mathrm{n}=7)\end{array}$ & $\begin{array}{c}\text { American/CMC } \\
(\mathrm{n}=7)\end{array}$ \\
\hline $\begin{array}{c}\text { Exchanged } \\
\text { extensive info. }\end{array}$ & 4.28 & 4.50 & 5.01 & 5.07 \\
Examined causes & $(.81)$ & $(.50)$ & $(1.22)$ & $(.53)$ \\
& $(.48)$ & 4.42 & 4.74 & 4.64 \\
Examined effects & 4.50 & $(.53)$ & $(.90)$ & $(.37)$ \\
Weighed positive & $(.81)$ & 4.50 & 5.20 & 5.42 \\
consequences & $(.69)$ & $(.64)$ & $(.75)$ & $(.44)$ \\
Weighed negative & 4.57 & 4.5 & 5.33 & 5.28 \\
consequences & $(.83)$ & $(.75)$ & $(.83)$ & $(.69)$ \\
& & & $(1.14)$ & 5.71 \\
Respected differing & 4.07 & 4.28 & 5.60 & $(.48)$ \\
viewpoints & $(.44)$ & $(.75)$ & $(.96)$ & 5.71 \\
Demonstrated & 4.28 & 4.71 & 5.33 & $(.69)$ \\
enthusiasm & $(.48)$ & $(.48)$ & $(1.15)$ & 5.28 \\
Provided new ideas & 4.92 & 4.64 & 5.30 & $(.90)$ \\
& $(.53)$ & $(.55)$ & $(1.60)$ & 5.50 \\
& & & & $(.70)$ \\
\hline
\end{tabular}

Note. Standard deviations are reported in parenthesis.

Table 7-12 Judges' Average Ratings by Condition 
The above table suggests some differences in rating between the conditions. To explore the differences further, the groups were reorganized by culture and mode, and then compared using $t$-tests. This result is presented in Table 7-13. 


\begin{tabular}{|c|c|c|c|c|}
\hline & \multicolumn{2}{|c|}{ Comparison by Culture } & \multicolumn{2}{|c|}{ Comparison by Mode } \\
\hline & $\begin{array}{c}\text { Korean } \\
(\mathrm{n}=14)\end{array}$ & $\begin{array}{c}\text { American } \\
(\mathrm{n}=14)\end{array}$ & $\begin{array}{c}\mathrm{FtF} \\
(\mathrm{n}=14)\end{array}$ & $\begin{array}{c}\mathrm{CMC} \\
(\mathrm{n}=14) \\
\end{array}$ \\
\hline $\begin{array}{c}\text { Exchanged } \\
\text { extensive info. }\end{array}$ & $\begin{array}{l}4.39 \\
(.17)\end{array}$ & $\begin{array}{l}5.04^{*} \\
(.24)\end{array}$ & $\begin{array}{l}4.58 \\
(.29)\end{array}$ & $\begin{array}{l}4.78 \\
(.15)\end{array}$ \\
\hline Examined causes & $\begin{array}{l}4.10 \\
(.15)\end{array}$ & $\begin{array}{l}4.66^{*} \\
(.17)\end{array}$ & $\begin{array}{l}4.16 \\
(.23)\end{array}$ & $\begin{array}{l}4.53 \\
(.12)\end{array}$ \\
\hline Examined effects & $\begin{array}{l}4.50 \\
(.18)\end{array}$ & $\begin{array}{c}5.33^{* *} \\
(.16)\end{array}$ & $\begin{array}{l}4.79 \\
(.24)\end{array}$ & $\begin{array}{l}4.96 \\
(.19)\end{array}$ \\
\hline $\begin{array}{l}\text { Weighed positive } \\
\text { consequences }\end{array}$ & $\begin{array}{l}4.39 \\
(.17)\end{array}$ & $\begin{array}{c}5.29 * * \\
(.20)\end{array}$ & $\begin{array}{l}4.70 \\
(.25)\end{array}$ & $\begin{array}{l}4.89 \\
(.20)\end{array}$ \\
\hline $\begin{array}{l}\text { Weighed negative } \\
\text { consequences }\end{array}$ & $\begin{array}{l}4.64 \\
(.20)\end{array}$ & $\begin{array}{c}5.58 * * \\
(.22)\end{array}$ & $\begin{array}{l}4.91 \\
(.29)\end{array}$ & $\begin{array}{l}5.21 \\
(.27)\end{array}$ \\
\hline $\begin{array}{l}\text { Respected differing } \\
\text { viewpoints }\end{array}$ & $\begin{array}{l}4.17 \\
(.16)\end{array}$ & $\begin{array}{c}5.66^{* *} \\
(.22)\end{array}$ & $\begin{array}{l}4.70 \\
(.29)\end{array}$ & $\begin{array}{l}5.00 \\
(.27)\end{array}$ \\
\hline $\begin{array}{l}\text { Demonstrated } \\
\text { enthusiasm }\end{array}$ & $\begin{array}{l}4.50 \\
(.13)\end{array}$ & $\begin{array}{l}5.29 * \\
(.27)\end{array}$ & $\begin{array}{l}4.70 \\
(.27)\end{array}$ & $\begin{array}{l}5.00 \\
(.20)\end{array}$ \\
\hline Provided new ideas & $\begin{array}{l}4.78 \\
(.14)\end{array}$ & $\begin{array}{l}5.41 \# \\
(.31)\end{array}$ & $\begin{array}{l}5.08 \\
(.30)\end{array}$ & $\begin{array}{l}5.07 \\
(.20)\end{array}$ \\
\hline
\end{tabular}

Note. $\# p<.10 .{ }^{*} p<.05 .{ }^{* *} p<.01 .{ }^{* * *} p<.001$. Standard errors are reported in parenthesis.

Table 7-13 Judges' Average Ratings by Culture and Mode

As clearly indicated in Table 7-13, the judges rated American groups' deliberation higher than Korean groups in every dimension. However, there was no statistically significant rating difference between the FtF condition and the CMC condition.

\subsection{Reasoned Arguments}

The proportion of reasoned arguments to total speech in number of words is calculated as follows. The reported numbers in Table 7-14 are the average of the 
proportions for each condition. According to the table, Americans both in the FtF and CMC conditions featured more reasoned arguments than Koreans in the FtF and CMC conditions.

\begin{tabular}{ccccc}
\hline & $\begin{array}{c}\text { Korean/FtF } \\
(\mathrm{n}=7)\end{array}$ & $\begin{array}{c}\text { Korean/CMC } \\
(\mathrm{n}=7)\end{array}$ & $\begin{array}{c}\text { American/FtF } \\
(\mathrm{n}=7)\end{array}$ & $\begin{array}{c}\text { American/CMC } \\
(\mathrm{n}=7)\end{array}$ \\
\hline & & & & \\
$\begin{array}{c}\text { Proportion of } \\
\text { justified } \\
\text { arguments }\end{array}$ & .47 & .41 & .50 & .49 \\
\hline
\end{tabular}

Note. Standard deviations are reported in parenthesis.

Table 7-14 Average Proportions of Reasoned Arguments by Condition

To explore the differences further, the groups were reorganized by culture and mode, and then compared using $t$-tests. This result is presented in the following table. As seen in Table 7-15, American groups, when compared to Korean groups, featured more reasoned arguments. There was no statistically significant difference between the FtF and CMC conditions, however. 


\begin{tabular}{|c|c|c|c|c|}
\hline \multirow{2}{*}{ 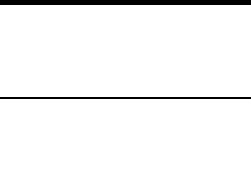 } & \multicolumn{2}{|c|}{ Comparison by Culture } & \multicolumn{2}{|c|}{ Comparison by Mode } \\
\hline & $\begin{array}{l}\text { Korean } \\
(\mathrm{n}=14)\end{array}$ & $\begin{array}{c}\text { American } \\
(\mathrm{n}=14)\end{array}$ & $\begin{array}{c}\mathrm{FtF} \\
(\mathrm{n}=14)\end{array}$ & $\begin{array}{c}\text { CMC } \\
(n=14)\end{array}$ \\
\hline \multirow{2}{*}{$\begin{array}{l}\text { Proportion of } \\
\text { justified } \\
\text { arguments }\end{array}$} & .44 & $.50^{*}$ & .49 & .45 \\
\hline & $(.11)$ & $(.14)$ & $(.13)$ & $(.12)$ \\
\hline
\end{tabular}

Note. $\# p<.10 .^{*} p<.05 .{ }^{* *} p<.01 . * * * p<.001$. Standard errors are reported in parenthesis.

Table 7-15 Average Proportions of Reasoned Arguments by Culture and Mode

\subsection{Equality of Participation}

Every discussant's number of spoken words was counted for all sessions. Then the proportion of individual spoken words to the group's total spoken words was measured. The following table presents the average proportion of individual spoken words and standard deviation by condition. As shown in the table, the Korean/FtF condition has the highest average standard deviation (.12), suggesting that participation to discussion was least equal in that condition. The Korean/CMC condition has the lowest average standard deviation (.06), suggesting that participation was the most equal in that condition. 


\begin{tabular}{ccccc}
\hline & $\begin{array}{c}\text { Korean/FtF } \\
(\mathrm{n}=7)\end{array}$ & $\begin{array}{c}\text { Korean/CMC } \\
(\mathrm{n}=7)\end{array}$ & $\begin{array}{c}\text { American/FtF } \\
(\mathrm{n}=7)\end{array}$ & $\begin{array}{c}\text { American/CMC } \\
(\mathrm{n}=7)\end{array}$ \\
\hline $\begin{array}{c}\text { Average } \\
\text { Proportion of } \\
\text { Individual } \\
\text { Spoken Words }\end{array}$ & .16 & .22 & .25 & .22 \\
$\begin{array}{c}\text { Average } \\
\text { Standard } \\
\text { Deviation }\end{array}$ & .12 & .06 & .10 & .08 \\
\hline
\end{tabular}

Table 7-16 Proportions of Spoken Words and Standard Deviations by Condition

Again, the groups were reorganized by culture and mode. This result is presented in the following table. As seen in the table, the Korean condition's average standard deviation is larger than that of the American condition's, suggesting that there was more variation in terms of participation for Korean groups. The large average standard deviation of the FtF condition as opposed to the CMC condition suggests that participation was less equal in the FtF condition.

\begin{tabular}{|c|c|c|c|c|}
\hline & \multicolumn{2}{|c|}{ Comparison by Culture } & \multicolumn{2}{|c|}{ Comparison by Mode } \\
\hline & $\begin{array}{l}\text { Korean } \\
(\mathrm{n}=14)\end{array}$ & $\begin{array}{c}\text { American } \\
(\mathrm{n}=14)\end{array}$ & $\begin{array}{c}\text { FtF } \\
(n=14)\end{array}$ & $\begin{array}{c}\text { CMC } \\
(\mathrm{n}=14)\end{array}$ \\
\hline $\begin{array}{c}\text { Average } \\
\text { Proportion of } \\
\text { Individual } \\
\text { Spoken Words }\end{array}$ & .18 & .23 & .19 & .23 \\
\hline $\begin{array}{l}\text { Average } \\
\text { Standard } \\
\text { Deviation }\end{array}$ & $.11^{* * *}$ & .08 & $.14 * * *$ & .05 \\
\hline
\end{tabular}

Table 7-17 Proportions of Spoken Words and Standard Deviations by Culture and Mode 
Various analyses have been conducted so far to answer the research questions and to test the hypotheses. The results are diverse and it would be of interest to summarize them before proceeding to discuss them in detail in the next chapter. The following table presents what's been found and relevant methods used. 
RQ1. What is the level of deliberativeness in each deliberation condition?
- Americans featured more arguments than Koreans

- Americans received higher judges' ratings than Koreans

- Participation in discussion was more equal for Americans than Koreans

- No strong difference between $\mathrm{CMC}$ and $\mathrm{FtF}$

- However, CMC was discursively more equal than $\mathrm{FtF}$

RQ2. What is the discussants' self-assessment of deliberation in each deliberation condition?

RQ3. What are the magnitudes and directions of opinion changes in each deliberation condition?

RQ4. What are the magnitudes of opinion variances in each deliberation condition before and after deliberation?

RQ5. To what extent does deliberation affect discussants' political efficacy in each condition?

Table 7.18 Summary of Findings
- Americans reported a more positive assessment than Koreans did

- No strong difference between $\mathrm{CMC}$ and $\mathrm{FtF}$

- Some significant opinion changes occurred for all conditions

- Some participants with no particular issue positions took a perspective after deliberation

- No strong variance changes occurred

- Efficacy increased for all conditions

- However, Americans reported higher efficacy increase than Koreans
- Content analysis

- Judges' ratings

- Group comparison statistics

- Self-report survey analysis

- Multi-level modeling

- Self-report survey analysis

- Self-report survey analysis

- Self-report survey analysis

- Multi-level model 
(Table 7-18, Continued)

H1. East Asian discussants will score higher on the collectivism scale than Western discussants will, and Western discussants will score higher on the individualism scale than East Asian discussants will. (Table 7-18, Continued)

H2a. Overall, discussants in the CMC condition will feel more freedom to express views than discussants in the FtF condition

H2b. Collectivist discussants in the FtF condition will feel less freedom to express their views than discussants in other conditions.
- H1 supported

- H2a not supported. Statistically not significant, but in the anticipated direction

- H2b supported

H2c. Older discussants (higher in school rank) will have more freedom to express their views in the collectivist, FtF deliberation condition when compared to other conditions.
- Self-report survey analysis

- Group comparison statistics
- Self-report survey

- multi-level model

- Self-report survey

- multi-level model

- Self-report survey

- multi-level model

Table 7.18 Summary of Findings 


\section{CHAPTER 8}

\section{DISCUSSION}

In this chapter, the findings of the study are discussed. The discussion not only probes the tested hypotheses in detail but also seeks to provide a larger implication to the field of deliberative democracy. Whilst doing so, strengths and limitations of the study and suggestions for future research are offered as well.

\subsection{Interpreting the Results}

The overall results suggest that deliberation had significant and positive effects on participants regardless of conditions. Consistent with previous research (e.g., Fishkin \& Luskin, 1999), deliberation significantly changed issue opinions of the discussants. In particular, the number of participants who initially chose the “don't know / neutral” position in the pre-deliberation survey decreased after deliberation. This can be interpreted as deliberation contributing to individuals' "perspective-taking” (Gastil \& Dillard, 1999). Furthermore, deliberation statistically significantly increased political efficacy for all conditions. This result is also in line with previous research that deliberation can promote positive civic attitudes (Gastil \& Dillard, 1999; Min, 2007). In general, the above results suggest that rational talk in the public setting can promote a “public spirit” to a certain extent. 


\subsubsection{Deliberative Differences between Cultures}

Although deliberation had some positive effects on all conditions in general, the evidence gleaned from this study points toward marked differences in the degree of those effects and in the process of deliberation based on the cultural factor. The American and Korean discussants in this study, although all came from the same community and were similar in other characteristics, showed different cultural orientations. As evidenced in the Hypothesis 1 testing, Koreans were associated with a higher level of collectivism (or interdependent self-construal) whereas Americans were associated with a higher level of individualism (independent self-construal). This cultural difference may have contributed to the differences in the process and effects of deliberation. First of all, Americans clearly appreciated deliberation more than Koreans did. Americans reported a statistically significantly higher score for positive assessment of deliberation than Koreans. They also reported significantly higher freedom to express opinions during deliberation than Koreans. Koreans in the FtF condition, in particular, showed the least freedom to express opinion. This supports the observation that collectivist East Asians can be more easily influenced by social cues in an FtF setting.

Not only self report, but also other measures of deliberation revealed similar differences. The content analysis found that American deliberation sessions featured more reasoned argument than Korean sessions. Reasoned argumentation is an important characteristic of deliberation and it may be suggested that Americans in this study featured more rationality. Such an interpretation, however, must be accompanied with a caution, because the present analysis did not consider the quality of reasoning. Therefore, perhaps it would be safer to say that American deliberation sessions were not so much 
rational as argumentative when compared to Korean deliberation. The same content analysis also found that American deliberation sessions were more equal in terms of discussants’ participation in discussion. This was evidenced by the lower average standard deviation of the amount of individual speech in American sessions.

The external judges' assessment of deliberation is in line with the above findings. The two judges employed in this study were bilingual in Korean and English and were oblivious to the purpose of the study. They consistently rated American sessions higher than Korean ones in all eight deliberation dimensions.

Although deliberation increased political efficacy regardless of conditions, the degree of increase was higher for the American condition, as evidenced by the multi-level model that utilized post-deliberation efficacy as the dependent variable. Efficacy is an important deliberation effect and it may be argued that the positive effect of deliberation was stronger for Americans.

There were some unexpected results, however. It had been suggested that Koreans may feature lower opinion variance after deliberation due to their tendency to support group harmony. This was not the case, however. For the most part, there were no significant changes in opinion variance after deliberation for all conditions. Moreover, the Korean groups' opinion variance actually increased after deliberation for issue 3, which contradicted the literature review. Why such a result was obtained is not clear.

\subsubsection{The Effect of Online Deliberation}

Some discussion should take place about the deliberation in the CMC setting. Overall, the results suggest that online deliberation is not radically different from FtF deliberation. The discussants' assessment of deliberation, political efficacy increase, 
proportion of reasoned arguments, and judges' rating of deliberation were similar between the FtF and CMC conditions. These results suggest that online deliberation can be as effective as face-to-face deliberation, which is in line with some previous research (e.g., Luskin, Fishkin, \& Iyengar, 2004; Min, 2007). In addition, further beneficial effects of online deliberation were observed in this study. The study found that participation in discussion was far more equal in the $\mathrm{CMC}$ condition than in the FtF condition. As evidenced in Table 7-17, there was a very marked difference in average standard deviation of the amount of speech between the FtF and CMC conditions. The very low standard deviation of the CMC groups suggests that individuals' participation in discussion was relatively equal. The enhanced equality of online deliberation shouldn't be surprising. In FtF discussion, it's easy for some individuals to dominate the discussion. The domination of discussion in the FtF setting is often facilitated by social and linguistic cues such as social status, gender, volume of the voice, locution, and so on. However, in CMC discussion, everything is equal and thus all discussants are encouraged to contribute.

The increased equality may be related to an increased freedom to express opinion in the CMC condition. With no social and visual cues, freedom to express opinion must have been higher for CMC discussion. In the present study, freedom to express opinion was higher for CMC groups as seen in Table 7-3. The coefficients for "mode” were all positive in Table 7-4, meaning that as mode changes one unit, that is from FtF to CMC, freedom to express opinion increased. However, it was not to a statistically significant degree. 
Another important issue tested in this study was the interaction between culture and mode. As described in Chapter 4, collectivists who are often hedged by social influence in FtF public talk, may find it easier to deliberate online. The interaction between culture and mode was tested by interaction terms in the multi-level models. However, the coefficients for the interaction terms did not turn out to be statistically significant, although they were in the anticipated direction. For example, as illustrated in Model 3 of Table 7-2, the interaction coefficient for culture and mode on the dependent variable of self-assessment of deliberation was .87, meaning, assuming it is significant, being Korean and being in the CMC setting would increase the self-assessment score by .87. Similarly, the interaction coefficient for culture and mode on the dependent variable of freedom to express was .14, as shown in Model 3 of Table 7-3, meaning, assuming it is significant, being Korean and being in the CMC setting increased freedom to express by .14. These coefficients were only marginally significant at the $\alpha$ level of .10.

Separately, the cross-level interactions between culture and rank, and mode and rank were very small in effect and they did not turn out to be statistically significant. Therefore, Hypothesis 2c that older discussants will have more freedom to express in the Korean/FtF deliberation than in other conditions was not supported. This is understandable considering the fact that the main effect of mode on the outcome variables was not strong. It would have been difficult to expect some significant interaction effect when the main effect was weak. Furthermore, it appears that the manipulation of rank (age) may have not been good enough in the experiment. First, both Korean and American discussants in the sample were skewed toward senior students, 
making the age variation less than desirable. Second, the students in the beginning of each deliberation introduced their rank, but how much such an age cue is primed their minds is unclear, given the relatively short interaction time.

\subsection{Strengths and Limitations of the Study}

The results of the study should be interpreted with caution as there are some limitations of the study. The first issue that needs to be addressed is the validity of the individualism-collectivism cultural distinction. Although it was a popular cultural distinction, it has been a contested construct (for critique of the construct and scale, see, for example, Oyerserman, Coon, \& Kemmelmeir, 2002). As is typical with studies involving culture, this study may have over-generalized the cultural traits of some societies. We know that there is variation within each culture and between individuals. For example, unlike many Japanese, Osakans are renowned for their straightforwardness in talk; it may be also problematic to use Koreans as representing the "collectivist culture” as there will be many variations within collectivism itself.

Indeed, culture is an elusive construct to study. However, the individualismcollectivism dimension of culture has the most well established tradition in cross-cultural studies and social science wide and thus should provide a useful framework to explore the applicability of deliberation in cross-cultural communication contexts. In other words, the individualism and collectivism construct is perhaps the most viable cultural dimension existing today. In future studies, however, a more sophisticated approach to operationalizing cultural distinctions may be necessary. Exploring the communication patterns of other collectivist countries such as China and Japan will be necessary as well. 
The second issue concerns the sample. The Korean and American participants were roughly equal in terms of gender composition, mean age, and the level of political interest and shyness. However, the age distribution between the two samples was slightly different, which might have presented some problems in the manipulation of age in the experiment. Another issue with the sample was that the Korean students employed in this study were Koreans residing in the United States. These Koreans may have been acculturated into the American culture. However, they were all native Koreans whose average length of stay in the United States was only about three years. Koreans, even those who were born and raised in the United States, tend to keep their ethnic heritage and distinctive communication behavior (Gudykunst, 2001). Therefore, it is inconceivable that the Korean students in this study were acculturated into the mainstream American culture in only three years. On the contrary, using Koreans residing in the United States provided some advantages. Because the Koreans and Americans used in this study all came from the same community and shared the same interests and concerns, more direct comparison between the two samples in terms of cultural differences was possible. Had the study used Koreans residing in Korea, there would have been too many intervening variables due to different environmental characteristics.

Third, the judges’ ratings of deliberation require some caution in interpretation. The reliability statistics for the deliberation evaluation items were relatively low. As seen in Table 6-2, two items failed to reach the acceptable reliability level of .80, recommended by Krippendorff (2004). The reliabilities for other items, although over .80, were relatively low compared to the levels reported in other studies. Therefore, 
one should be cautious to make a conclusion that the American deliberation sessions were more deliberative, as it might be the case that the judges were not satisfactorily objective.

One major strength of this study is that it measured deliberation in a multifaceted way. In this study, deliberation was measured by participants' self-assessment, external judges' evaluation, and content analysis. Most previous studies of deliberation used only one measurement. Some studies even didn't bother to measure deliberation and presumed that deliberation is just "out there.” But by adopting three measures of deliberation, the present study increased the validity of the measurement. Granted, the content analysis portion was very simple and mechanical, as it did not consider the quality of reasoning. Future studies would require a more sophisticated content analysis.

In terms of methodology, the study utilized advanced multi-level modeling where applicable. This is a major advancement from previous studies. Previous deliberation research often violated the standard statistical assumption of independence because it did not consider nesting of discussants in small groups. By using multi-level modeling, however, this study accounted for dependence among observations within groups and increased precision of the model. The size of sample used in this study $(\mathrm{n}=147)$ tended to be small for multi-level modeling, which is typically a large-sample statistical technique. This small sample size contributed to only minimum statistical power. A larger sample would probably have increased the statistical power and supported some hypotheses that were not confirmed in the present, smaller-sample study.

Perhaps the most significant contribution of this study would be that it has explored a previously untapped area of deliberation research. A key theme that 
differentiated the present study from others is that it probed discussants' differences in how they deliberate based on their cultural backgrounds. The role of culture has never been examined in previous research and thus it deserves due attention. The vibrant dynamics of deliberative democracy are now spreading to other parts of the globe, but we know very little about how deliberation, ingrained in Western philosophy, may work in non-Western cultural contexts. Therefore, the importance of cross-cultural investigation of deliberation in this increasingly globalized world has never been greater. 


\section{CHAPTER 9}

\section{CONCULSION}

This final, concluding chapter presents some outlook on deliberation in nonWestern societies. How the present study may contribute to the advancement of the field will also be discussed.

Prior to the discussion, however, some of the overall, important results of this study need to be highlighted again. First of all, the evidence garnered from the study clearly indicates that deliberation processes and outcomes were different based on the cultural factor and that deliberation perhaps worked better for individualist American discussants. Second, online deliberation was shown to be as good as FtF deliberation in many aspects, and in some cases, it was superior. Online deliberation appeared to promote equality and freedom to express opinions and might be particularly beneficial to discussants of collectivist cultural origins, although the statistical evidence here is rather weak.

Perhaps the most noticeable finding in this study is that American discussants liked deliberation more than Koreans did and that deliberation worked better for Americans than for Koreans. One has to be very careful in this interpretation, however. The results should not be interpreted in such an ethnocentric way that Americans are good at deliberation whereas East Asians lack the capability of deliberating rationally. 
What this study intended was to explore how deliberation theory and practice that have been developed predominantly in Western contexts may be applied to non-Western cultures such as East Asian societies. The results thus should be understood such that the deliberation enterprise, as practiced currently, has a Western bias, and when these Western-induced deliberative norms are imposed on non-Western societies, there emerge some issues to be resolved; therefore, deliberation theorists and practitioners have to provide special care if they want to expand deliberation beyond their Western contexts. Much of this paper has focused on the characteristics of East Asian societies that are antithetical to the current practice of deliberation. To be fair, however, one has to also consider possible cultural traits of East Asia that may be hospitable to deliberation. Therefore, it will be necessary to review some Confucian characteristics potentially supporting deliberative norms. Then how deliberative democracy can bloom in East Asia and in non-Western cultures in general will be discussed.

In the West, the Enlightenment gave birth to the Kantian notion of an autonomous and reflexive individual. "Individuality" since then has been celebrated as the trailblazer of human progress and the beacon of light that guards against the tyranny of despotism. ${ }^{1}$ Park (2000) argues that deliberation is an indispensible factor of individuality as it helps develop individuals’ independent values, opinions, and self-assurance. Echoing Park, some scholars suggest that a stream of deliberation influenced by this individuality tradition relates to the sophistication, consistency, and certainty of individual views through speech, and behaviorally, to individual ability to argue those preferences

\footnotetext{
${ }^{1}$ The term 'individuality' is somewhat different from individualism in that it denotes a modern philosophical thought related with Enlightenment philosophers.
} 
assertively (Price, Cappella, \& Nir, 2002). However, there is another important dimension of deliberation, which often fails to receive due attention. According to Park, individuality should always be accompanied by "civility.” Civility as understood in deliberation refers to awareness of others and willingness to sacrifice individual interests for the common good. Park argues that in the behavioral manifestation of deliberation, individuality is mostly realized by the act of speaking and argumentation, and civility is best realized by the act of listening and compromise.

The problem in Western deliberation scholarship and practice is that it values individuality and downplays civility. In Western academia, deliberation studies predominantly concern the "speech" and "opinion expression” side of deliberation, focusing on such issues as opinion quality and sophistication (e.g., Fishkin, 1991; Gastil \& Dillard, 1999). The "listening" side of deliberation is relatively ignored in research. In terms of practice, furthermore, a high degree of individuality that may lead to antagonism among participants is often observed in Western deliberative forums (Mendelberg \& Oleske, 2000). Indeed, communication strategies such as domination, strong opinion expression, and aggressiveness are favored in some Western interpersonal and social relationships involving conflicts (Ting-Toomey, Oetzel, \& Yee-Jung, 2001). On the other hand, collectivists in East Asia prefer such communication strategies as integration and compromise, which may be pro-deliberative and promote mutual understanding and accommodation. This observation opens up very important discussion for the future of deliberation research: The Confucian tradition of valuing social harmony may offer some insights to Western deliberation theorists and practitioners, inspiring appreciation of and learning from the cultural values of other societies. 
Beyond the Confucian value of social harmony, there may exist other cultural sources in non-Western societies favorable to deliberation. Indeed, some argue that although the modern heritage of deliberation can be traced to the Enlightenment ideals and to the ancient Greek democracy, there are other rich traditions of deliberation and public reasoning in non-Western cultures. The Kettering Foundation recently launched a project identifying historical deliberative practices around the world (Marin, 2006). The foundation's case studies show that diverse types of public reasoning and community problem solving have existed in groups from an indigenous people of Cameroon to a community in Fiji. The chief lesson here is that, even though not all people have deliberated in the modern Western sense - weighing pros and cons under strict rulesthere do exist similar local public reasoning traditions around the world. This is in line with Sen’s (2003) argument that deliberative democracy has "global roots.” Sen shows that some non-Western cultures have long traditions of public deliberation. According to him, early Buddhist intellectuals had attached a value to public deliberation and this led to extensive communications on religious and secular subjects and open general meetings aimed at settling disputes throughout India and East and Southeast Asia.

Sen's insights suggest that there may be resources for public reasoning and deliberation in non-Western cultures, and that they should be identified and renewed. This is important, because these local practices will allow deliberative practices to be more easily revived and will simultaneously permit them to be customized to appreciate local cultures. As Mathews (2006, p. 189) argues, “importing political practices from outside was certain to invite resistance, while building on their own traditions was more likely to be successful." 
Efforts to locate and revive local deliberative traditions can be found in the work of several prominent scholars of Chinese politics. For example, He (2006) develops the notion of "authoritarian deliberation" that combines some elements of authoritarianism and deliberation. Bell (1999) proposes institutionalized deliberation among selected elites that he claims will meet the Confucian traditions. This version of deliberative democracy actually resonates with Rawls’s (1993) rather aristocratic vision that emphasizes experts’ deliberation in such places as the U.S. Supreme Court. Such proposals are not without problems, but the point to be made here is that there should be a creative effort to adapt deliberation to non-Western societies and this may be facilitated by intellectual dialogue across cultures. As Dryzek (2006) points out, there are different venues of deliberation and how deliberation is pursed varies across political and cultural systems.

Overall, theorists need to broaden the concept of deliberation and deliberative democracy in a globalized world. In particular, we may need to strengthen what Habermas (1998) called the “weak” public sphere, briefly discussed in Chapter 2. Drawing from Fraser's (1992) critique, Habermas now differentiates between the weak and strong public spheres. To reiterate, the weak public sphere refers to the broad civil society and the strong public sphere refers to parliamentary assemblies and other formal, institutionalized bodies. Weak communicative action is oriented toward reaching understanding and strong communicative action is oriented toward consensus. In the weak public sphere, broad opinions are formed through free and open citizen communication, but will-formation and decision making are reserved for institutionalized deliberation in the political system. 
Although both strong and weak public spheres are equally important for democracy, the current deliberation theory and practices tend to focus on deliberation in the strong public sphere and strong communicative action that posits strict rules and structures. Some lament that this “instrumental deliberation,” whereby public reasoning is used to solve problems and to make decisions, is overshadowing "dialogic deliberation,” whereby citizens freely interact to create identities and find shared values (Kim \& Kim, 2008). The weak public sphere and dialogic deliberation are powerful in that they can encourage participants to prepare for a more rational and critical talk later. Strengthening the weak public sphere will be useful for many East Asians, who are not accustomed to the Western culture's style of discussion. Some empirical studies of cross cultural communication introduced in Chapter 3 suggest that East Asians tend to forge human affections and emotional ties first, before engaging in any serious discussion involving disagreement. These studies show that intimate East Asian discussants can be very argumentative whereas a high level of conformity exists among East Asian discussants who do not know each other (Harris \& Niebler, 1998; Singhal \& Nagao, 1993). If so, a major function of the weak public sphere should be that of forming human relationships and creating and sharing identities to serve as resources for more purposive public reasoning later. This is similar to Fraser's (1992) proposal for subaltern public spheres. She conceives multiple public spheres where individuals of different backgrounds and abilities partake in communicative action. In Confucian societies where power inequalities are relatively strong, Fraser's proposal sounds particularly promising. The idea of less powerful individuals and groups coming together to formulate a view before entering a more formal public sphere can be one way to deal with the problems of 
power differentials in Confucian societies. Here, some structural mechanisms such as providing more deliberative resources to the less powerful will be necessary.

In terms of discursive practice in actual citizen forums, it will be necessary to promote "dialogue" in line with deliberation. Whereas deliberation involves rational talk aimed at problem-solving and decision making, dialogue is more concerned with bridging differences and developing human ties. Its purpose is "to create a group environment that is conducive to honest self-expression, careful self-reflection, and thoughtful probing and perspective taking.” (Levine, Fung, \& Gastil, 2005, p.283). An extensive and reflexive dialogue preceding actual deliberation would well serve East Asians who tend to be concerned about human affections and emotional ties.

Strengthening the weak public sphere is particularly important in East Asian contexts, but it is also useful for deliberation theory in general. By accommodating diverse ways of speaking and reasoning, a vibrant weak public sphere can respond to the scathing critique of Young (1996) and Sanders (1997) that deliberation is full of elitist rules disadvantageous to minorities. After all, the critique of Young and Sanders comes from their conceptualization of deliberation occurring in the strong public sphere with strict rules and regulations. As Benhabib (2002, p. 139) argues, however: "The decentered public sphere consists of mutually overlapping networks and associations of opinion-forming as well as decisional bodies. Within these multiple and overlapping networks of publicity, different logics of reason giving, greeting, storytelling, and embedded speech can flourish.”

In addition, as suggested in the empirical portion of the present study, public deliberation forums facilitated by new media technologies should be considered as a part 
of vibrant, multiple public spheres. The study of new media started occupying a significant portion of recent empirical research of deliberative democracy, but deliberation theorists have rather ignored this important technological development. Despite controversies over the Internet's impact on deliberation, its characteristics, including interactivity, horizontal-egalitarian networking, low costs and non-territoriality, offer great potential to enhance public deliberation in principle. The anonymity or decreased identity cues of Internet communication have often been blamed for encouraging irrational communicative behavior (Blanchard \& Horan, 1998). At the same time, however, the decreased social cues contribute to more egalitarian communication, since the role of power and status is not prominent in computer-mediated-communication. This feature can be especially useful for East Asian deliberators, who are often constrained by the Confucian norms of social hierarchy and status in face-to-face discussion. Although not strong statistically, some of such possibilities were suggested in the present study. Today, online political forums are flourishing in China, Korea, and Japan and this development warrants special attention.

As deliberative democratic practices extend their reach in the increasingly globalized world, new opportunities and challenges arise. The issue of culture and technology in particular asks deliberation theorists and practitioners to review their assumptions to have a more contextualized understanding of deliberation and deliberative democracy. 


\section{BIBLIOGRAPHY}

Aikens, G. S. (1997). American democracy and computer-mediated communication: A Case study in Minnesota. Doctoral dissertation in social and political sciences, Cambridge University.

Amichai-Hamburger, Y., Wainapel, G., \& Fox, S. (2002). On the Internet no one knows I'm an introvert: Extroversion, neuroticism, and Internet interaction. CyberPsychology \& Behavior, 5, 125-128.

Asch, S. (1951). Effects of group pressure upon the modification and distortion of judgment. In H. Guetzkow (Ed.), Groups, leadership, and men (pp. 177-190). Pittsburgh, PA: Carnegie Press.

Bell, D. (1999). Democratic deliberation: The problem of implementation. In S. Macedo (Ed.), Deliberative politics: Essays on democracy and disagreement (pp. 70-87). New York: Oxford University Press.

Benhabib, S. (2002). The claims of culture: Equality and diversity in the global era. Princeton, NJ: Princeton University Press.

Black, L., Burkhalter, S., Gastil, J., \& Stromer-Galley, J. (2009). Methods for analyzing and measuring group deliberation. In E. Bucy \& R. L. Holbert (Eds.), Sourcebook of political communication research: Methods, measures, and analytical techniques. New York: Routledge.

Blanchard, A., \& Horan, T. (1998). Virtual community and social capital. Social Science Computer Review, 16, 293-307.

Bohman, J. (2004). Expanding dialogue: The Internet, the public sphere, and prospects for transnational democracy. Sociological Review, 52, 131-155.

Bond, R., \& Smith, P. (1996). Culture and conformity: A meta-analysis of studies using Asch's line judgment task. Psychological Bulletin, 119, 111-137.

Brislin, R.W. (1970). Back-translation for cross-cultural research. Journal of Crosscultural Psychology, 1, 185-216. 
Brunsting, S., \& Postmes, T. (2002). Social movement participation in the digital age: Predicting offline and online collective action. Small Group Research, 33, 525-555.

Burgoon, J., Buller, D., \& Woodall, W. (1989). Normative communication: The unspoken dialogue. New York: Harper \& Row.

Burkhalter, S., Gastil, J., \& Kelshaw, T. (2002). A conceptual definition and theoretical model of public deliberation in small face-to-face groups. Communication Theory, 12, 398-422.

Cappella, J., Price, V., \& Nir, L. (2002). Argument repertoire as a reliable and valid measure of opinion quality: Electronic dialogue during campaign 2000. Political Communication, 19, 73-93.

Chambers, S. (1996). Reasonable democracy: Jürgen Habermas and the politics of discourse. Ithaca, NY: Cornell University Press.

Cheek, J. (1983). The Revised Cheek and Buss Shyness scale (RCBS). Unpublished manuscript. Wellesley College, Wellesley, MA.

Chen, G.M., \& Chung, J. (1994). The impact of Confucianism on organizational communication. Communication Quarterly, 42, 93-105.

Cohen, J. (1989). Deliberation and democratic legitimacy. In A. Hamlin \& P. Pettit (Eds.), The good polity (pp. 17-34). Oxford: Blackwell.

Cole, M. (1996). Cultural psychology: Once and future discipline. Cambridge, MA: Belknap-Harvard.

Conover, P., Searing, D., \& Crew, I. (2002). The deliberative potential of political discussion. British Journal of Political Science, 32, 21-62.

Cooke, M. (2000). Five arguments for deliberative democracy. Political Studies, 48, 947969.

Daft, R.L., \& Lengel, R.H. (1984). Organizational information requirements, media richness, and structural design. Management Science, 32, 554-571.

Dahlberg, L. (2001a). Computer-mediated communication and the public sphere: A critical analysis. Journal of Computer-Mediated Communication, 7. Retrieved May 18, 2008, from http://jcmc.indiana.edu/vol7/issue1/dahlberg.html.

Dahlberg, L. (2001b). The Internet and democratic discourse: Exploring the prospects of online deliberative forums. Information, Communication, \& Society, 4, 615-633. 
Delanty, G. (1997). Habermas and occidental rationalism: The politics of identity, social learning, and the cultural limits of moral universalism. Sociological Theory, 15, 3059.

Delli Carpini, M.X., Cook, F.L., \& Jacobs, L.R. (2004). Public deliberation, discursive participation, and citizen engagement: A review of empirical literature. Annual Review of Political Science, 7, 315-344.

Dewey, J. (1927). The public and its problems. New York: Holt.

Dryzek, J. (2000). Deliberative democracy and beyond: Liberals, critics, contestations. New York: Oxford University Press.

Dryzek, J. (2006). Deliberative democracy in different places. In E. Leib, \& B. He (Eds.), The search for deliberative democracy in China (pp. 23-36). New York: PalgraveMacmillan.

Elliot, S., Scott, M., Jensen, A., \& McDonough, M. (1982). Perceptions of reticence: A cross-cultural investigation. In M. Burgoon (Ed.), Communication Yearbook, 5 (pp. 591-602). Thousands Oaks, CA: Sage

Ettema, J. (2007). Journalism as reason-giving: Deliberative democracy, institutional accountability, and the news media's mission. Political Communication, 24, 143160.

Etzioni, A., \& Etzioni, O. (1999). Face-to-face and computer-mediated communities: A comparative analysis. The Information Society, 15, 241-248.

Eveland, W.P. (2004). The effect of political discussion in producing informed citizens: The roles of information, motivation, and elaboration. Political Communication, 21, 177-193.

Fishkin, J.S. (1991). Democracy and deliberation: New directions for democratic reform. New Haven, CT: Yale University Press.

Fishkin, J.S., \& Luskin, R.C. (1999). Bringing deliberation to the democratic dialogue. In M. McCombs \& A. Reynolds (Eds.), The poll with a human face: The National Issues Convention experiment in political communication (pp. 3-38). Mahwah, NJ: Lawrence Erlbaum.

Fraser, N. (1992). Rethinking the public sphere: A contribution to the critique of actually existing democracy. In C. Calhoun (Ed.), Habermas and the public sphere (pp.109142). Cambridge, MA: MIT.

Gambetta, D. (1998). “Claro!”: An essay on discursive machismo. In J. Elster (Ed.), Deliberative democracy (pp. 19-43). Cambridge, UK: Cambridge University Press. 
Gastil, J., \& Dillard, J.P. (1999). Increasing political sophistication through public deliberation. Political Communication, 16, 3-23.

Gastil, J., \& Sawyer, K. (2004). When process matters: An exploration of different operational definitions of public deliberation. Paper presented at the annual convention of the Western States Communication Association, Albuquerque, NM, February, 2004.

Gastil, J., Black, L., \& Moscovitz, K. (2008). Ideology, attitude change, and deliberation in small face-to-face groups. Political Communication, 25, 23-46.

Giles, H., Coupland, N., \& Wiemann, J. (1992). Talk is cheap... but my word is my bond: Beliefs about talk. In K. Bolton, \& H. Kwok (Eds.), Sociolinguistics today: International perspectives (pp. 218-243). New York: Routledge.

Glazer, C. (2002). Playing nice with others: The communication of emotion in online classroom. Paper presented at the 9th Annual Distance Education Conference, Austin, Texas, January, 2002.

Goffman, E. (1967). Interaction ritual: Essays on face-to-face behavior. New York: Pantheon.

Gouran, D., \& Hirokawa, R. (1983). The role of communication in decision-making groups: A functional perspective. In M. Mander (Ed.), Communications in transition (pp. 168-185). New York: Praeger.

Gudykunst, W., Matsumoto, Y., Ting-Toomey, S., Nishida, T., Kim, K., \& Heyman, S. (1996). The influence of cultural individualism-collectivism, self-construal, and individual values on communication styles across cultures. Human Communication Research, 22, 510-543.

Gudykunst, W. (2001). Asian American ethnicity and communication. Thousand Oaks, CA: Sage.

Gudykunst, W., \& Lee, C. M. (2002). Cross-cultural communication theories. In W. Gudykunst \& B. Mody (Eds.), Handbook of international and intercultural communication (2nd edition) (pp. 25-50). Thousands Oaks, CA: Sage.

Gunaratne, S. (2006). Public sphere and communicative rationality: Interrogating Habermas’s Eurocentrism. Journalism and Mass Communication Monographs, 8, 93-156.

Gutmann, A., \& Thompson, D. (2004). Why deliberative democracy? Princeton, NJ: Princeton University Press. 
Habermas (1962/1989). The structural transformation of the public sphere (T. Burger, Trans.). Cambridge, MA: Polity. (Original work published in German in 1962)

Habermas, J. (1975). Legitimation crisis. Boston: Beacon Press.

Habermas, J. (1984). The theory of communicative action, Vol.1: Reason and the rationalization of society (T. McCarthy, Trans.). Boston: Beacon Press.

Habermas, J. (1987). The theory of communicative action, Vol. 2: Lifeworld and system: A critique of functionalist reasoning (T. McCarthy, Trans.). Boston: Beacon Press.

Habermas, J. (1990). Moral consciousness and communicative action (C. Lenhardt \& S. Nicholsen, Trans.). Cambridge, MA: MIT Press.

Habermas, J. (1996). Between facts and norms. Cambridge, MA: Cambridge University Press.

Habermas, J. (1998). On the pragmatics of communication. Cambridge, MA: MIT Press.

Habermas, J. (2006). Political communication in media society: Does democracy still enjoy an epistemic dimension? The impact of normative theory on empirical research. Communication Theory, 16, 411-426.

Hall, E. T. (1976). Beyond culture. Garden City, NY: Anchor.

Hardin, G. (1968). The tragedy of the commons. Science, 162, 1243-1248.

Harris, K., \& Nibler, R. (1998). Decision making by Chinese and U.S. students. Journal of Psychology, 138, 102-114.

Hayes, A. F., \& Krippendorff, K. (2007). Answering the call for a standard reliability measure for coding data. Communication Methods and Measures, 1, 77-89.

He, B. (2006). Western theories of deliberative democracy and the Chinese practice of complex deliberative governance. In E. Leib, \& B. He (Eds.), The search for deliberative democracy in China (pp. 133-148). New York: Palgrave-Macmillan.

Hirokawa, R. (1985). Discussion procedures and decision-making performance: A test of a functionalist perspective. Human Communication Research, 12, 203-224.

Ho, S., \& McLeod, D. (2008). Social-psychological influence on opinion expression in Face-to-Face and computer-mediated communication. Communication Research, $35,190-207$.

Hofstede, G., \& Bond, M. (1988). The Confucius connection: From cultural roots to economic growth. Organizational Dynamics, 16, 5-21. 
Hofstede, G. (1991). Cultures and organizations: Software of the mind. London: HarperCollins.

Hofstede, G. (2001). Culture's consequences: Comparing values, behaviors, institutions, and organizations across nations (2nd edition). Thousands Oaks, CA: Sage.

Hove, T. (2009). The filter, the alarm system, and the sounding board: Critical and warning functions of the public sphere. Communication and Critical/Cultural Studies, 6, 19-38.

Huang, H. (2005). A cross-cultural test of the spiral of silence. International Journal of Public Opinion Research, 17, 324-345.

Ikeda, K., \& Richey, S. (2005). Japanese network capital: The impact of social networks on Japanese political participation. Political Behavior, 23, 23-51.

Jacobson, T. (2008). Harmonious society, civil society, and the media: A communicative action perspective. China Media Research, 4, 31-38.

Johnson, K., \& Paulenich, C. (2001). Beneath a single moon: Buddhism in contemporary American poetry. Boston, MA: Shambhala.

Katz, E. (1992). On parenting a paradigm: Gabriel Tarde's agenda for opinion and communication research. International Journal of Public Opinion Research, 4, 8085.

Kaynay, J. (1998). Contexts of uninhibited online behavior: Flaming in social newsgroups on Usenet. Journal of the American Society for Information Science, 49, 1135-1141.

Kim, J., \& Kim, E.J. (2008). Theorizing dialogic deliberation: Everyday political talk as communicative action and dialogue. Communication Theory, 18, 51-70.

Kim, J., Wyatt, R.O., \& Katz, E (1999). News, talk, opinion, participation: The part played by conversation in deliberative democracy. Political Communication, 16, 361-385.

Kim, M.S., Tasaki, K., Kim, I.D., \& Lee, H.R. (2007). The influence of social status on communication predispositions. Journal of Asian Pacific Communication, 17, 303329.

Kim, Y.M., \& Min, S.J. (2007). New logic of collective action in the Internet age: The impact of the Internet on the transformation of political activism and mobilization. Paper presented at the 2007Association for Education in Journalism and Mass Communication annual conference, Washington, DC 9-12, Aug. 2007. 
Kline, H. (1999). Tocqueville in cyberspace: Using the Internet for citizen associations. The Information Society, 15, 213-220.

Knight, J., \& Johnson, J. (1994). Aggregation and deliberation: On the possibility of democratic legitimacy. Political Theory, 22, 277-296.

Kohlberg, L. (1981). Essays on moral development, Vol.1: The philosophy of moral development. New York: Harper \& Row.

Kohlberg, L. (1984). Essays on moral development, Vol. 2: The psychology of moral development. New York: Harper \& Row.

Kraut, R., Lundmark, V., Patterson, M., Kiesler, S., Mukhopadhyay, T.,\& Scherlis, W. (1998). Internet paradox: A social technology that reduces social involvement and psychological well-being? American Psychologist, 53, 1017-1031.

Krippendorff, K. (2004). Content analysis: An introduction to its methodology (2nd edition). New York: Sage.

Lea, M., \& Spears, R. (1991). Computer-mediated communication, deindividuation and group decision-making. International Journal of Man-Machine Studies, 34, 283301.

Lea, M., \& Spears, R. (1995). Love at first byte? Building personal relationships over computer networks. In J. T. Wood \& S. Duck (Eds.), Understudied relationships: Off the beaten track (pp. 197-233). Newbury Park, CA: Sage.

LeDoux, J. (1996). The emotional brain. New York: Simon \& Schuster.

Lee, W., Detenbar, B.H., Willnat, L., Aday, S., \& Graf, J. (2004). A cross-cultural test of the spiral of silence theory in Singapore and the United States. Asian Journal of Communication, 14, 205-226.

Leib, E.J., \& He, B. (Eds.). (2006). The search for deliberative democracy in China. New York: Palgrave Macmillian.

Levine, P., Fung, A., \& Gastil, J. (2005). Future directions for public deliberation. In J. Gastil \& P. Levine (Eds.), Deliberative democracy handbook: Strategies for effective civic engagement in the $21^{\text {st }}$ century (pp.271-288). San Francisco: JosseyBass.

Li, C. (1999). The Tao encounters the West. Albany, NY: State University of New York Press. 
Luskin, R.C., Fishkin, J.S., \& Iyengar, S. (2004). Considered opinions on U.S. foreign policy: Face-to-face versus online deliberative polling. Paper presented at the International Communication Association Conference, New Orleans, LA, May 2731.

Ma, H.K. (1988). The Chinese perspectives on moral judgment development. International Journal of Psychology, 23, 201-227.

Ma, H.K. (1989). Moral orientation and moral judgment in adolescents in Hong Kong, mainland China, and England. Journal of Cross-Cultural Psychology, 20, 152-177.

Mansbridge, J. (1999). Everyday talk in the deliberative system. In S. Macedo (Ed.), Deliberative politics (pp. 211-239). New York: Oxford University Press.

Marcus, G., Neuman, R., \& Mackuen, M. (2000). Affective intelligence and political judgment. Chicago: The University of Chicago Press.

Margolis, M., \& Resnik, D. (2000). Politics as usual: The cyberspace "revolution." Thousand Oaks, CA: Sage Publications.

Marin, I. (Ed.). (2006). Collective decision making around the world: Essays on historical deliberative practices, Dayton $\mathrm{OH}$ : Kettering Foundation.

Mathews, D (2006). Afterword. In I. Marin (Ed.), Collective decision making around the world: Essays on historical deliberative practices (pp. 183-193). Dayton, OH: Kettering Foundation.

McGrath, J.E., Arrow, H., \& Berdahl, J. L. (2000). The study of groups: Past, present, and future. Personality and Social Psychology Review, 4, 95-105.

Mead, G.H. (1934). Mind, self, and society. Chicago: The University of Chicago Press.

Mendelberg, T., \& Oleske, J. (2000). Race and public deliberation. Political Communication, 17, 169-191.

Mendelberg, T. (2002). The deliberative citizen: Theory and evidence. In M.X. Delli Carpini, L. Huddy, \& R. Shapiro (Eds.), Research in micropolitics: Political decision making, deliberation and participation (pp. 151-193). Greenwich, CT: JAI Press.

Min, S.J. (2007). Online vs. face-to-face deliberation: Effects on civic engagements. Journal of Computer-Mediated Communication, 12, 1369-1387. Retrieved May 18, 2008, from http://jcmc.indiana.edu/vol12/issue4/min.html

Mouffe, C. (1999). Deliberative democracy or agnostic pluralism? Social Research, 66, 745-758. 
Mutz, D. (2006). Hearing the other side: Deliberative versus participatory democracy. New York: Cambridge University Press.

Neblo, M. (2005). Thinking though democracy: Between the theory and practice of deliberative democracy. Acta Politica, 40, 169-181.

Noelle-Neumann, E. (1993). The spiral of silence: Public opinion - our social skin (2nd edition). Chicago: The University of Chicago Press.

Oetzel, J. (1998). Explaining individual communication processes in homogeneous and heterogeneous groups through individualism-collectivism and self-construal. Human Communication Research, 25, 202-224

Oetzel, J., \& Ting-Toomey, S. (2003). Face concerns in interpersonal conflict: A cross cultural empirical test of face negotiation theory. Communication Research, 30, 599624.

Olson, M. (1965). The logic of collective action: Public goods and the theory of groups. Boston, MA: Harvard.

Oyserman, D., Coon, H., \& Kemmelmeier, M. (2002). Rethinking individualism and collectivism: Evaluations of theoretical assumptions and meta-analysis. Psychological Bulletin, 123, 3-72.

Papacharissi, Z. (2004). Democracy online: Civility, politeness, and the democratic potential of online political discussion groups. New Media \& Society, 6, 259-283

Park, S.G. (2000). The significance of civility in deliberative democracy. Korean Journal of Journalism and Communication Studies, 45, 162-194.

Pearce, W., \& Cronen, V. (1980). Communication, action, and meaning: The creation of social realities. New York: Praeger.

Peng, K., \& Nisbett, R. (1999). Culture, dialectics, and reasoning about contradiction. American Psychologist, 54, 741-754.

Postmes, T., Spears, R., \& Lea, S. (1998). Breaching or building social boundaries? SIDE-effects of computer-mediated communication. Communication Research, 25, 689-715.

Price, V., Cappella, J., \& Nir, L. (2002). Does disagreement contribute to more deliberative opinion? Political Communication, 19, 95-112.

Price, V., Nir, L., \& Cappella, J. (2006). Normative and informational influences in online political discussions. Communication Theory, 16, 47-74. 
Prunty, A., Klopf, D., \& Ishii, S. (1990). Argumentativeness: Japanese and American tendencies to approach and avoid conflict. Communication Research Reports, 7 , 75-79.

Quene, H., \& Van den Bergh, H. (2004). On multilevel modeling of repeated measures designs: A tutorial. Speech Communication, 43, 103-121.

Raudenbush, S., \& Bryk, A. (2002). Hierarchical linear models: Applications and data analysis methods (2nd edition). London: Sage.

Rawls, J. (1993). Political liberalism. New York: Columbia University Press.

Rheingold, H. (1993). The virtual community: Homesteading on the electronic frontier. New York: Addison-Wesley.

Rice, R.E. (1993). Media appropriateness: using social presence theory to compare traditional and new organizational media. Human Communication Research, 19, 451-484.

Richey, S. (2006). Hierarchy in political discussion. Paper presented at the 2006 Annual Meeting of the American Political Science Association, Philadelphia, PA, Aug. 31Sep.1, 2006.

Rosenberg, S. (2006). Human nature, communication, and culture: Rethinking democratic deliberation in China and the West. In E. Leib, \& B. He (Eds.), The search for deliberative democracy in China (pp. 77-112). New York: PalgraveMacmillan.

Ryfe, D. (2005). Does deliberative democracy work? Annual Review of Political Science, $8,49-71$.

Ryfe, D. (2006). Narrative and deliberation in small group forums. Journal of Applied Communication Research, 34, 72-93.

Sanders, L (1997). Against deliberation, Political Theory, 25, 347-376.

Schaefer, D.J., \& Dervin, B. (2002). Dialoguing in electronic public spheres: Reconceptualizing participation as verbing micro-practices. Paper presented at the Rochester Intercultural Conference, "The intercultural world and the digital connection,” Rochester Institute of Technology, Rochester, NY, July 19-21, 2001.

Schneider, S. (1997). Expanding the public sphere through computer-mediated communication: Political discussion about abortion in a Usenet newsgroup. Ph.D. dissertation, Department of Political Sciences, Massachusetts Institute of Technology. 
Schumpeter, J. (1942). Socialism and democracy. New York: Harper.

Sen, A. (2003). Democracy and its global roots. The New Republic, October 2003, 28-35.

Shane, P. (Ed.) (2004). Democracy online: The prospects for political renewal through the Internet. New York: Routledge.

Sheeks, M., \& Birchmeier, Z. (2007). Shyness, sociability, and the use of computer mediated-communication in relationship development. CyberPsychology \& Behavior, 10, 64-70.

Short, J., Williams, E., \& Christie, B. (1976). The social psychology of telecommunications. London: John Wiley.

Singhal, A., \& Nagao, M. (1993). Assertiveness as communication competence: A comparison of American and Japanese students. Asian Journal of Communication, $3,1-18$.

Spears, R., \& Lea, M. (1992). Social influence and the influence of the "social" in computer-mediated communication. In M. Lea (Ed.), Contexts of Computermediated Communication (pp. 30-65). London: Harvester-Wheatsheaf.

Sproull, L., \& Kiesler, S. (1991). Connections: New ways of working in the networked organization. Cambridge, MA: MIT Press.

Steiner, J., Bachtiger, A., Spörndli, M., \& Steenbergen, M. (2004). Deliberative politics in action: Analyzing parliamentary discourse. Cambridge, UK: Cambridge University Press.

Stromer-Galley, J. (2002). New voices in the public sphere: A comparative analysis of interpersonal and online political talk. Javnost-The Public, 9, 23-41.

Stromer-Galley, J. (2007). Measuring deliberation's content: A coding scheme. Journal of Public Deliberation, 3. http://services.bepress.com/jpd/vol3/iss1/art12

Sunstein, C. (2003). Why societies need dissent. Cambridge, MA: Harvard.

Tarde, G. (1969/1898). Opinion and conversation. In T.N. Clark (Ed.), Gabriel Tarde on communication and social influence (pp. 297-318). Chicago: The University of Chicago Press. (Original work was published in French in 1898).

Ting-Toomey, S. (1988). Intercultural conflict styles: A face-negotiation theory. In Y.Y. Kim \& W. Gudykunst (Eds.), Theories in intercultural communication (pp. 213235). Newbury Park, CA: Sage. 
Ting-Toomey, S., Gao, G., Trubisky, P., Yang, Z., Kim, H. S., Lin, S.L., \& Nishida,T. (1991). Culture, face maintenance, and styles of handling interpersonal conflict: A study in five cultures. International Journal of Conflict Management, 2, 275-296.

Ting-Toomey, S., \& Kurogi, A. (1998). Facework competence in intercultural conflict: An updated face-negotiation theory. International Journal of Intercultural Relations, 22, 187- 225.

Ting-Toomey, S., Oetzel, J., \& Yee-Jung, K. (2001). Self-construal types and conflict management styles. Communication Reports, 14, 87-104.

Trentholm, S. (1991). Human communication theory. Englewood Cliffs, NJ: Prentice Hall.

Triandis, C. (1995). Individualism and collectivism. Boulder, CO: Westview Press.

Tsujimura, A. (1987). Some characteristics of the Japanese way of communication. In D. Kincaid (Ed.), Communication theory: Eastern and Western perspectives (pp. 115126). San Diego: Academic Press.

Turner, J. W., Grube, J. A., \& Meyers, J. (2001). Developing an optimal match within online communities: An exploration of CMC support communities and traditional support. Journal of Communication, 51, 231-251.

Verstraeten, H. (1996). The media and the transformation of the public sphere. European Journal of Communication, 11, 347-370.

Wallace, P. (1999). The psychology of the Internet. Cambridge: Cambridge University Press.

Walther, J.B. (1992). Interpersonal effects in computer-mediated interaction: A relational perspective. Communication Research, 19, 52-90.

Walther, J. B. (1993). Impression development in computer-mediated interaction. Western Journal of Communication, 57, 381-398.

Warren, M (1992). Democratic theory and self-transformation. American Political Science Review, 86, 8-23.

Wilhelm, A. (2000). Democracy in the digital age. New York: Routledge.

Wright, S., \& Street, J. (2007). Democracy, deliberation, and design: The case of online discussion forums. New Media \& Society, 9, 849-869. 
Young, I. M. (1996). Communication and the other: Beyond deliberative democracy. In S. Benhabib (Ed.), Democracy and difference: Contesting the boundaries of the political (pp. 120-136). Princeton, NJ: Princeton University Press.

Young, I.M. (2000). Inclusion and democracy. New York: Oxford University Press.

Yum, J.O. (1988). The impact of Confucianism on interpersonal relationships and communication patterns in East Asia. Communication Monographs, 55, 374-388. 
APPENDIX A

SURVEY QUESTIONNAIRE FOR DISCUSSANTS 


\section{PRE-SURVEY}

Now that you read the discussion guide, please think over the issues and tell us your opinion by answering the following questions.

1) "OSU should install CCTVs on High Street and major campus locations to prevent crimes."

$\begin{array}{ccccccc}1 & 2 & 3 & 4 & 5 & 6 & 7 \\ \text { Strongly } & \text { Disagree } & \text { Slightly } & \text { Not Sure / } & \text { Slightly } & \text { Agree } & \text { Strongly } \\ \text { Disagree } & & \text { Disagree } & \text { Don't know } & \text { Agree } & & \text { Disagree }\end{array}$

2) "Police officers should be permitted to patrol college dormitories in order to enhance campus safety."

$\begin{array}{ccccccc}1 & 2 & 3 & 4 & 5 & 6 & 7 \\ \text { Strongly } & \text { Disagree } & \text { Slightly } & \text { Not Sure / } & \text { Slightly } & \text { Agree } & \text { Strongly } \\ \text { Disagree } & & \text { Disagree } & \text { Don’t know } & \text { Agree } & & \text { Disagree }\end{array}$

3) "Students should be allowed to carry concealed handguns on campus for self defense."

$\begin{array}{ccccccc}1 & 2 & 3 & 4 & 5 & 6 & 7 \\ \text { Strongly } & \text { Disagree } & \text { Slightly } & \text { Not Sure / } & \text { Slightly } & \text { Agree } & \text { Strongly } \\ \text { Disagree } & & \text { Disagree } & \text { Don't know } & \text { Agree } & & \text { Disagree }\end{array}$

Thinking about yourself, please answer the following questions:

1) "Ifeel tense when I'm with people I do not know well."

$\begin{array}{ccccccc}1 & 2 & 3 & 4 & 5 & 6 & 7 \\ \text { Strongly } & \text { Disagree } & \text { Slightly } & \text { Not Sure / } & \text { Slightly } & \text { Agree } & \text { Strongly } \\ \text { Disagree } & & \text { Disagree } & \text { Don't know } & \text { Agree } & & \text { Disagree }\end{array}$

2) "I am socially somewhat awkward."

$\begin{array}{ccccccc}1 & 2 & 3 & 4 & 5 & 6 & 7 \\ \text { Strongly } & \text { Disagree } & \text { Slightly } & \text { Not Sure / } & \text { Slightly } & \text { Agree } & \text { Strongly } \\ \text { Disagree } & & \text { Disagree } & \text { Don't know } & \text { Agree } & & \text { Disagree }\end{array}$


3) "When I am in a group of people, it is difficult for me to think of the right things to talk about."

$\begin{array}{lcccccc}1 & 2 & 3 & 4 & 5 & 6 & 7 \\ \text { Strongly } & \text { Disagree } & \text { Slightly } & \text { Not Sure / } & \text { Slightly } & \text { Agree } & \text { Strongly } \\ \text { Disagree } & & \text { Disagree } & \text { Don't know } & \text { Agree } & & \text { Disagree }\end{array}$

4) "I think that I am better informed about school issues than other students."

$\begin{array}{ccccccc}1 & 2 & 3 & 4 & 5 & 6 & 7 \\ \text { Strongly } & \text { Disagree } & \text { Slightly } & \text { Not Sure / } & \text { Slightly } & \text { Agree } & \text { Strongly } \\ \text { Disagree } & & \text { Disagree } & \text { Don't know } & \text { Agree } & & \text { Disagree }\end{array}$

5) "I feel I have a pretty good understanding of the important issues facing my school."

$\begin{array}{ccccccc}1 & 2 & 3 & 4 & 5 & 6 & 7 \\ \text { Strongly } & \text { Disagree } & \text { Slightly } & \text { Not Sure / } & \text { Slightly } & \text { Agree } & \text { Strongly } \\ \text { Disagree } & & \text { Disagree } & \text { Don't know } & \text { Agree } & & \text { Disagree }\end{array}$

6) "I consider myself well qualified to participate in school affairs."

$\begin{array}{ccccccc}1 & 2 & 3 & 4 & 5 & 6 & 7 \\ \text { Strongly } & \text { Disagree } & \text { Slightly } & \text { Not Sure / } & \text { Slightly } & \text { Agree } & \text { Strongly } \\ \text { Disagree } & & \text { Disagree } & \text { Don't know } & \text { Agree } & & \text { Disagree }\end{array}$

7) "My personal identity is important to me."

$\begin{array}{ccccccc}1 & 2 & 3 & 4 & 5 & 6 & 7 \\ \text { Strongly } & \text { Disagree } & \text { Slightly } & \text { Not Sure / } & \text { Slightly } & \text { Agree } & \text { Strongly } \\ \text { Disagree } & & \text { Disagree } & \text { Don't know } & \text { Agree } & & \text { Disagree }\end{array}$

8) "I prefer to be self-reliant rather than depend on others."

$\begin{array}{ccccccc}1 & 2 & 3 & 4 & 5 & 6 & 7 \\ \text { Strongly } & \text { Disagree } & \text { Slightly } & \text { Not Sure / } & \text { Slightly } & \text { Agree } & \text { Strongly } \\ \text { Disagree } & & \text { Disagree } & \text { Don't know } & \text { Agree } & & \text { Disagree }\end{array}$

9) "I will sacrifice my self-interest for the benefit of my group."

$\begin{array}{ccccccc}1 & 2 & 3 & 4 & 5 & 6 & 7 \\ \text { Strongly } & \text { Disagree } & \text { Slightly } & \text { Not Sure / } & \text { Slightly } & \text { Agree } & \text { Strongly } \\ \text { Disagree } & & \text { Disagree } & \text { Don't know } & \text { Agree } & & \text { Disagree }\end{array}$


10) "I stick with my group even through difficulties."

$\begin{array}{ccccccc}1 & 2 & 3 & 4 & 5 & 6 & 7 \\ \text { Strongly } & \text { Disagree } & \text { Slightly } & \text { Not Sure / } & \text { Slightly } & \text { Agree } & \text { Strongly } \\ \text { Disagree } & & \text { Disagree } & \text { Don't know } & \text { Agree } & & \text { Disagree }\end{array}$

11) "I respect decisions made by the group."

$\begin{array}{ccccccc}1 & 2 & 3 & 4 & 5 & 6 & 7 \\ \text { Strongly } & \text { Disagree } & \text { Slightly } & \text { Not Sure / } & \text { Slightly } & \text { Agree } & \text { Strongly } \\ \text { Disagree } & & \text { Disagree } & \text { Don't know } & \text { Agree } & & \text { Disagree }\end{array}$

12) "I maintain harmony in the groups of which I am a member."

$\begin{array}{ccccccc}1 & 2 & 3 & 4 & 5 & 6 & 7 \\ \text { Strongly } & \text { Disagree } & \text { Slightly } & \text { Not Sure / } & \text { Slightly } & \text { Agree } & \text { Strongly } \\ \text { Disagree } & & \text { Disagree } & \text { Don’t know } & \text { Agree } & & \text { Disagree }\end{array}$

13) "I respect the majority's wishes in groups of which I am a member."

$\begin{array}{ccccccc}1 & 2 & 3 & 4 & 5 & 6 & 7 \\ \text { Strongly } & \text { Disagree } & \text { Slightly } & \text { Not Sure / } & \text { Slightly } & \text { Agree } & \text { Strongly } \\ \text { Disagree } & & \text { Disagree } & \text { Don't know } & \text { Agree } & & \text { Disagree }\end{array}$

14) "I take responsibility for my own actions."

$\begin{array}{ccccccc}1 & 2 & 3 & 4 & 5 & 6 & 7 \\ \text { Strongly } & \text { Disagree } & \text { Slightly } & \text { Not Sure / } & \text { Slightly } & \text { Agree } & \text { Strongly } \\ \text { Disagree } & & \text { Disagree } & \text { Don't know } & \text { Agree } & & \text { Disagree }\end{array}$

15) "It is important to consult close friends and get their ideas before making a decision."

$\begin{array}{lcccccc}1 & 2 & 3 & 4 & 5 & 6 & 7 \\ \text { Strongly } & \text { Disagree } & \text { Slightly } & \text { Not Sure / } & \text { Slightly } & \text { Agree } & \text { Strongly } \\ \text { Disagree } & & \text { Disagree } & \text { Don't know } & \text { Agree } & & \text { Disagree }\end{array}$

16) "It is important for me to act as an independent person."

$\begin{array}{ccccccc}1 & 2 & 3 & 4 & 5 & 6 & 7 \\ \text { Strongly } & \text { Disagree } & \text { Slightly } & \text { Not Sure / } & \text { Slightly } & \text { Agree } & \text { Strongly } \\ \text { Disagree } & & \text { Disagree } & \text { Don’t know } & \text { Agree } & & \text { Disagree }\end{array}$


17) "I should decide my future on my own."

$\begin{array}{ccccccc}1 & 2 & 3 & 4 & 5 & 6 & 7 \\ \text { Strongly } & \text { Disagree } & \text { Slightly } & \text { Not Sure / } & \text { Slightly } & \text { Agree } & \text { Strongly } \\ \text { Disagree } & & \text { Disagree } & \text { Don't know } & \text { Agree } & & \text { Disagree }\end{array}$

18) "I enjoy being unique and different from others."

$\begin{array}{ccccccc}1 & 2 & 3 & 4 & 5 & 6 & 7 \\ \text { Strongly } & \text { Disagree } & \text { Slightly } & \text { Not Sure / } & \text { Slightly } & \text { Agree } & \text { Strongly } \\ \text { Disagree } & & \text { Disagree } & \text { Don't know } & \text { Agree } & & \text { Disagree }\end{array}$

19) "I am interested in politics."

$\begin{array}{lcccccc}1 & 2 & 3 & 4 & 5 & 6 & 7 \\ \text { Strongly } & \text { Disagree } & \text { Slightly } & \text { Not Sure / } & \text { Slightly } & \text { Agree } & \text { Strongly } \\ \text { Disagree } & & \text { Disagree } & \text { Don’t know } & \text { Agree } & & \text { Disagree }\end{array}$

Thinking of your political orientation, please tell where you stands on a 7-point ideology scale: 1 indicates "very conservative" and 7 indicates "very liberal."

$\begin{array}{lllcccc}1 & 2 & 3 & 4 & 5 & 6 & 7 \\ \text { Very } & & & \text { Moderate } & & & \text { Very } \\ \text { Conservative } & & & & & \text { Liberal }\end{array}$

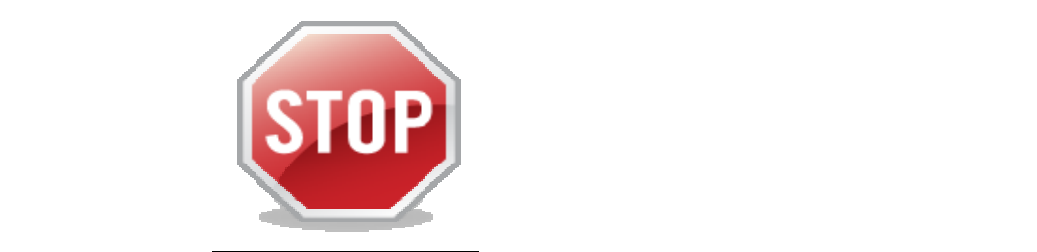

You will fill out the rest of the survey after group discussion 


\section{POST- SURVEY}

Now that you finished the discussion, we would like to ask you some more questions on the issues and the discussion process. First, please rethink the issues and answer the following questions.

1) "OSU should install CCTVs on High Street and major campus locations to prevent crimes."

$\begin{array}{lcccccc}1 & 2 & 3 & 4 & 5 & 6 & 7 \\ \text { Strongly } & \text { Disagree } & \text { Slightly } & \text { Not Sure / } & \text { Slightly } & \text { Agree } & \text { Strongly } \\ \text { Disagree } & & \text { Disagree } & \text { Don't know } & \text { Agree } & & \text { Disagree }\end{array}$

2) "Police officers should be permitted to patrol college dormitories in order to enhance campus safety."

$\begin{array}{ccccccc}1 & 2 & 3 & 4 & 5 & 6 & 7 \\ \text { Strongly } & \text { Disagree } & \text { Slightly } & \text { Not Sure / } & \text { Slightly } & \text { Agree } & \text { Strongly } \\ \text { Disagree } & & \text { Disagree } & \text { Don't know } & \text { Agree } & & \text { Disagree }\end{array}$

3) "Students should be allowed to carry concealed handguns on campus for self defense."

$\begin{array}{ccccccc}1 & 2 & 3 & 4 & 5 & 6 & 7 \\ \text { Strongly } & \text { Disagree } & \text { Slightly } & \text { Not Sure / } & \text { Slightly } & \text { Agree } & \text { Strongly } \\ \text { Disagree } & & \text { Disagree } & \text { Don't know } & \text { Agree } & & \text { Disagree }\end{array}$

Thinking of the discussion process, please answer the followings:

1) "I felt free to express my views during the discussion"

$\begin{array}{ccccccc}1 & 2 & 3 & 4 & 5 & 6 & 7 \\ \text { Strongly } & \text { Disagree } & \text { Slightly } & \text { Not Sure / } & \text { Slightly } & \text { Agree } & \text { Strongly } \\ \text { Disagree } & & \text { Disagree } & \text { Don't know } & \text { Agree } & & \text { Disagree }\end{array}$

2) "I had plenty of chances to speak during our group discussion."

$\begin{array}{ccccccc}1 & 2 & 3 & 4 & 5 & 6 & 7 \\ \text { Strongly } & \text { Disagree } & \text { Slightly } & \text { Not Sure / } & \text { Slightly } & \text { Agree } & \text { Strongly } \\ \text { Disagree } & & \text { Disagree } & \text { Don't know } & \text { Agree } & & \text { Disagree }\end{array}$


3) "I understood almost everything that other group members said during our discussion."

$\begin{array}{lcccccc}1 & 2 & 3 & 4 & 5 & 6 & 7 \\ \text { Strongly } & \text { Disagree } & \text { Slightly } & \text { Not Sure / } & \text { Slightly } & \text { Agree } & \text { Strongly } \\ \text { Disagree } & & \text { Disagree } & \text { Don't know } & \text { Agree } & & \text { Disagree }\end{array}$

4) "I was very mentally alert and involved in our group's discussion."

$\begin{array}{ccccccc}1 & 2 & 3 & 4 & 5 & 6 & 7 \\ \text { Strongly } & \text { Disagree } & \text { Slightly } & \text { Not Sure / } & \text { Slightly } & \text { Agree } & \text { Strongly } \\ \text { Disagree } & & \text { Disagree } & \text { Don't know } & \text { Agree } & & \text { Disagree }\end{array}$

5) "I carefully considered what other group members said during our discussion."

$\begin{array}{ccccccc}1 & 2 & 3 & 4 & 5 & 6 & 7 \\ \text { Strongly } & \text { Disagree } & \text { Slightly } & \text { Not Sure / } & \text { Slightly } & \text { Agree } & \text { Strongly } \\ \text { Disagree } & & \text { Disagree } & \text { Don't know } & \text { Agree } & & \text { Disagree }\end{array}$

6) "The other group members respected my own views on the issue."

$\begin{array}{ccccccc}1 & 2 & 3 & 4 & 5 & 6 & 7 \\ \text { Strongly } & \text { Disagree } & \text { Slightly } & \text { Not Sure / } & \text { Slightly } & \text { Agree } & \text { Strongly } \\ \text { Disagree } & & \text { Disagree } & \text { Don't know } & \text { Agree } & & \text { Disagree }\end{array}$

7) "The other group members were rude and impolite towards me."

$\begin{array}{ccccccc}1 & 2 & 3 & 4 & 5 & 6 & 7 \\ \text { Strongly } & \text { Disagree } & \text { Slightly } & \text { Not Sure / } & \text { Slightly } & \text { Agree } & \text { Strongly } \\ \text { Disagree } & & \text { Disagree } & \text { Don't know } & \text { Agree } & & \text { Disagree }\end{array}$

Please answer the following questions about yourself.

1) "I think that I am better informed about school issues than other students."

$\begin{array}{ccccccc}1 & 2 & 3 & 4 & 5 & 6 & 7 \\ \text { Strongly } & \text { Disagree } & \text { Slightly } & \text { Not Sure / } & \text { Slightly } & \text { Agree } & \text { Strongly } \\ \text { Disagree } & & \text { Disagree } & \text { Don't know } & \text { Agree } & & \text { Disagree }\end{array}$

2) "I feel I have a pretty good understanding of the important issues facing my school."

$\begin{array}{ccccccc}1 & 2 & 3 & 4 & 5 & 6 & 7 \\ \text { Strongly } & \text { Disagree } & \text { Slightly } & \text { Not Sure / } & \text { Slightly } & \text { Agree } & \text { Strongly } \\ \text { Disagree } & & \text { Disagree } & \text { Don't know } & \text { Agree } & & \text { Disagree }\end{array}$


3) "I consider myself well qualified to participate in school affairs."

$\begin{array}{ccccccc}1 & 2 & 3 & 4 & 5 & 6 & 7 \\ \text { Strongly } & \text { Disagree } & \text { Slightly } & \text { Not Sure / } & \text { Slightly } & \text { Agree } & \text { Strongly } \\ \text { Disagree } & & \text { Disagree } & \text { Don't know } & \text { Agree } & & \text { Disagree }\end{array}$

Was your discussion face-to-face or over the Internet?

Face-to-face Internet

What is your gender?

Male

Female

How old are you?

What is your rank?

Freshmen Sophomore Junior Senior

What is your race/ethnicity?

White

African American

Latino/Latina

Asian

Other

Are you an American or international student?

American International

This is the end of the survey. Your participation will greatly contribute to our research. Thank you very much. 
APPENDIX B

DISCUSSION GUIDE 


\section{Campus Safety: \\ How Do We Protect Our Campus? \\ - A Community Discussion Guide}

\section{Overview: Rising crime concerns}

There have been rising crime alerts on the OSU campus: From minor thefts to vandalism, reports of crime incidents have increased in number over the last several months and we are worried about crimes. According to a recent Lantern poll, 87 percent of Ohio State students feel that OSU has a crime problem. Recent incidents of shooting in Virginia Tech and Northern Illinois University, furthermore, make us wonder how much we are prepared against possible deadly attack. Are you worried about campus crimes? How do we protect our campus? Let us know.

Some specific proposals to improve campus safety are being discussed currently. Below are the three issues that have received the most attention and controversy. We'd like to hear your voice in these issues. There is no "right" answer here. The discussion is to help you get acquainted with the issues and reach the best decision for the Ohio State community.

\section{Issue 1: Video surveillance on and around campus?}

The Ohio State community is discussing a plan to install CCTVs (Video surveillance) on major campus locations and High Street. Do you think the expansion of video surveillance help prevent crimes? Here are some pro and con arguments for the proposal.

\begin{tabular}{|c|c|}
\hline \multicolumn{1}{|c|}{ Pro Arguments } & \multicolumn{1}{c|}{ Con Arguments } \\
\hline $\begin{array}{l}\text { "Yes, video surveillance is an effective } \\
\text { way to fight crimes." }\end{array}$ & $\begin{array}{l}\text { "I would feel very uncomfortable if I'm } \\
\text { being watched." }\end{array}$ \\
$\begin{array}{l}\text { Cameras are a useful law- } \\
\text { enforcement tool. People who } \\
\text { have done nothing wrong should } \\
\text { not feel threatened by video } \\
\text { surveillance. }\end{array}$ & $\begin{array}{l}\text { Even in public, people should have } \\
\text { a right to be free of scrutiny by } \\
\text { authorities. Surveillance cameras } \\
\text { have the potential for abuse and are } \\
\text { not subject to sufficient oversight. }\end{array}$ \\
\hline
\end{tabular}




\section{Issue 2: Police Patrol of Residence Halls?}

Over the past several years, universities in the country have responded to a rise in oncampus criminal activity by ordering an increased police presence on campus. OSU followed this route and now random police patrols are underway to eliminate certain criminal activities including property theft, illicit drug use, and underage drinking. But some are opposing this measure saying it infringes upon students' personal freedom. What do you think? Is police's random patrol of residence hall acceptable?

\begin{tabular}{|c|c|}
\hline \multicolumn{1}{|c|}{ Pro Arguments } & \multicolumn{1}{c|}{ Con Arguments } \\
\hline $\begin{array}{l}\text { "Policing of residence hall makes me feel } \\
\text { safer." }\end{array}$ & $\begin{array}{l}\text { "Hey, residence halls are akin to } \\
\text { private residence. I want privacy!" }\end{array}$ \\
$\begin{array}{l}\text { - Allowing police officers to patrol } \\
\text { dormitory hallways and other } \\
\text { public spaces bolsters the security } \\
\text { of students, faculty, and other } \\
\text { members of the local college } \\
\text { community. }\end{array}$ & $\begin{array}{l}\text { The presence of police officers in } \\
\text { dorms does little to curb crime } \\
\text { while doing much to } \\
\text { inconvenience students and violate } \\
\text { their right to privacy. }\end{array}$ \\
\end{tabular}




\section{Issue 3: Guns on Campus?}

Ohio's law allows licensed individuals to carry concealed handguns in many public settings. But the law prohibits carrying handguns on campus. With a rising crime concern on campus, however, some suggest that students should be allowed to carry handguns on campus as well. The OSU community, including the Undergraduate Student Government, is engaged in debates about this issue. Should students be allowed to carry handguns on campus? What do you think?

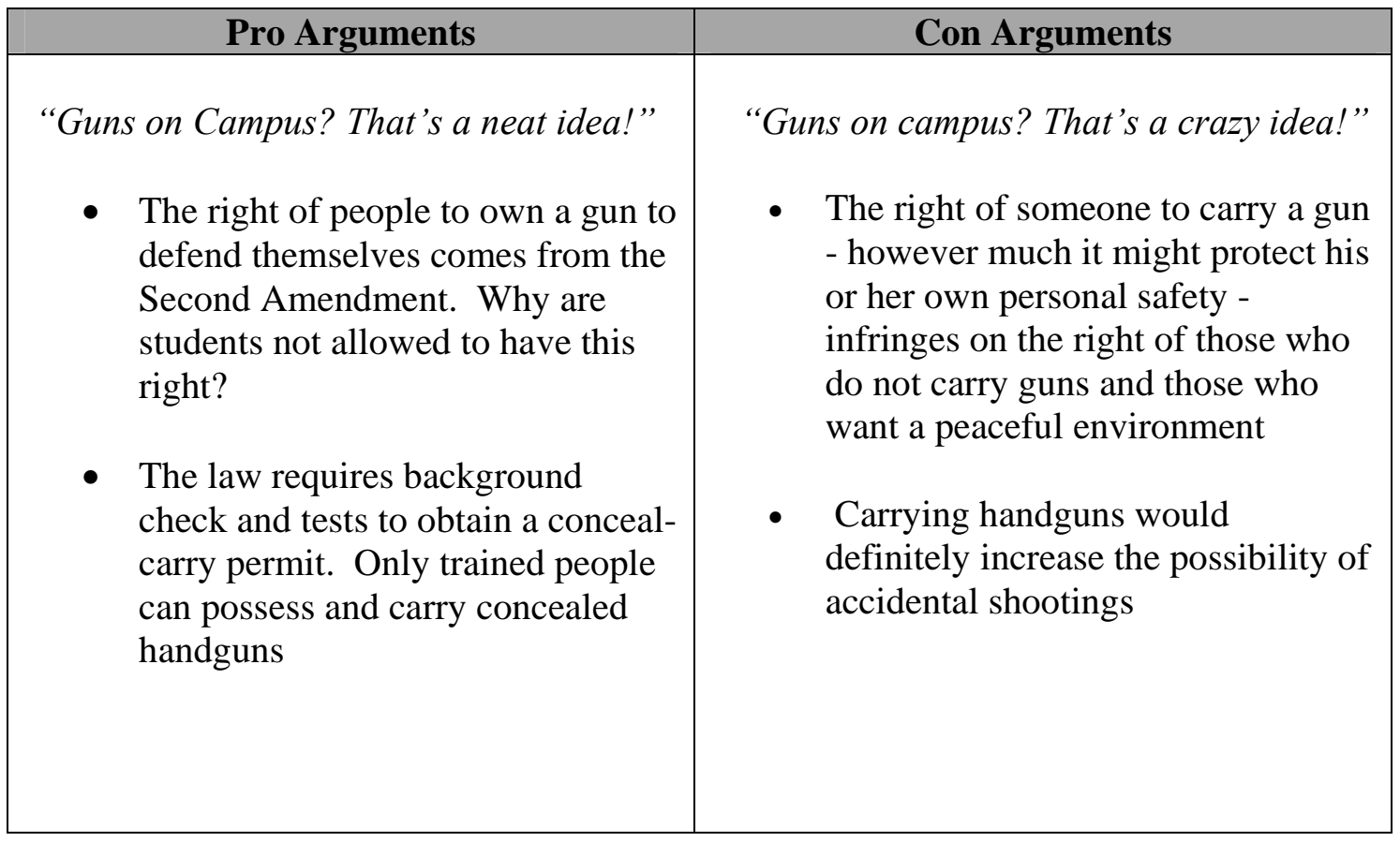

Are you worried about crimes taking place in OSU?

$>$ Do you think installing video surveillance on and around campus will prevent crimes?

$>$ Do you think police has the right to random police residence halls?

Do you think carrying handguns will relieve crime problems of OSU?

What would be the best solution to protect our campus?

\section{Your opinion will matter!}


APPENDIX C

MODERATOR'S GUIDE 


\section{Moderator's Guide}

\section{Introduction (approx. 10 minutes)}

\section{$\underline{\text { Welcome }}$}

- Greet the participants

- Introduce yourself

- Ask each participant to introduce himself/herself. Each discussant should say their name (or pseudonym in CMC) and rank in school

- Say the topic and emphasize the importance of collective problem solving efforts:

E.g.) Now we are going to talk about an important school issue. We are worried about crime possibilities on and around campus. Recent incidents of campus shooting in Virginia Tech and Northern Illinois University make us wonder how much we are prepared against possible deadly attack. President Gordon Gee earlier this year said "Ohio State is a prime terror target. We are very vulnerable.” The Ohio State community is now making every effort to make the campus safer. Measures to improve campus safety, however, requires a collective problem solving commitment from the administration, law enforcement, students, and the entire Ohio State community. Some measures to improve safety, furthermore, may come at the expense of personal freedom. We gathered here today to seek your opinions on the campus safety issue. This will be a very valuable opportunity for us to share our views. It is very important for us to listen to students' voice. Your opinion will matter greatly for the Ohio State community to choose a right policy. Remember that we are one community sharing a same goal and this discussion is an attempt to benefit everyone in the community.

- Tell them their discussion will be recorded and used for no other purposes than research.

\section{Share the discussion protocol}

- Make sure that the forum is not a debate. Stress that there is work to do, and that the work is to move toward making a choice on a school policy issue. The work will be done through "deliberation."

- Stress that there is no "right” opinion or policy choice. Each participant should respect others' opinion. 
- Each participant should have an equal opportunity to talk.

- The participants do not have to reach a consensus, but the goal is to work toward an acceptable decision to all.

\section{Body (approx. 40 minutes)}

\section{Warming-up and Understanding}

- Discuss whether OSU has a crime problem and if so, how serious it is.

- Connect the issue to people's lives and concerns.

e.g.) Are you concerned about campus crimes?

How has the safety issue affected you personally?

- Introduce three policy issues. Check whether the participants understood the issues.

e.g.)What is the issue at stake?

Did you understand why the handgun issue/surveillance/policing issue is controversial?

Now structure the discussion according to specific issues.

\section{Issue 1:Video Surveillance}

- Briefly introduce the issue at stake.

- Poll the participants on the issue:

e.g.) How many of you support the idea of video surveillance on and around campus?

- Ask why or why not they support the proposal.

- Let them evaluate the effectiveness of the proposal. Ask them to carefully evaluate possible situations.

e.g.) - How effective will the video surveillance be?

- Are they any other benefits or problems associated with video surveillance?

- What are the cost of installing video surveillance and who pays for it?

- What trade-offs are we willing to accept to adopt this policy? What tradeoffs are we unwilling to accept to adopt this policy?

\section{Issue 2: Policing of residence halls}

- Briefly introduce the issue at stake.

- Poll the participants on the issue: 
e.g.) How many of you support the idea of policing of residence halls?

- Ask why or why not they support the proposal.

- Let them evaluate the effectiveness of the proposal. Ask them to carefully evaluate possible situations.

e.g.) - How effective is random residence hall policing?

- Are there any other benefits or problems associated with residence hall policing?

- What trade-offs are we willing to accept to adopt this policy? What tradeoffs are we unwilling to accept to adopt this policy?

\section{Issue 3: Guns on campus}

- Briefly introduce the issue at stake.

- Poll the participants on the issue:

e.g.) How many of you support the idea of allowing concealed handguns on campus?

- Ask why or why not they support the proposal.

- Let them evaluate the effectiveness of the proposal. Ask them to carefully evaluate possible situations.

e.g.) - What would result from students’ carrying handguns on campus? Can you give us an example?

- Does allowing handguns on campus contribute to the prevention of possible deadly attack?

- What trade-offs are we willing to accept to adopt this policy? What tradeoffs are we unwilling to accept to adopt this policy?

\section{Ending the Forum (approx. 10 minutes)}

- Ask each participant the followings:

- How has your thinking about the issues changed?

- How has your thinking about other people's views changed?

- Let them evaluate what would be the best strategy - including the three measures discussed - to prevent crimes on campus.

- Ask them the following:

- Can we identify any shared sense of purpose or direction for the campus safety issue?

- Thank the participants and end the forum 
APPENDIX D

OBSERVATIONAL RATING SHEET 


\section{Observational Rating Sheet}

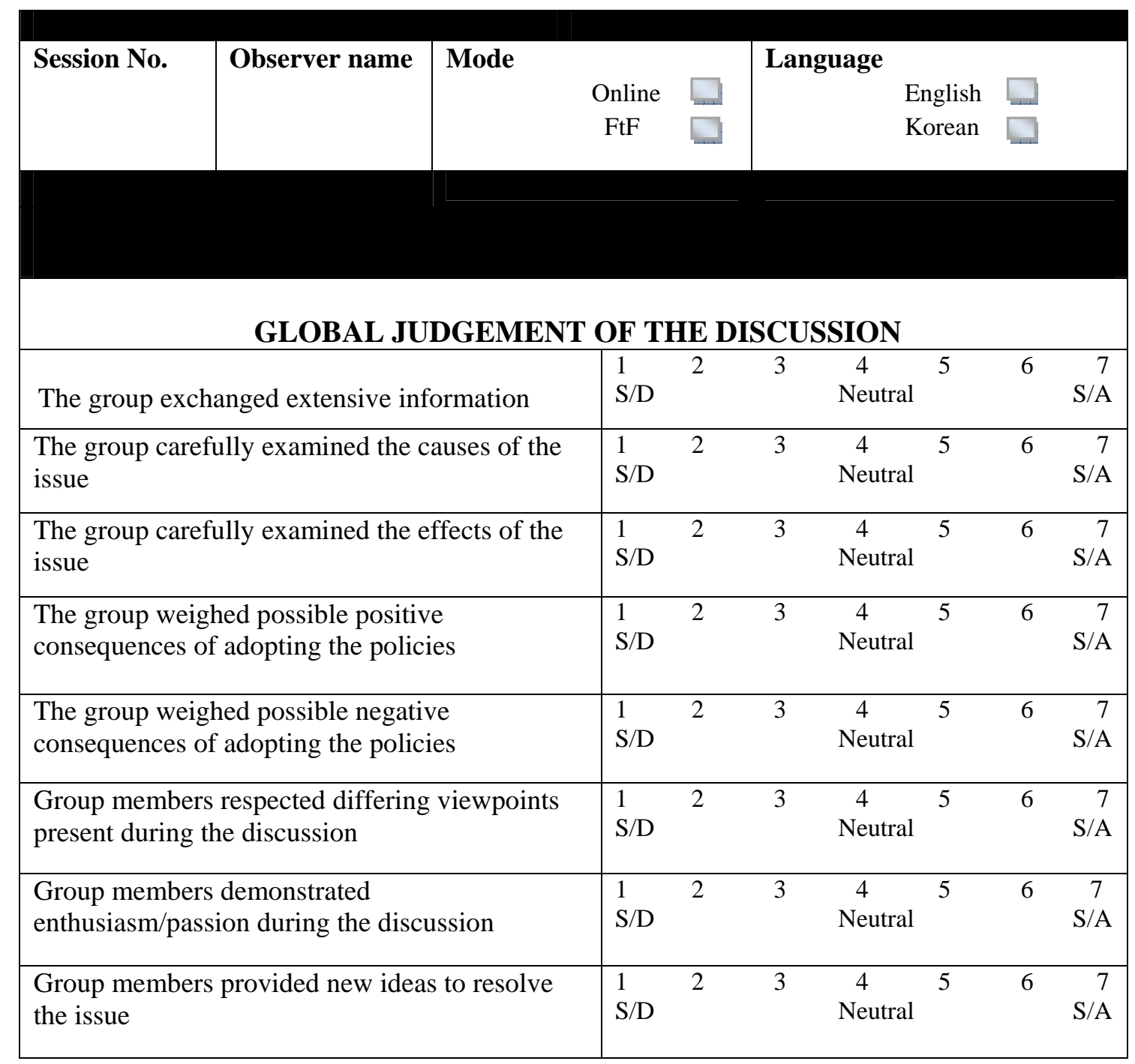

